Visualização, kernels e subespaços: um estudo prático

Adriano Oliveira Barbosa 

Data de Depósito:

Assinatura:

Adriano Oliveira Barbosa

\title{
Visualização, kernels e subespaços: um estudo prático
}

\begin{abstract}
Tese apresentada ao Instituto de Ciências Matemáticas e de Computação - ICMC-USP, como parte dos requisitos para obtenção do título de Doutor em Ciências - Ciências de Computação e Matemática Computacional. VERSÃO REVISADA

Área de Concentração: Ciências de Computação e Matemática Computacional

Orientador: Prof. Dr. Luis Gustavo Nonato
\end{abstract}


Ficha catalográfica elaborada pela Biblioteca Prof. Achille Bassi e Seção Técnica de Informática, ICMC/USP, com os dados fornecidos pelo(a) autor(a)

Oliveira Barbosa, Adriano
Visualização, kernels e subespaços: um estudo
prático / Adriano Oliveira Barbosa, orientador Luis
Gustavo Nonato. -- São Carlos, 2016.
89 p.
Tese (Doutorado - Programa de Pós-Graduação em
Ciências de Computação e Matemática Computacional) --
Instituto de Ciências Matemáticas e de Computação,
Universidade de São Paulo, 2016.
1. kernel. 2. subspace clustering. 3. projeção
multidimensional. 4. visualização. I. Gustavo
Nonato, Luis, orient. II. Título.


Adriano Oliveira Barbosa

\section{Visualization, kernels and subspaces: a practical study}

Doctoral dissertation submitted to the Instituto de Ciências Matemáticas e de Computação - ICMCUSP, in partial fulfillment of the requirements for the degree of the Doctorate Program in Computer Science and Computational Mathematics. FINAL VERSION

Concentration Area: Computer Science and Computational Mathematics

Advisor: Prof. Dr. Luis Gustavo Nonato

USP - São Carlos

February 2017 

Este trabal ho é dedicado a mi nha esposa e meus pais. 

Agradeço aos meus pais, Cicero e Cicera, que sempre investi ram em minha educação e acreditaram em meus sonhos. À minha esposa, Karla, pelo incondicional apoio, dedicação, paciência, cumplicidade e companherismo em todos os momentos.

Agradeço a todos os amigos, professores e funcionários da Universidade de São Paulo pelo apoio durante essa jornada, em especial aos grandes amigos que fiz no LCAD/LMACC e aos prof essores que mi nistraram as disciplinas durante o doutorado. Pelas ótimas lembranças dos presentes e dos que se foram.

Agradeço ao grande amigo Douglas pel as infinitas discussões e ajuda.

Agradeço aos col aboradores acadêmicos Afonso, Fabiano, Filip, Fernando e Siome pela imensa ajuda.

Agradeço imensamente ao meu orientador Gustavo pela ajuda, tempo dedicado e pelo exemplo de profissional.

Agradeço à CAPES e à Universidade de São Paulo pelo apoi o financeiro. 

"Se A é o sucesso, então A éi igual a $X$ mais $Y$ mais $Z$.

O trabalho éX; Yé o lazer; e Z é manter a boca fechada."

(Albert Einstein) 



\section{RESUMO}

BARBOSA, A. O. Visualização, kernels e subespaços: um estudo prático. 2017. 89 p. Tese (Doutorado em Ciências - Ciências de Computação e Matemática Computacional) - Instituto de Ciências Matemáticas e de Computação, Universidade de São Paulo, São Carlos-SP, 2017.

Dados de alta di mensão são tipicamente tratados como pertencentes a um único subespaço do espaço onde estão imersos. Entretanto, dados utilizados em aplicações reais estão usual mente distribuídos entre subespaços independentes e com dimensões distintas. Um objeto de estudo surge a partir dessa afirmação: como essa distribuição em subespaços independentes pode auxiliar tarefas de visual ização?

Por outro lado, se o dado parece estar embaral hado nesse espaço de alta dimensão, como visual izar seus padrões e real izar tarefas como cl assificação? Podemos, por exemplo, mapear esse dado num outro espaço utilizando uma função capaz de o desembaral har, de modo que os padrões intrínsecos fiquem mais claros e, assim, facil litando nossa tarefa de visualização ou classificação.

Essa Tese apresenta dois estudos que abordam ambos os problemas. Para o primeiro, utilizamos técnicas de subspace clustering para definir, quando existente, a estrutura de subespaços do dado e estudamos como essa informação pode auxiliar em visual izações utilizando projeções multidimensionais. Para o segundo problema, métodos de kernel, bastante conhecidos na literatura, são as ferramentas a nos auxiliar. Utilizamos a medida de similaridade do kernel para desenvolver uma nova técnica de projeção multidimensional capaz de lidar com dados imersos no espaço de características induzi do implicitamente pelo kernel.

Palavr as-chave: kernel, subspace clustering, projeção multidimensional, visualização. 



\section{ABSTRACT}

BARBOSA, A. O. Visualization, kernels and subspaces: a practical study. 2017. $89 \mathrm{p}$. Tese (Doutorado em Ciências - Ciências de Computação e Matemática Computacional) - Instituto de Ciências Matemáticas e de Computação, Universidade de São Paulo, São Carlos-SP, 2017.

High-dimensional data are typically handled as laying in a single subspace of the original space. However, data involved in real applications are usual ly spread around in distinct subspaces which may have different dimensions. We would like to study how the subspace structure information can be used to improve visual ization tasks.

On the other hand, what if the data is tangled in this high-dimensional space, how to visualize it's patterns or how to accomplish classification tasks? One could, for example, map the data in another high-dimensional space using a mapping capable of untangle the data making the patterns clear, rendering the visual ization or classification an easy task.

This dissertation presents an study for both problems pointed out above. For the former, we use subspace clustering techniques to define, when it exists, a subspace structure, studying how this information can be used to support visual ization tasks based on multidimensional projections. For the latter problem we employ kernel methods, well known in the literature, as a tool to assist visual ization tasks. We use a similarity measure given by the kernel to devel op a completely new multidi mensional projection technique capable of dealing with data embedded in the implicit feature space defined by the kernel.

Keywords: kernel methods, subspace clustering, multidimensional projection, visualization. 



\section{LISTA DE ILUSTRAÇÕES}

Figura 1 - Ilustração daaplicação de umatécnica de subspace clustering: dados contidos em subespaços de di mensão 1 e 2 imersos em $\mathrm{R}^{3}$ são classificados. . . . . . .

Figura2 - Imersão dos dados $X$ no espaço de alta dimensão $H$ transformando um padrão não linear numa estrutura linear. . . . . . . . . . . . . . . . . . . . . 29

Figura 3 - A posição do novo ponto $x_{k}$ é dada pela interseção dos círcul os definidos pel os pontos já proj etados, $x_{i}$ e $x_{j}$, e com raio igual a distância entre o ponto projetado e o novo ponto no espaço original. . . . . . . . . . . . . . 34

Figura 4 - Matriz A com pontos de controle $p_{3}$ e $p_{6} \ldots \ldots \ldots \ldots$. . . . . . 35

Figura 5 - Comparação entre escol ha por agrupamento e al eatória testada em dois conjuntos de dados diferentes. . . . . . . . . . . . . . . . . .

Figura 6 - (a) Swiss Roll. (b) PLP usando Force Scheme e distância euclidiana para posicionar os pontos de controle. (c) PLP usando I somap para posicionar os pontos de controle. (d) PLMP usando Isomap para posicionar os pontos de

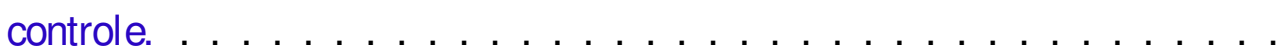

Figura 7 - Medida de stress da LAMP com relação a quantidade de pontos de controle tomados para gerar a projeção. . . . . . . . . . . . . . . . . . 38

Figura 8 - Mani pul ação do usuário para escolher as classes de cada imagem. . . . . . 39

Figura 9 - Resultados da técnica CSMP. . . . . . . . . . . . . . . . . . . . 39

Figura 10 - Técnicas Isomap (B), Laplacian Eigenmap (C) e LLE (D) aplicadas a varie

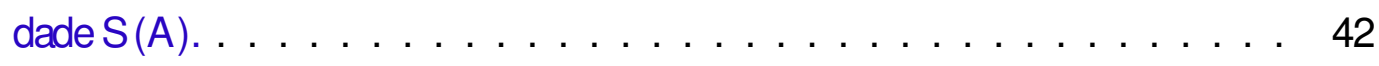

Figura 11 - Pipeline da técnica Kernel Sammon Map. . . . . . . . . . . . . . . . 43

Figura 12 - Exemplos de erros comuns presentes no dado: (a) o dado possui perturbações;

(b) o dado contém entradas com erros, falta de informação, por exemplo;

(c) instâncias de dado (colunas) estão distantes. . . . . . . . . . . . . . 46

Figura 13 - Pipeline do método: (a) dado sem informação de classes; (b) dado com a informação de classes gerada pel o subspace clustering; (c) visual ização do dado utilizando $L D A . \ldots \ldots \ldots$. . . . . . . . . . . . 51

Figura 14 - Resultado da LRR no dado artificial. . . . . . . . . . . . . . . . 52

Figura 15 - Projeção com LDA do dado artificial . . . . . . . . . . . . . . . . . 52

Figura 16 - Resultado da LRR aplicado ao Iris. . . . . . . . . . . . . . . . . 53

Figura 17 - Projeção com LDA do Iris. . . . . . . . . . . . . . . . . 53

Figura 18 - Box plot do stress e tempo em cada conjunto de dado. . . . . . . . . . . 65 
Figura 19 - Gráfico de distância original x distância projetada. Os números no canto superior significam stress e tempo de execução (em segundos). Val ores em negrito são os mel hores para cada conjunto de dado. . . . . . . . . . . . . .

Figura 20 - Mel horando a coesão e separabilidade dos grupos usando a Kelp. A silhueta (S) é maior para as projeções da Kelp comparada com técnicas baseadas em distância Euclidiana . . . . . . . . . . . . . . . . . . . . .

Figura 21 - Comparando a sensi bilidade da Kelp quanto a intervenção do usuário. Canto superior direito mostra a posição dos pontos de controle. . . . . . . . . . . 68

Figura 22 - Variando o número de pontos de controle: o stress estabiliza próximo dos $5 \%$

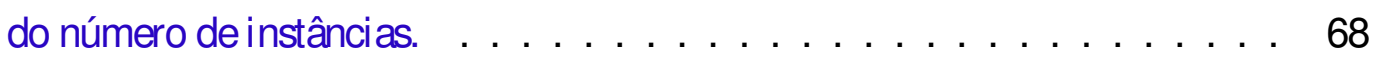

Figura 23 - Espaço de cores util lizado na análise de tears e fal sos vizinhos. . . . . . . . 69

Figura 24 - Verificando a qualidade da projeção segundo a metodol ogia Check Viz: (a) projeção de um conjunto de dados artificial com 150 instâncias e quatro dimensões; (b) regiões roxas indicam falsos vizinhos e regiões indicam tears. 70

Figura 25 - Visualizando como o kernel af eta as estruturas de vizinhança: magnitude das coordenadas diferenciais com layout gerado pel a PLMP com distância Euclidiana em (a), pelaKel p com kernel Gaussiano em (b) ekernel polinomial em (d); magnitude da razão com Kelp-Gaussiano em (c) e Kelp-Polinomial $\mathrm{em}(\mathrm{e}) \ldots \ldots \ldots \ldots \ldots \ldots . \ldots \ldots$

Figura 26 - Função de transferência. . . . . . . . . . . . . . . . . . . . . . . 72

Figura 27 - Modelo intuitivo da separação feita no espaço de características quando aplicamos SVM. . . . . . . . . . . . . . . . . . . . . . 73

Figura 28 - Realizando o modelo intuitivo do SVM: (a) projeção inicial onde a linha de separação não é clara e (b) projeção após a manipul ação dos pontos de controle. A figura no canto superior apresenta o posicionamento dos pontos de controle. . . . . . . . . . . . . . . . . . . . . . 74

Figura 29 - Nosso pi peline de segmentação: a imagem de entrada é projetada, onde cada pixel é uma instância de dado, em seguida os grupos são definidos na projeção e o resultado desse agrupamento é exibido como uma imagem segmentada. . 


\section{LISTA DE ALGORITMOS}

Algoritmo 1 - Solução do problema (3.6) . . . . . . . . . . . . . . . 48

Algoritmo 2 - Segmentação do dado em subespaços . . . . . . . . . . . . . . 48

Algoritmo 3 - Estimativa para o número de subespaços . . . . . . . . . . . . . . . 49

Algoritmo $4-\mathrm{O}$ al goritmo da Kelp $\ldots \ldots \ldots \ldots 63$ 



\section{LISTA DE TABELAS}

Tabela 1 - Conjuntos de dado utilizados. Da esquerda para direita, as colunas correspondem a: nome do conjunto de dados, número de instâncias, dimensão (número de atributos) efonte. . . . . . . . . . . . . . . . . . . . . . . 54

Tabela 2 - Resultados obtidos. Da esquerda para direita as colunas correspondem a conjunto de dado, técnica e métricas: stress, preservação de vizinhança e silhuetas. Val ores em negrito são os mel hores para cada conjunto de dado e métrica . . . . . . . . . . . . . . . . . . . 55

Tabela 3 - Conjuntos de dados utilizados nas comparações, da esquerda para direita as colunas correspondem ao nome do conjunto de dados, tamanho, dimensão e fonte. . . . . . . . . . . . . . . . . . . . . . . . . . 66 



\section{LISTA DE ABREVIATURAS E SIGLAS}

ALM Augmented Lagrange Multiplier (LIN et al., 2009)

CSMP Class-Specific Multidimensional Projection (JOIA et al., 2012)

Kelp Kernel-based Linear Projection (BARBOSA et al., 2016)

KPCA Kernel PCA (SCHÖLKOPF; SMOLA; MÜLLER, 1998)

LAMP Local Affine Multidimensional Projection (JOIA et al., 2011)

LDA Linear Discriminant Analysis (BISHOP, 2006)

LLE Locally Linear Embedding (HAM et al., 2004)

LRR Low-Rank Representation (ZHANG et al., 2014)

LSP Least Square Projection (PAULOVICH et al., 2008)

MDS Multidimensional Scaling (JOURDAN; MELANCON, 2004)

PCA Principal Component Analysis (BISHOP, 2006)

PLMP Part-Linear Multidimensional Projection (PAULOVICH; SILVA; NONATO, 2010)

PLP Piece-wise Laplacian-based Projection (PAULOVICH et al., 2011)

SVD Decomposição em Val ores Singulares (BISHOP, 2006)

SVM Support Vector Machine (SCHÖLKOPF; SMOLA, 2001)

t-SNE t-Distributed Stochastic Neighbor Embedding (MAATEN; HINTON, 2008) 



\section{LISTA DE SÍMBOLOS}

$\mathrm{R}^{\mathrm{n}}$ - Espaço cartesiano de dimensão $\mathrm{n}$

H - Espaço de características (Hilbert) definido implicitamente pelo kernel

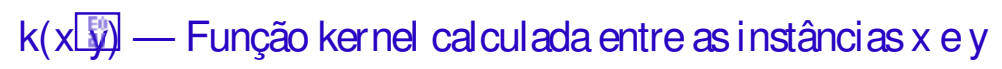

$x^{\top} y$ - Produto interno entre os vetores $x$ e $y$

$\varphi(x)$ - Mapeamento implícito definido pela função kernel

$M_{i j}$ - Entradaij da matriz $M$

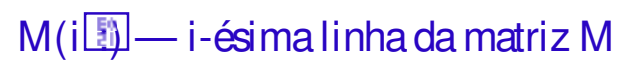

$M(:$ 河 — j-ésima coluna da matriz $M$

$M(m \times n)-$ Espaço das matrizes $m \times n$

$\mathbb{1}_{\mathrm{m}}$ - Matriz $\mathrm{m} \times \mathrm{m}$ cujas entradas são todas iguais $\mathrm{a} \frac{1}{\mathrm{~m}}$

$1_{n}-$ Vetor de dimensão $n$ cujas entradas são todas iguais a $\frac{1}{n}$

$\mathrm{rx}_{\mathrm{x}} \mathrm{Gij}_{\mathrm{H}}$ - Produto interno entre as instâncias $\mathrm{x}$ ey no espaço $\mathrm{H}$

$[\mathrm{M} \mathbb{\mathrm { N }}]$ - Concatenação das matrizes $\mathrm{M}$ e $\mathrm{N}$ horizontal mente

$[\mathrm{M} ; \mathrm{N}]$ - Concatenação das matrizes $\mathrm{M}$ e N verticalmente 

INTRODUÇÃO . . . . . . . . . . . . . . . . . 27

2 TRABALHOS RELACIONADOS .............. 31

$2.1 \quad$ Subspace clustering $\ldots \ldots \ldots \ldots \ldots \ldots \ldots \ldots$

$2.2 \quad$ Projeções Multidimensionais . . . . . . . . . . . . . . . 33

2.3 Projeções utilizando dados kernelizados . . . . . . . . . . . 40

3 UM ESTUDO SOBRE SUBSPACE CLUSTERING E PROJEÇÕES MULTIDIMENSIONAIS . . . . . . . . . . . . . . . . . 45

$3.1 \quad$ Low-Rank Representation . . . . . . . . . . . . . . . 45

$3.2 \quad$ Linear Discriminant Analysis . . . . . . . . . . . . . . . . . 49

3.3 Estudando o efeito de subspace clustering em projeções multidimensionais . . . . . . . . . . . . . . . . 50

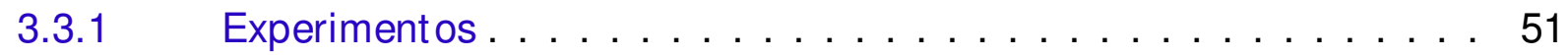

3.3.2 Resultados e discussão . . . . . . . . . . . . . . . 53

3.3.3 Limitações . . . . . . . . . . . . . . . . . . . . . 54

4 KERNEL BASED LINEAR PROJECTION . . . . . . . . . . 57

$4.1 \quad$ Fundamentação matemática . . . . . . . . . . . . . 57

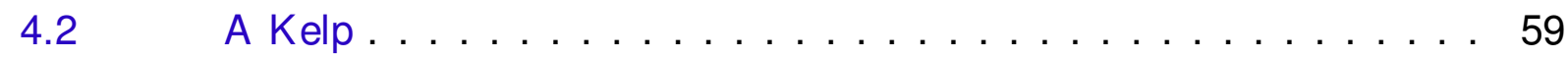

$4.3 \quad$ Centralização no espaço de características . . . . . . . . . . 61

$4.4 \quad$ Projeção dos pontos de controle . . . . . . . . . . . . . 62

$4.5 \quad$ Aspectos computacionais. . . . . . . . . . . . . 63

$4.6 \quad$ Result ados e comparações . . . . . . . . . . . . . . . . . 64

$4.7 \quad$ Aplicações . . . . . . . . . . . . . . . . . . 69

4.7.1 Mudança de vizinhança induzidas pelo kernel . . . . . . . . 70

4.7 .2 Visualização de SVM . . . . . . . . . . . . . . 73

4.7.3 Segmentação de imagem baseada em kernel . . . . . . . . . . . 74

4.8 Discussão e limit ações . . . . . . . . . . . . . . . . . . . 75

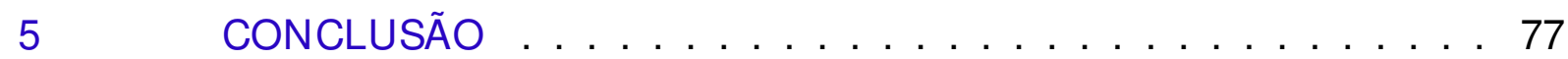

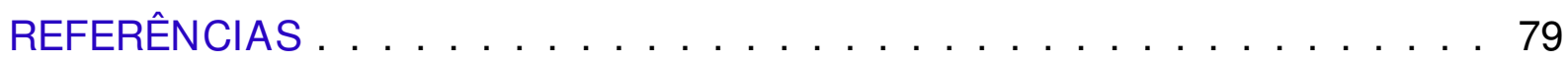


APÊNDICES

APÊNDICE A Ü DEMONSTRAÇÕES ................. 87 
CAPÍTULO

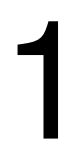

1

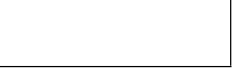

INTRODUÇÃO

Dados de alta di mensão podem ser coletados de várias fontes, incluindo pesquisa de campo, experimentos físi cos e coleções de imagens. Esse tipo de dado é usual mente descrito em termos de coordenadas em um espaço cartesiano de al ta dimensão ( $R^{n}$ com $n$ grande). Como não conseguimos visual izar esse espaço di retamente, utilizamos ferramentas matemáticas e computacionais, como projeção multidimensional, que tem a capacidade de processar e apresentar esse tipo de dado de uma forma compreensível.

Algumas técnicas de projeção multidi mensional assumem que os dados estão contidos ou próximo a um único subespaço ou variedade de dimensão menor que o espaço cuja di mensão é dada pel o número de atributos dos dados. Entretanto, não há razão para que essa suposição seja sempre verdade. Suponha que as instâncias de dado estão imersas em subespaços independentes. Essa suposição nos leva diretamente para um problema de segmentação de subespaços (subspace clustering), cujo objetivo é segmentar as instâncias em grupos, cada um pertencendo a um subespaço. Técnicas de subspace clustering são capazes de detectar estrutura de subespaços, mesmo que a quantidade e dimensão dos subespaços seja desconhecida. A Figura 1 ilustra o funcionamento de uma técnica de subspace clustering onde o dado é composto por instâncias pertencentes a um pedaço de plano e a um segmento de reta não paral el os, ambos com ruído e imersos no espaço tridi mensional. As instâncias são identificadas como pertencentes a um dos subespaços. Tais técnicas mostram sua importância em várias áreas como visão computacional (COSTEIRA; KANADE, 1998; KANATANI, 2001; ZELNIK-MANOR; IRANI, 2003), processamento de imagem (YANG et al., 2008; HONG et al., 2006) e sistemas de identificação (ZHANG; BITMEAD, 2005)

Técnicas de projeção multidimensional são ferramentas importantes por conseguir lidar com um grande número de atributos e instâncias (PAULOVICH et al., 2011), tornando-as ideais para visual ização de dados de al ta dimensão. Uma vez que deteç̧ão de subespaço tem se mostrado útil em diversos contextos, seria possível empregálas em conjunto com projeções 
Figura 1 - Ilustração da aplicação de uma técnica de subspace clustering: dados contidos em subespaços de dimensão 1 e 2 imersos em $\mathrm{R}^{3}$ são classificados.

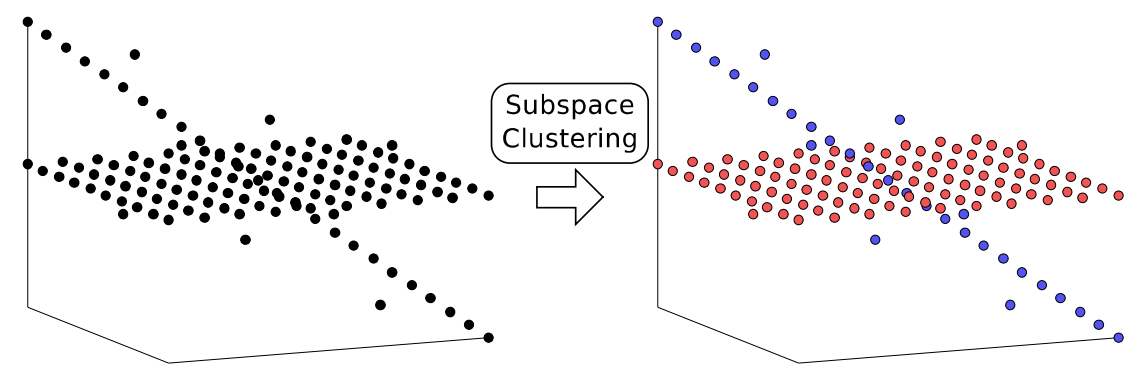

multidimensional a fim de gerar visual izações ainda mai s informativas?

No Capítulo 3 apresentaremos um estudo (BARBOSA; SADLO; NONATO, 2015) sobre efeito da aplicação de técnicas de subspace clustering, como a Low-Rank Representation (ZHANG et al., 2014) (LRR), no auxílio a projeções multidimensionais. Utilizamos a segmentação em subespaços gerada pela LRR como rótulo para as instâncias de dado e ef etua mos redução de dimensi onalidade com Linear Discriminant Analysis (BISHOP, 2006) (LDA). Comparamos a qual idade dessas projeções com técnicas bastante conhecidas na literatura como a Local Affine Multidimensional Projection (JOIA et al., 2011) (LAMP) e t-Distributed Stochastic Neighbor Embedding (MAATEN; HINTON, 2008) (t-SNE). Esse é um primeiro estudo no sentido de apl icar técni cas de subspace clustering combi nadas com técni cas de visual ização e redução de dimensionalidade. Além disso, propomos uma mudança na LAMP para que possa fazer uso da informação de subespaços do dado durante o processo de projeção.

Outra grande ferramenta que surge para auxiliar no estudo de projeções multidimensionais envol ve técnicas de kernel. O crescente interesse nesses métodos é motivado pel os resultados positivos obti dos em apl icações de agrupamento e classificação (SCHÖLKOPF; SMOLA, 2001). Funções kernel podem ser vistas como medidas de similaridade entre instâncias de dados e fornecem uma maneira de transformar dados para um novo espaço de características (espaço de Hilbert $\mathrm{H}$ ), permitindo que estruturas e padrões presentes no dado sejam mel hor caracterizados neste espaço. Dessa forma, tarefas de classi ficação e agrupamento podem ser efetuadas com mais facilidade e eficiência.

Associado a uma função kernel existe uma mapeamento implícito $\varphi$ responsável por levar o dado do seu espaço original para o espaço de características $\mathrm{H}$ (dado kernelizado). Esse mapeamento é geralmente difícil de ser encontrado, tornando compl exo o entendimento de estruturas intrínsecas dos dados, como vizinhança. A Figura 2 ilustra o mapeamento $\varphi$ associado a uma função kernel transformando uma estrutura não linear no espaço original numa estrutura linear no espaço de características.

Entender como um kernel real iza o mapeamento dos dados no espaço de características é muito importante, principalmente para auxiliar a confecção de kernels com propriedades específicas e entender como as rel ações de vizinhança são af etadas. 
Figura 2 - Imersão dos dados $X$ no espaço de al ta dimensão $H$ transformando um padrão não linear numa estrutura linear.
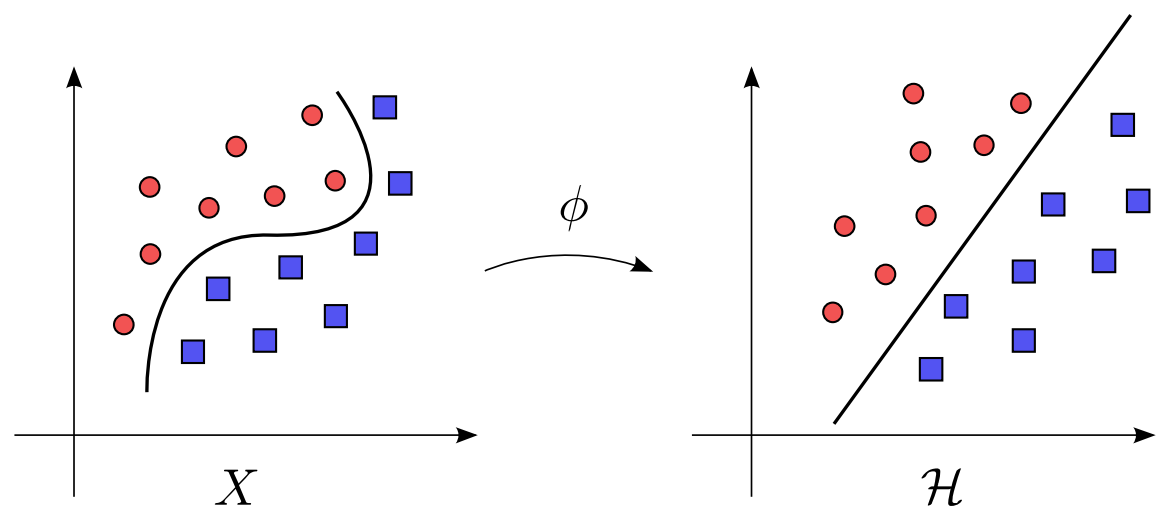

No Capítulo 4 propomos uma técnica de visual ização de informação chamada Kernelbased Linear Projection (BARBOSA et al., 2016) (Kelp) capaz de lidar com dados kernelizados, mesmo sem conhecer suas coordenadas. A Kelp permite visual izar como a imersão realizada por um kernel no espaço de características af eta a estrutura de vizinhança dos dados. Nossa técnica é composta por dois passos principais. Primeiramente, um subconjunto pequeno de instânciaspontos de controle - é proj etado no espaço visual através de uma estratégia de forças que busca minimizar uma função de energia Em seguida, todo o conjunto de dados é projetado tomando como ref erência o posi cionamento dos pontos de controle. Fazemos também uma comparação entre os resul tados obtidos pela Kelp e técnicas de projeção multidimensional que utilizam distância como dado de entrada.

A ideia do método é assumir que conhecemos a imersão $\varphi$ dos dados no espaço de características associada a função kernel, ou seja, sua imagem nesse espaço. Com base na posição dos pontos de controle no espaço visual, definimos uma transformação linear que interpola tal posicionamento e projeta o conjunto de dados utilizando essa transformação linear. As contribuições desse trabal ho incluem uma nova técnica de projeção multidimensional com base matemática sólida capaz de visualizar dados kernelizados. Além disso, combinamos a Kel p com uma versão kernelizada das coordenadas diferenciais (LIPMAN et al., 2004) a fim de entender como a estrutura de vizinhança dos dados é af etada durante o mapeamento da função $\varphi$ associada ao kernel.

As principais contribuições desta tese são:

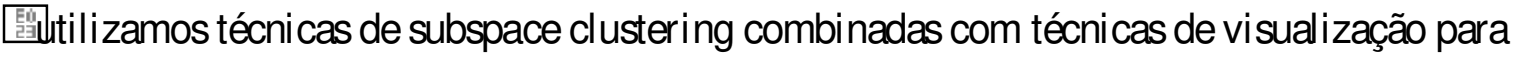
redução de dimensi onalidade;

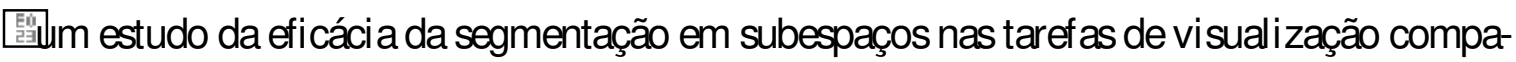
rando técnicas que necessitam da informação de classe;

鼠uma modificação na LAMP para que possa utilizar a informação de classe; 
腎Uma nova técnica de projeção multidimensional chamda Kelp capaz de lidar com dados kernelizados;

監 uso da Kelp, como ferramenta de visual ização, para auxiliar em aplicações baseadas em kernel; por exemplo, classificação e segmentação de imagem;

與Uma versão kernelizada das coordenadas diferenciais combinada com a Kelp a fim de entender como o kernel afeta as estruturas de vizinhança do dado durante o mapeamento para o espaço de características.

Esta tese está estruturada da segui nte forma:

Capítulo 2: fazemos uma revisão bibliográfica dos principais trabal hos das áreas de subspace clustering e proj eção mul tidimensional, incl uindo al guns trabal hos que utilizam técnicas de kernel;

Capítulo 3: descrevemos nosso estudo sobre o efeito do uso das técnicas de subspace clustering no auxílio de projeções multidimensionais (BARBOSA; SADLO; NONATO, 2015);

Capítul o 4: descrevemos a técnica Kelp (BARBOSA et al., 2016), principal resultado do doutorado;

Capítul o 5: concl usões sobre os trabal hos e sobre suas contribuições;

Apêndice: contém as demonstrações dos resul tados mais relevantes utilizados na fundamentação teórica dos problemas tratados na tese. 
CAPÍTULO

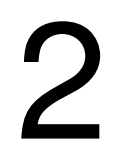

.

\section{TRABALHOS RELACIONADOS}

A presentaremos trabal hos rel evantes na área de subspace clustering e visual ização, tanto no que diz respeito a projeções mul tidimensi onais quanto na utilização da teoria de kernel para fins de visual ização. Os trabal hos discutidos neste capítul o foram escolhidos por se tratarem de estudos clássicos da área ou por representarem o estado da arte no contexto da tese. As técnicas discutidas possuem uma característica em comum: possibilidade do usuário intervir na projeção, ou seja, são técnicas assistidas pelo usuário.

\subsection{Subspace clustering}

Em vários problemas, o dado é representado como instâncias imersas em um espaço de al ta dimensão, frequentemente na vizinhança de subespaços independentes desse espaço. Motivado por esse fato, uma série de técnicas vêm sendo desenvolvidas para detectar tal estrutura de subespaço. Por exemplo, Principal Component Analysis (BISHOP, 2006) (PCA) assume que o dado pertence a um único subespaço e busca as di reções de maior variância dos dados para formar a base do subespaço procurado. Entretanto, supor que o dado pode estar contido num único subespaço é bem restritivo. Técnicas de subspace clustering assumem que o dado pode estar distribuido próximo a vários subespaços independentes, mesmo sem saber a quantidade desses subespaços ou a qual subespaço cada instância de dado pertence. Quando o número de subespaços é igual a 1, o problema se reduz ao PCA. O obj etivo das técnicas de subspace clustering é estimar, caso exista, a estrutura de subespaços, o número e a dimensão de cada subespaço para, em seguida, determinar a qual subespaço cada instância pertence.

Alguns problemas principais surgem quando tentamos estimar a estrutura de subespaços presente nos dados:

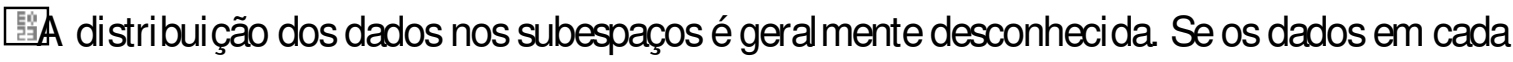
subespaço estão distribuidos em grupos e esses grupos são distantes entre si, o problema 
se torna mais simples. Por outro lado, se a distribuição dos dados se dá de modo que as instâncias estão próximas da interseção dos subespaços, então o problema acaba se tornando mais difícil;

[OS dados podem estar corrompidos, conter ruído e outliers, por exemplo. Esse problema pode fazer com que a esti mativa dos subespaços seja compl etamente errada;

毆Fscol ha do model o de estimativa: no PCA, basta saber a dimensão do subespaço (que pode ser encontrada buscando o subespaço de menor dimensão que comporta os dados). Por outro lado, no caso de múltiplos subespaços, podemos encaixar os dados desde n subespaços de dimensão 1 a um único subespaço de dimensão d. A dificul dade está em definir a combinação do número de subespaços e suas dimensões.

Técnicas de subspace clustering podem ser dividas em quatro tipos: al gébricas (GEAR, 1998; COSTEIRA; KANADE, 1998; BOULT; BROWN, 1991), as quai s estão interessadas em obter a separação do dado a partir da fatoração da matriz do mesmo em matrizes de posto baixo; iterativas (AGARWAL; MUSTAFA, 2004; BRADLEY; MANGASARIAN; PARDALOS, 2000; TSENG, 2000), concebidas para mel horar os resultados obtidos pel os al goritmos al gébricos em dados com ruído - utilizam a segmentação obti da pel os al goritmos al gébricos e aplicam PCA para cada subespaço, iterando entre esse dois passos e refinando o resultado de segmentação do dado em subespaços. Enquanto as técnicas acima utilizam propriedades al gébricas e geométricas, não estão preocupadas com a distribui ção do dado (ou do ruído) nos subespaços. Para preencher essa lacuna, surgem as técnicas denomi nadas estatísticas (TIPPING; BISHOP, 1999; DERKSEN et al., 2007). A classe de métodos espectrais (ELHAMIFAR; VIDAL, 2009; ZHANG et al., 2014) gera uma matriz de afinidade cuja entrada $i j$ mede a similaridade entre as instâncias $i$ e j. Idealmente, entradas com valor 1 significam que as instâncias i e j pertencem ao mesmo subespaço. De posse de uma matriz desse tipo, a segmentação do dado nos seus respectivos subespaços pode ser obtida aplicando o al goritmo k-means aos autovetores da matriz Laplaciana associada a matriz de afinidade.

Um bom tutorial sobre subspace clustering pode ser encontrado em (VIDAL, 2010). A técni ca Low-Rank Representation (LRR) (Capítul o 3) busca, como o nome diz, uma representação (decomposição) em função de uma matriz de posto baixo através de um processo de otimização com restrição. A LRR écapaz de resolver os três princi pais problemas descritos aci ma, estimando o número de subespaços e gerando uma correspondência entre as instâncias de dado e os subespaços. Esta foi a técnica utilizada no estudo descrito no Capítul o 3.

Um trabal ho envolvendo subspace clustering e visual ização pode ser encontrado em (LIU et al., 2015), onde a base e a dimensão dos subespaços são estimados utilizando a distância Grassmanniana, permitindo uma exploração visual interativa do dado através de projeções dinâmicas. 


\subsection{Projeções Multidimensionais}

Sammon (1969) desenvolveu uma técnica cujo objetivo é criar uma projeção dos dados multidimensionais de forma que as distâncias no espaço original sejam preservadas da mel hor forma possível, baseado na medida de stress

$$
E=\frac{1}{\sum_{i<j} \delta_{i j}} \sum_{i<j} \frac{\left(\delta_{i j}-d_{i j}\right)^{2}}{\delta_{i j}}
$$

onde $d_{i j}$ representa a distância entre a instânciai ea instância j no espaço original e $\delta_{i j}$ adistância entre as mesmas instâncias no espaço visual. Inicial mente as instâncias são mapeadas no espaço visual (podendo ser posicionados al eatoriamente) e em seguida o stress dessa configuração é cal cul ado. A partir daí, o posicionamento dos pontos no espaço visual é alterado em pequenos passos de modo a mel horar o resul tado da função de erro dado pelo stress. Esse procedi mento é repetido até que seja encontrado um mínimo da função de erro.

Dois problemas são inerentes à técnica de Sammon: a complexidade do al goritmo pois o cál cul o da função de stress tem compl exidade $\mathrm{O}\left(\mathrm{n}^{2}\right)$, onde $n$ indica a quantidade de pontos a serem projetados - e o fato de ser necessário refazer todo o processo caso um novo ponto precise ser projetado.

Para contornar as dificuldades inerentes ao Sammon Mapping, Pekal ska et al. (1999) apresentou uma generalização da técnica de Sammon. Primeiramente, foi real izado um estudo sobre os al goritmos que poderiam ser utilizados para ef etuar a mi nimização do stress. Em seguida foi proposta uma forma de ef etuar a projeção em função de um subconjunto dos dados. $\mathrm{Na}$ proposta de Pekalska, um subconjunto dos dados seria projetado seguindo o al goritmo original e a partir do posicionamento deles o resto dos dados seria posicionado de modo a evitar distorções no stress.

Três maneiras de posicionar as instâncias restantes foram estudadas: triangul ação, redes neurais e mapeamento de distância A primei ra utiliza dois pontos já projetados como guia para a projeção de cada novo ponto como ilustrado na Figura 3.

A abordagem por redes neurais utiliza como conjunto de treinamento o dado original e a saída produzida é a projeção no espaço visual. Desejamos que a sá́da produzida possa ser ilimitada, e्gntretanto nessętipo de abordagem é comum o uso de funções de ativação como a sigmoide $f(x)=\frac{1}{1+e^{-x}}$ que retorna val ores no intervalo [0國]. Para contornar essa dificuldade, pode-se utilizar outra função de ativação, como uma função linear, por exemplo. Por outro lado, funções de ativação lineares tornam o treino mais complexo, uma vez que é mais difícil encontrar um mínimo para a função de erro.

A última proposta é definir uma transformação linear T que atua na matriz de distâncias de uma amostra dos dados no espaço original, $D_{S}$, resultando no posicionamento dos pontos no espaço visual $Y_{S}$. Para um conjunto de dados $n$ dimensional com $N$ instâncias, toma-se uma 
Figura 3 - A posição do novo ponto $x_{k}$ é dada pela interseção dos círculos definidos pelos pontos já projetados, $x_{i}$ e $x_{j}$, e com raio igual a distância entre o ponto projetado e o novo ponto no espaço original.

(a) Escolhe-se um dos pontos $x_{k}^{1}$ ou $x_{k}^{2}$ como a posição do ponto $x_{k}$

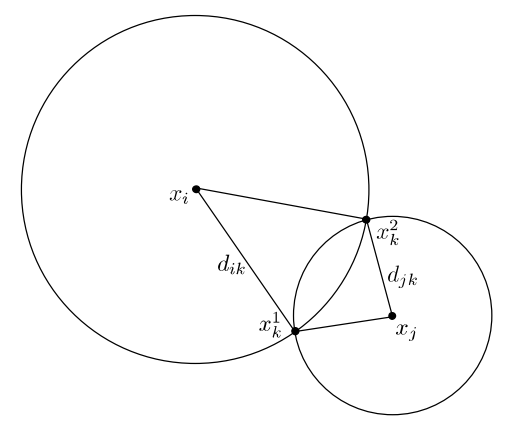

(b) $x_{k}$ é o ponto de interseção entre os círculos

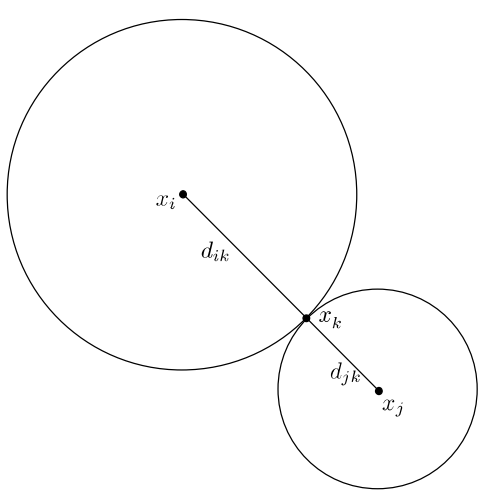

(c) $x_{k}$ é posicionado após fazer uma média ponderada que tem como pesos os raios dos círculos

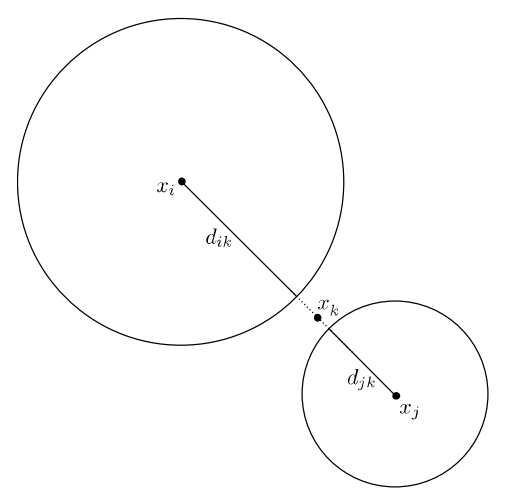

amostra com $\mathrm{k}(\mathrm{k}<\mathrm{N})$ instâncias e define-se a transformação linear:

$$
T_{p \times k} D_{S_{k \times k}}=Y_{S_{p \times k}}
$$

e utiliza-se essa transformação linear para mapear as instâncias restantes

$$
T_{p \times k} D_{k \times(N-k)}^{\prime}=Y_{p \times(N-k)}^{\prime}
$$

resultando na projeção dos $\mathrm{N}$ - k pontos restantes.

Paul ovich et al. (2008) apresenta a técnica chamada Least Square Projection (PAULOVICH et al., 2008) (LSP), a qual é baseada em aproximações feitas por mínimos quadrados.

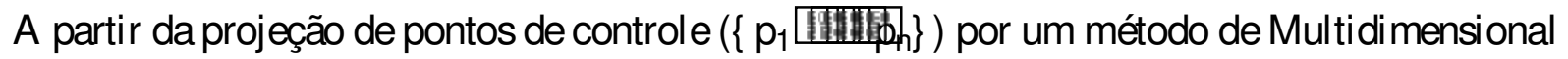

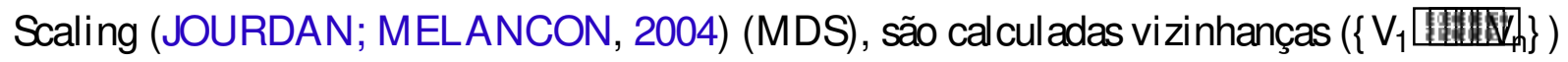
de cada ponto e a partir de cada uma é definida uma matriz que dá origem a um conjunto de sistemas lineares:

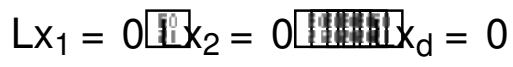

onde $L$ é uma matriz $n \times n$ com entradas

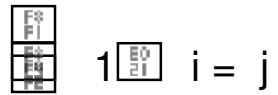

$$
\begin{aligned}
& \mathrm{I}_{\mathrm{ij}}=\mathrm{\alpha}_{\mathrm{ij}} \mathrm{E}_{i=1} \mathrm{p}_{\mathrm{j}} \in \mathrm{V}_{\mathrm{i}} \\
& 0 \text { [ caso contrário. }
\end{aligned}
$$

Os parâmetros $\alpha_{i j}$ acima são tais que

$$
\begin{array}{r}
\tilde{p}_{i}-\sum_{p_{j} \in V_{i}} \alpha_{i j} \tilde{p}_{j}=0 \\
06 \alpha_{i j} 61 ; \sum \alpha_{i j}=1
\end{array}
$$


e $\tilde{p}_{i}$ são as coordenadas de $p_{i}$ no espaço visual.

Problemas com o posto das matrizes levaram Paulovich et al. (2008) a acoplar linhas que representam pontos de controle ao sistema linear, tornando o si stema sobredeterminado e resolvendo-o utilizando o método dos míni mos quadrados. Dessa forma, o sistema a ser resolvido é

$$
A x=b
$$

onde $A$ tem dimensões $(n+n c) \times n$ e é da forma

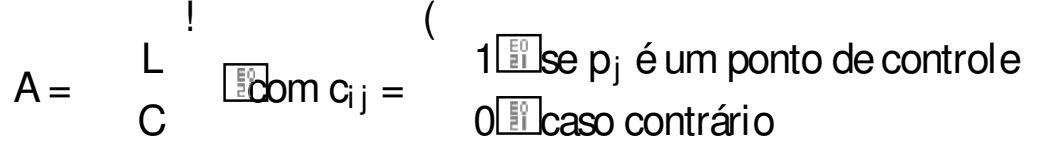

e

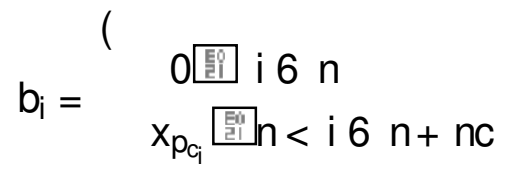

onde $\mathrm{x}_{\mathrm{p}_{\mathrm{c}_{\mathrm{i}}}}$ é uma das coordenadas do ponto de controle $\mathrm{p}_{\mathrm{c}_{\mathrm{i}}}$. A Figura 4 ilustra a construção do sistema para um conjunto de seis pontos. As soluções dos sistemas, dadas pelo método dos mínimos quadrados, retornam as projeções.

Figura 4 - Matriz A com pontos de controle $p_{3}$ e $p_{6}$. Figura retirada de (PAULOVICH et al., 2008)

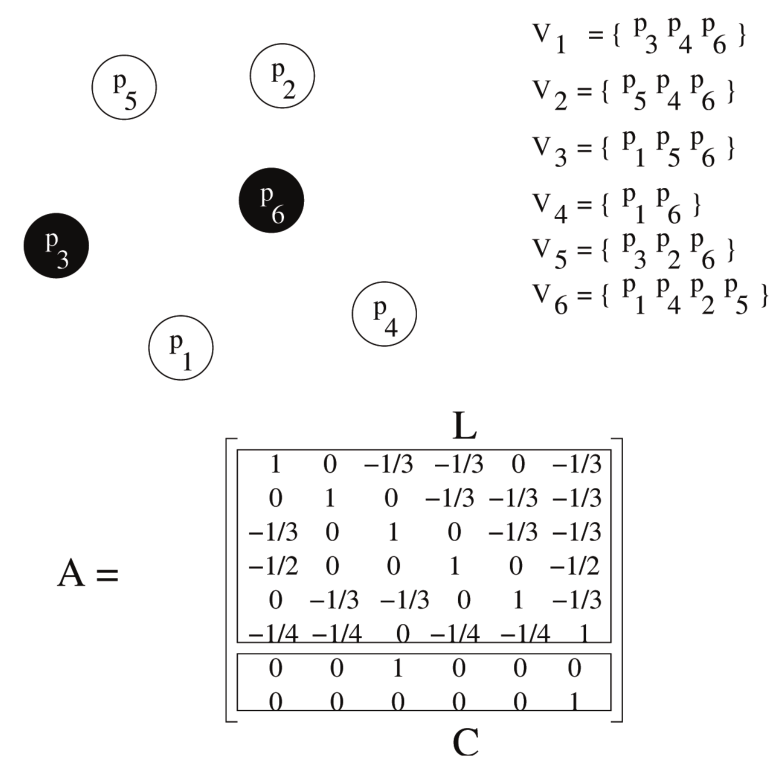

O algoritmo possui complexidade computacional $\mathrm{O}\left(\mathrm{k}^{2}+\mathrm{n}^{2}\right)$, onde $\mathrm{k}$ é o número de pontos de controle e $n$ a cardinalidade do conjunto de dados.

Outra técnica que faz projeção multidimensional é a Part-Linear Multidimensional Projection (PAULOVICH; SILVA; NONATO, 2010) (PLMP). O trabal ho apresenta uma técnica que tenta preservar a distância entre instâncias de dado no espaço original : matematicamente falando, a projeção $\Phi$ deve satisfazer

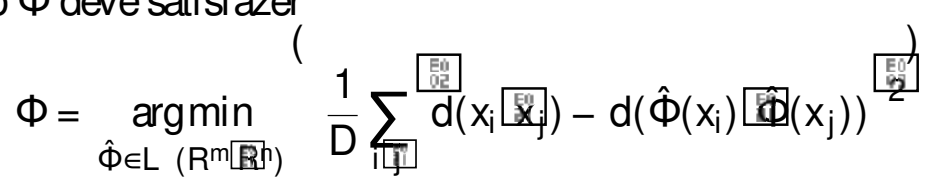


onde $D=\sum_{i[j]} d\left(x_{i}\left[E_{j}\right)^{2}\right.$ e $L \quad\left(R^{m}\left[\mathbb{B}^{n}\right)\right.$ é o espaço das funções lineares de $R^{m}$ em $R^{n}$.

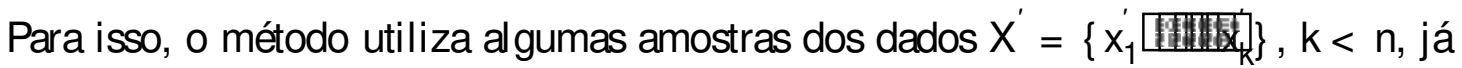
projetadas de modo a preservar distância da melhor forma possível. Daí, a projeção $\Phi$ deve satisfazer

$$
\Phi\left(x_{i}^{\prime}\right)=\bar{x}_{i}^{\prime}
$$

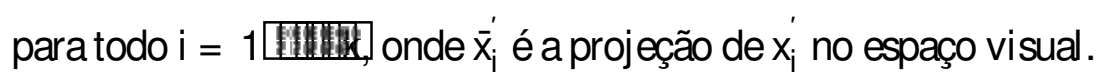

Para cada i, a equação (2.2) nos diz que

$$
\begin{array}{cc}
\varphi_{11} x_{1 i}^{\prime}+\cdots+\varphi_{i m} x_{1 m}^{\prime}= & \bar{x}_{i 1} \\
\varphi_{11} x_{2 i}^{\prime}+\cdots+\varphi_{i m} x_{2 m}^{\prime}= & \bar{x}_{i 2} \\
\vdots & \vdots \\
\varphi_{11} x_{k i}^{\prime}+\cdots+\varphi_{i m} x_{k m}^{\prime}= & \bar{x}_{i k}
\end{array}
$$

onde $\varphi_{i j}$ é a entrada da matriz $\Phi$ nalinhai e coluna j. Reescrevendo o sistema (2.3) $\operatorname{como} L \varphi \varphi_{1}=\bar{x}_{i}$, com $L_{k \times m}$, e assumindo que $k$ é maior que $m$, Paulovich, Silva e Nonato (2010) resolvem o sistema através da solução da equação normal

$$
L^{\top} L \varphi_{i}=L^{\top} \bar{x}_{i}
$$

Visto que a projeção final depende da escol ha dos pontos de controle, Paul ovich, Silva e Nonato (2010) fazem uma comparação entre duas formas de escolhêlos, agrupando ou escol hendo al eatoriamente. A Figura 5 mostra que a medida de stress estabiliza tanto quando se utiliza uma escol ha al eatória quanto uti lizando agrupamento quando a quantidade de amostras é próxima de $\overline{\bar{n}}$.

Figura 5 - Comparação entre escol ha por agrupamento e al eatória testada em dois conjuntos de dados diferentes. Figura retirada de (PAULOVICH; SILVA; NONATO, 2010)
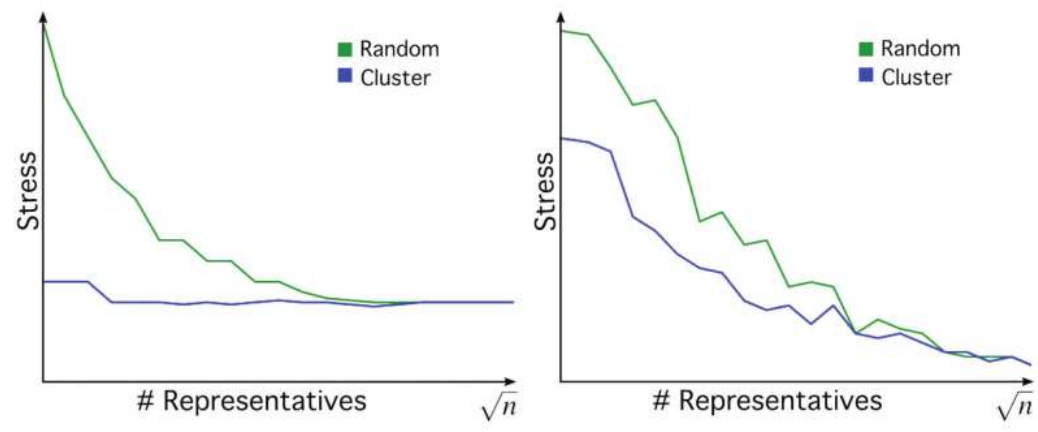

Paul ovich, Silva e Nonato (2010) fazem uma anál ise de custo computacional e o número de amostras $\mathrm{k}=\sqrt{\mathrm{n}}$ se apresenta uma boa escol ha, pois gera projeções de qual idade adequada $\mathrm{e}$ fazem o custo computacional do al goritmo ser linear (após o cál culo da transformação L) com relação a quantidade de instâncias de dado.

A PLMP apresenta as mesmas limitações que a LSP, pois se trata de uma projeção de natureza global. 
Uma técnica cujo ponto forte é a interatividade é a Piece-wise Laplacian-based Projection (PAULOVICH et al., 2011) (PLP). Ela é desenvolvida em três passos: amostragem, construção do grafo de vizinhança e sol ução do sistemalinear Laplaciano. A escol ha dos pontos de controle pode ser feita de acordo com a aplicação. Essa escol ha funciona de forma semel hante à feita na PLMP (al eatoriamente ou agrupamento, por exemplo). Essas amostras são utilizadas para dividir o conjunto de dados em subconjuntos que irão gerar o grafo de vizinhança que dá origem ao sistema Laplaciano. Sejam $p_{i}$ uma instância de dado que pertence ao subconjunto

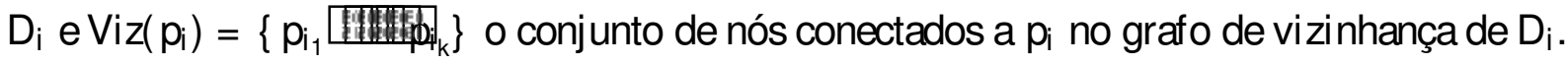
A nal ogamente a LSP, a PLP assume a hi pótese da combi nação convexa (equação (2.1)), dessa forma:

$$
\overline{p_{i}}=\left(x_{p_{i}} \bar{y}_{p_{i}}\right)=\sum_{p_{i j} \in \operatorname{Viz}\left(p_{i}\right)} \alpha_{i j}\left(x_{p_{i j}} \bar{y}_{p_{i j}}\right)
$$

onde $\alpha_{i j}>0, \sum \alpha_{i j}=1 e\left(x_{p_{i j}} g_{p_{i j}}\right)$ são as coordenadas de $p_{i_{j}}$ no espaço visual.

Daí são derivados dois sistemas lineares:

$$
L x=0 \text { e } L y=0
$$

onde

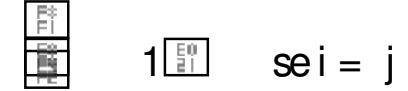

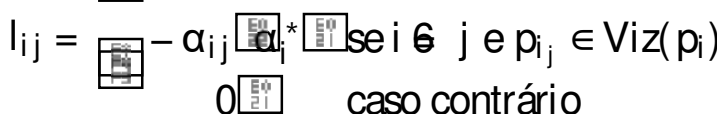

$e \alpha_{i}^{*}=\sum p_{i j} \in V i z\left(p_{i}\right) \alpha_{i j}$. Resolver os sistemas resul ta em encontrar a projeção.

Outra contribuição do trabal ho foi o desenvolvimento de um mecanismo para definir vizinhança no espaço de al ta dimensão a partir da vizinhança no espaço visual. A interatividade é utilizada no ajuste dos pontos projetados a fim de melhorar a projeção. Entretanto, esses ajustes fazem o custo computacional da técnica ser elevado. A Figura 6 apresenta um resul tado al cançado pela PLP.

A técnica Local Affine Multidimensional Projection (LAMP) (JOIA et al., 2011) foca na flexibilidade e interatividade com o usuário. O método cal cula, para cada ponto, uma apl icação afim

$$
\begin{array}{rl}
f: R^{n} & \rightarrow R^{2} \\
p & 7 \rightarrow f(p)=M p+t
\end{array}
$$

que mapeia os pontos no espaço visual obedecendo a restrição $\mathrm{MM}^{\top}=1$. A translação $t$ é escrita em função da matriz $\mathrm{M}$ e, com isso, para cal cular a transf ormação f é suficiente cal cular a matriz M. A restrição garante projeções com mel hor qual idade. O cál culo da matriz $M$ é feito através de um processo de otimização idêntico ao Problema de Procrustes (GOWER; DIJKSTERHUIS, 2004), cuja solução é dada por

$$
M=U V \mathrm{EA}^{\top} B=U D V
$$

onde UDV é a decomposição em val ores singulares de $A^{\top} B$. As matrizes $A$ e $B$ são matrizes construídas durante o processo de mi ni mização. A grande vantagem da técni ca se deve ao fato de 
Figura 6 - (a) Swiss Roll. (b) PLP usando Force Scheme e distância euclidiana para posicionar os pontos de controle. (c) PLP usando Isomap para posi cionar os pontos de controle. (d) PLMP usando Isomap para posicionar os pontos de controle. Figura retirada de (PAULOVICH et al., 2011)

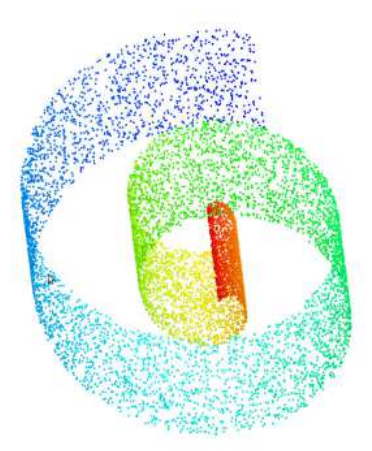

(a)

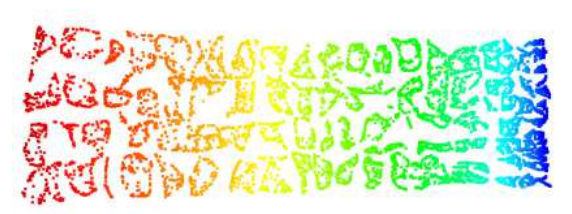

(c)

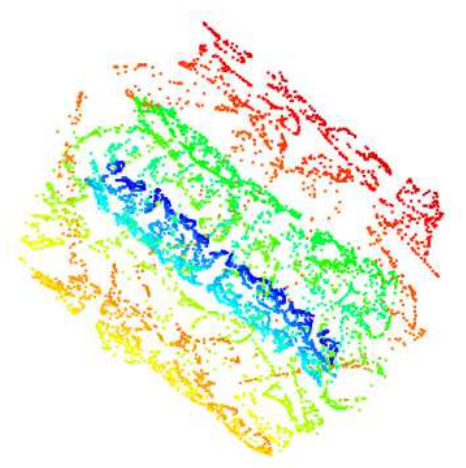

(b)

utilizar pouquíssi mos pontos de controle quando comparado as demais e ainda assim conseguir apresentar resul tados muito bons com a métrica de stress, como ilutrado na Figura 7.

Figura 7 - Medida de stress da LAMP com rel ação a quantidade de pontos de controle tomados para gerar a projeção. Figura retirada de (JOIA et al., 2011)

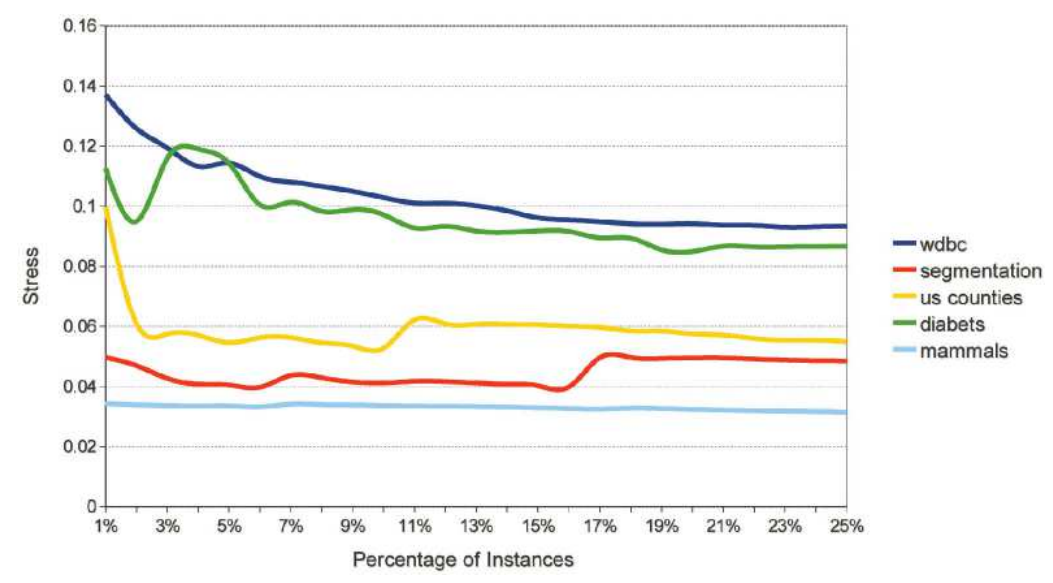

Em consequência da grande possibilidade de aplicações, Joia et al. (2012) desenvolveu a Class-Specific Multidimensional Projection (JOIA et al., 2012) (CSMP), uma técnica interativa e que tem a capacidade de ef etuar buscas multiobjetivas (multi-objective searches) e é aplicada no contexto de Content-Based Image Retrieval (CBIR). O método usa métricas específicas e projeção multidimensional na classificação e visual ização das imagens. Primei ramente é feita extração de características das imagens e em seguida, com base nos objetivos da pesquisa, é criada uma métrica específica para cada um del es. Uma grande vantagem da metodol ogia é poder 
escol her visual mente a qual classe pertence cada imagem dada como entrada na pesquisa como ilutrado na Figura 8.

Figura 8 - Manipulação do usuário para escol her as classes de cada imagem. Figura retirada de (JOIA et al., 2012)
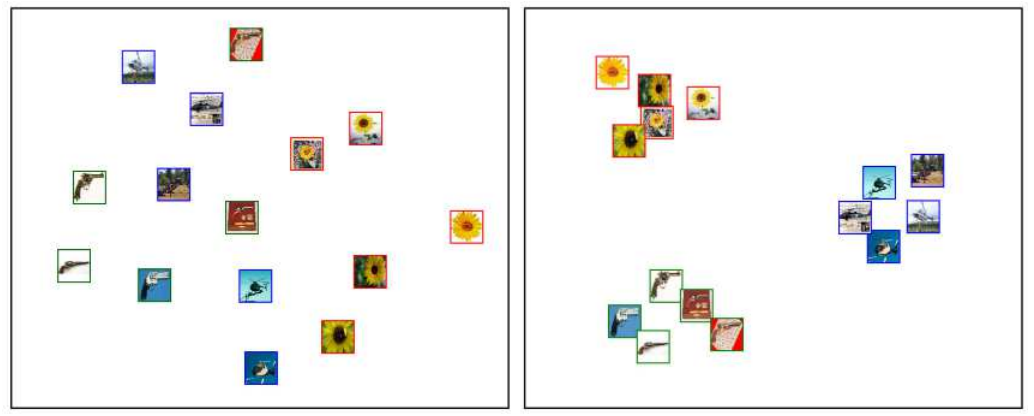

Sejam $Q_{i}$ um subconjunto das imagens de pesquisa que pertencem a mesma classe e

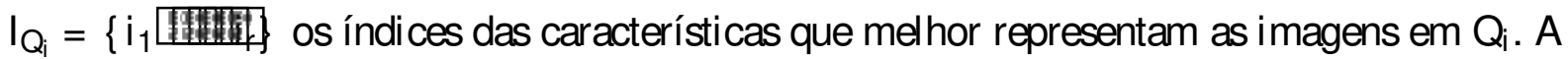
métrica da classe é definida por

$$
d_{Q_{i}}\left(\alpha[\beta)=\sum_{j \in \Phi_{Q_{i}}}\left(\alpha_{j}-\beta_{j}\right)^{2}\right.
$$

onde $\alpha_{\mathrm{j}}$ e $\beta_{\mathrm{j}}$ são as j-ési mas coordenadas das imagens $\alpha$ e $\beta$, respectivamente.

Essa métrica tem como base que imagens de um mesmo grupo tenham distância menor entre elas do que quando comparadas com imagens de outro grupo. Com base na dissi milaridade cal culada pel as métricas de cada grupo é feita a projeção no espaço visual. A técnica apresenta bons resultados tanto no contexto de projeção mul tidi mensional quanto no contexto de CBIR. As Figuras 9a e 9b mostram um comparativo da CSMP com outras técnicas no contexto de projeção multidimensional e CBIR, respectivamente.

Figura 9 - Resultados da técnica CSMP. Figura retirada de (JOIA et al., 2012)

(a) Comparação da CSMP com outras técnicas de projeção através da si lhueta

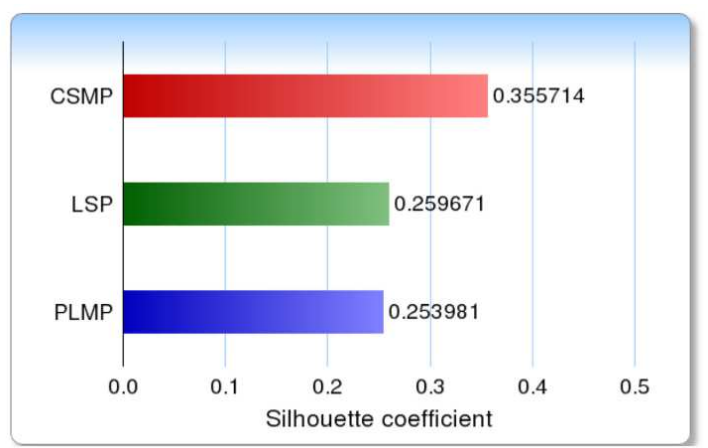

(b) Comparação da CSMP com a técnica FIRE no contexto de CBIR

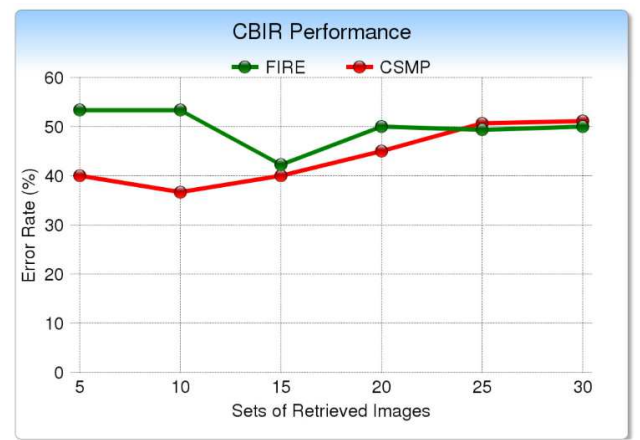

Um trabal ho que tem despertado cada vez mai s interesse da comunidade de visual ização é descrito por Maaten e Hinton (2008) devido a sua capacidade de manter a estrutura local dos 
dados e revelar importantes estruturas gl obais como agrupamento. A t-Distributed Stochastic Neighbor Embedding (t-SNE) é uma técnica não linear de redução de dimensional idade composta por dois estágios principais. Inicial mente uma medida de si milaridade é construída baseada em uma distribuição de probabilidades de modo que a probabilidade de que uma instância $x_{j}$ seja escolhida como vizinha de uma instância $x_{i}$ seja alta se essas instâncias são similares. Matematicamente, a t-SNE cal cula as probabilidades $p_{i j}$ entre as instâncias $x_{i}$ ex $x_{j}$ por

$$
p_{i j}=\frac{p_{j \mid i}+p_{i \mid j}}{2 n}
$$

onde n é o número de instâncias e

$$
p_{j \mid i}=\frac{\exp \left(-k x_{i}-x_{j} k^{2}\left[2 b_{i}^{2}\right)\right.}{\sum k \epsilon_{i} \exp \left(-k x_{i}-x_{k} k^{2}\left[2 \sigma_{i}^{2}\right)\right.}
$$

com $\sigma_{i}$ sendo a variância da gaussiana centrada em $x_{i}$.

Em segui da, outra medida de similaridade baseada em uma di stribui ção de probabilidades é construída, mas dessa vez utilizando as instâncias de dado mapeadas no espaço visual. Como o objetivo é encontrar um mapeamendo no espaço visual que preserve a medida $p_{i j}$ da melhor forma possível, define-se a medida de similaridade $q_{i j}$ entre $y_{i}$ e $y_{j}$ (projeções de $x_{i}$ e $x_{j}$ ) da seguinte forma

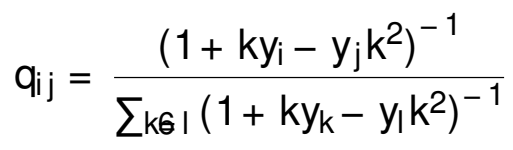

A posição das instâncias no espaço visual é determinada minimizando a divergência de Kullback-Leibler entre as distribuições $P$ e $Q$ acima, isto é

$$
K L(P \| Q)=\sum_{i \in j} p_{i j} \log \frac{p_{i j}}{q_{i j}}
$$

Para ef etuar a minimização, utiliza-se o gradiente

$$
\frac{\partial C}{\partial y_{i}}=4 \sum_{j}\left(p_{i j}-q_{i j}\right)\left(y_{i}-y_{j}\right)\left(1+k y_{i}-y_{j} k^{2}\right)^{-1}
$$

\subsection{Projeções utilizando dados kernelizados}

A extensão natural do PCA (BISHOP, 2006) para dados kernelizados foi feita por SchÖlkopf, Smola e MÜller (1998), chamada de Kernel PCA (SCHÖLKOPF; SMOLA; MÜLLER, 1998) (KPCA). Os autores utilizam a mesma metodologia do PCA, mas aplicada aos dados

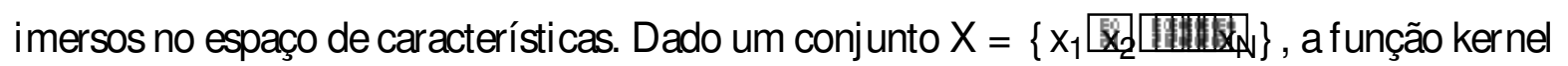

$$
\begin{aligned}
\mathrm{k}: \mathrm{X} \times \mathrm{X} & \rightarrow \mathrm{R} \\
\left(\mathrm{x}_{\mathrm{i}} \mathrm{E}_{\mathrm{j}}\right) & \rightarrow \mathrm{k}\left(\mathrm{x}_{\mathrm{i}} \text { 國 }\right)=\varphi\left(\mathrm{x}_{\mathrm{i}}\right)^{\top} \varphi\left(\mathrm{x}_{\mathrm{j}}\right)
\end{aligned}
$$

define um mapeamento não linear $\varphi: X \rightarrow H$ do conjunto $X$ num espaço de Hilbert $H$. A aplicação $\varphi$ é definida implicitamente pela função kernel. 
Uma vez que os dados foram imersos no espaço de características $H$, digamos $\varphi(X)=$

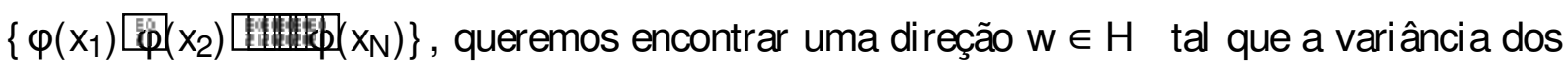
dados projetados nessa direção seja a máxima possível. Matematicamente,

$$
\underset{w}{\operatorname{argmax}}\left\{\operatorname{var}\left(w^{\top} \varphi(X)\right)\right\}=\underset{w}{\operatorname{argmax}}\left\{w^{\top} C w\right\}
$$

onde $C=\frac{1}{N} \sum_{i=1}^{N}\left(\varphi\left(x_{i}\right)-\mu\right)\left(\varphi\left(x_{i}\right)-\mu\right)^{\top}$ e $\mu=\sum_{i=1}^{N} \varphi\left(x_{i}\right)$.

Isso equivale a resolver o problema de autovetores e autoval ores

$$
C w=\lambda w
$$

e o autovetor associado ao maior autovalor é a di reção que maximiza a variância SchÖlkopf, Smola e MÜller (1998) mostram ainda que resolver o problema acima é equival ente a resolver o seguinte problema

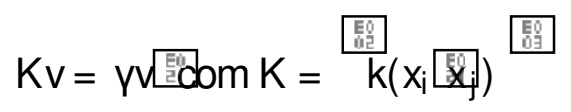

onde os autovetores e autoval ores de $\mathrm{C}(\mathrm{w}, \mathrm{\gamma})$ e K $(\mathrm{v}, \lambda)$ obedecem a seguinte relação

$$
\mathrm{V}=\mathrm{N} \lambda \text { e } \mathrm{w}=\sum_{i=1}^{\mathrm{N}} \mathrm{v}_{\mathrm{i}} \varphi\left(\mathrm{x}_{\mathrm{i}}\right) \text { 㹂 }
$$

Por fim, a projeção de uma instância de dado $\varphi\left(x_{j}\right)$ sobre a i-ésima direção principal $\mathbf{w}_{\mathrm{i}}$ é cal culada como

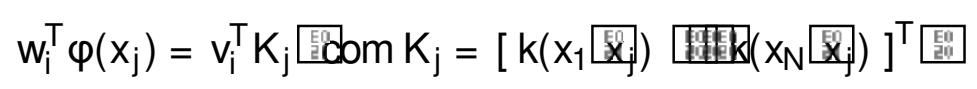

Ham et al. (2004) utiliza a teoria de kernel learning para fazer a interpretação de três al goritmos de redução de dimensionalidade, I somap, Laplacian Eigenmap, Locally Linear Embedding (LLE), utilizando uma abordagem por kernel. A abordagem constrói um mapeamento implíci to do conjunto de treinamento no espaço de características que preserva as propriedades importantes do dado. Esse mapeamento é descrito pel a matriz do kernel que representa o produto interno do espaço de características.

Para al cançar resultados semel hantes aos da Isomap, Ham et al. (2004) utilizam o kernel que retorna a matriz

$$
K_{\text {Isomap }}=-\frac{1}{2}\left(I-e e^{\top}\right) S\left(I-e e^{\top}\right)
$$

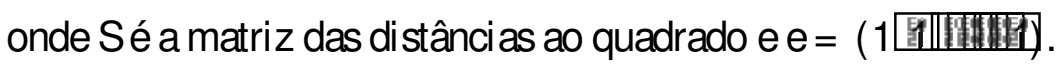

A técnica Laplacian eigenmap utiliza uma matriz de adjacências $W$, onde

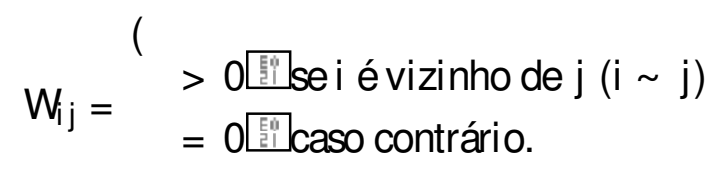


Além disso, o grafo Laplaciano $L$ definido em termos da matriz de adjacências $W$ é tal que

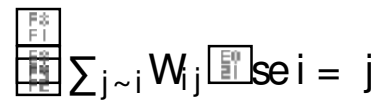

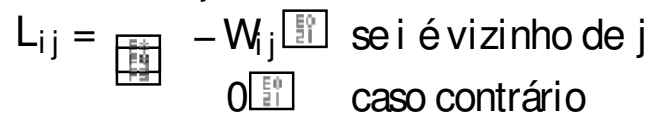

onde a matriz do kernel é dada pel a matriz dos autovetores associados aos maiores autoval ores da matriz pseudo-inversa de $L$.

Por fim, como o al goritmo Locally Linear Embedding (HAM et al., 2004) (LLE) constrói uma matriz de pesos W que leva em consi deração os vizinhos de cada instância de dado, Ham et al. (2004) definem a matriz

$$
M=\left(I-W^{\top}\right)(I-W)
$$

cujo maior autoval or é chamado $\lambda_{\max }$. Daí, a matriz do kernel utilizada é dada por

$$
K=\lambda_{\text {max }} I-M
$$

A Figura 10 apresenta o resultado das técni cas de redução de dimensional idade apl icadas à variedade $S$.

Figura 10 - Técnicas I somap (B), Laplacian Eigenmap (C) e LLE (D) aplicadas a variedade S(A). Figura retirada de (HAM et al., 2004)

A

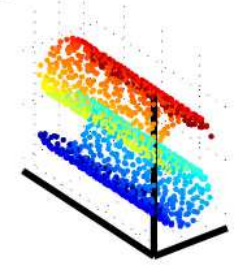

B

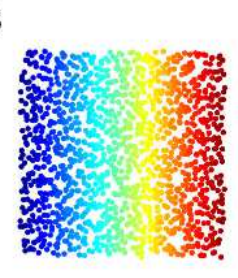

C

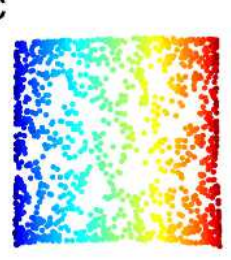

D

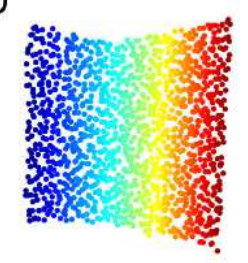

Uma proposta para interpolação para novas instâncias baseado em combinações lineares de instâncias já mapeadas é feita por Inaba, Sal les e Rauber (2011). Os autores utilizam a teoria de kernel para mapear os dados num espaço de Hilbert e a partir desses dados aplicar uma metodologia similar à feita por Sammon (1969). A distância utilizada no espaço de Hilbert é dada por

$$
\begin{aligned}
& D_{i j}^{2}=k \varphi\left(x_{i}\right)-\varphi\left(x_{j}\right) k^{2} \\
& =\varphi\left(x_{i}\right)^{\top} \varphi\left(x_{i}\right)-2 \varphi\left(x_{i}\right)^{\top} \varphi\left(x_{j}\right)+\varphi\left(x_{j}\right)^{\top} \varphi\left(x_{j}\right)
\end{aligned}
$$

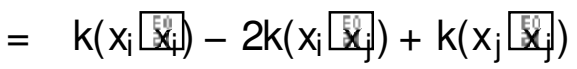

e é escrita em função do kernel. A Figura 11 ilustra o pipeline da técnica.

Uma contribuição de I naba, Salles e Rauber (2011) é a formulação de uma medida de stress definida em função de distância baseada em kernel no espaço de características

$$
E_{n}=E\left(\left\{y_{1} \text { TIIIII }\left.\right|_{n}\right\}\right)=\sum_{i<j}^{n} \frac{\left(D_{i j}-d_{i j}\right)^{2}}{D_{i j}}
$$


Figura 11 - Pipeline da técnica Kernel Sammon Map. Figura retirada de (INABA; SALLES; RAUBER, 2011)

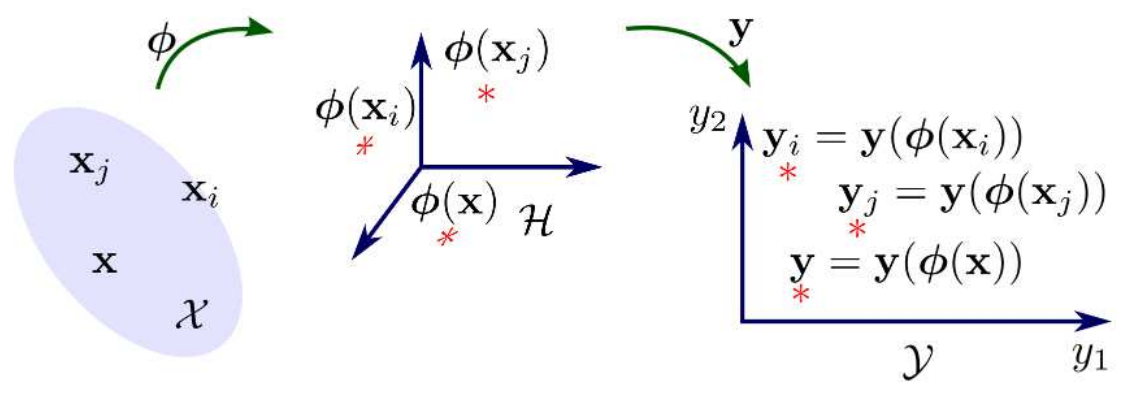

Além disso, Inaba, Sal les e Rauber (2011) apresentam uma metodologia para mapear novas instâncias de dados a projeção sem a necessi dade de recal cular todo mapeamento e de modo a não piorar o erro, pois para cal cular o erro

$$
E_{n+1}=E_{n}+\sum_{i=1}^{n} \frac{\left(D_{i} \text { 雷 } 1-d_{i} \text { 圆 }\right)^{2}}{D_{i} \text { 肙 }+1}
$$

só é necessário estimar a segunda parcela

Em (ALZATE; SUYKENS, 2008) é feita uma extensão da formul ação least squares support vector machine para o Kernel PCA (KPCA) utilizando uma general ização da função de perda, $L: R \rightarrow R$

$$
\min _{w \in} J_{p}(w i b)=\frac{Y}{2} \sum_{i=1}^{N} L(e)-\frac{1}{2} w^{\top} w
$$

onde, $\mathrm{e}_{\mathrm{i}}=\mathrm{w}^{\top} \varphi\left(\mathrm{x}_{\mathrm{i}}\right)+\mathrm{b}$.

Outro trabal ho que apresenta uma revisão do al goritmo I somap utilizando a teoria de kernel é devido a Choi e Choi (2004). Dada a matriz de distâncias geodésicas (aproximadas) $D^{2}$, é construída a matriz

$$
K\left(D^{2}\right)=-\frac{1}{2} H D^{2} H
$$

onde $\mathrm{H}$ é a matriz de centralização, dada por

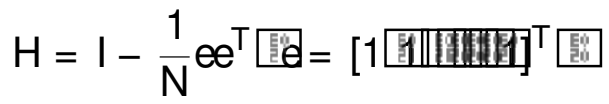

A partir daí, é cal culado o maior autoval or c da matriz

$$
\begin{array}{cc}
0 & 2 K\left(D^{2}\right) \\
-I & -4 K(D)
\end{array}
$$

e por fim, é cal culada a matriz do kernel

$$
K=K\left(D^{2}\right)+2 c K(D)+\frac{1}{2} c^{2} H \text { 辰 }
$$

As técni cas apresentadas nesse capítul o são o estado da arte no tocante a projeções de dados multidi mensionais (dados euclidianos). Entretanto, são limitadas ao lidar com dados que 
não estão imersos num espaço com coordenadas, seja pela fal ta de interatividade com o usuário ou pela incapacidade de lidar com dados kernelizados. Uma manei ra de contornar essa limitação é utilizar técni cas capazes de explorar propriamente esse novo paradigma de dados e que ainda permita a interação do usuário no processo de visual ização como a Kelp (Capítulo 4). 
CAPÍTULO

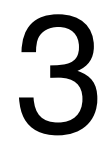

12

\section{UM ESTUDO SOBRE SUBSPACE CLUSTERING E PROJEÇÕES \\ MULTIDIMENSIONAIS}

Neste capítulo, apresentaremos um estudo sobre o efeito de técni cas de subspace clustering no auxílio a técni cas de projeção multidimensional. Faremos ini cial mente uma introdução às técnicas de subspace clustering e em seguida os resultados obtidos no estudo. Esse trabal ho foi primei ramente descrito em (BARBOSA; SADLO; NONATO, 2015).

\subsection{Low-Rank Representation}

Nesta seção apresentaremos brevemente al guns detal hes da técni ca de subspace clustering denominada Low-Rank Representation (LRR) (ZHANG et al., 2014). Sejam um conjunto

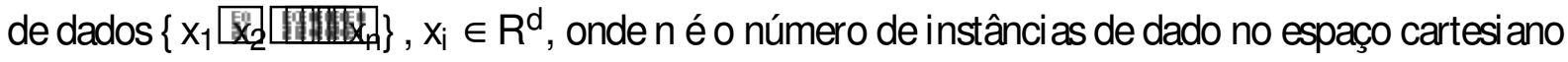
d-dimensional e $X$ sua representação matricial, onde cada instância $x_{i}$ é di sposta como coluna de $X$. Suponha que o dado possa ser decomposto da forma $X=D+E$, onde $D$ é o dado obtido de subespaços independentes e E é o "erro" no dado devido a outliers, ruído ou fal has na col eta, por exemplo. O objetivo da técnica LRR é encontrar uma matriz D de posto baixo a partir da matriz $X$ com erro $E$.

Podemos escrever a questão acima como o seguinte problema de mi nimização com regularização:

$$
\min _{D E} p o s t o(D)+\lambda k E k_{\ell} \text { Etal que } X=D+E
$$

onde $\lambda>0$ é um parâmetro e $\mathrm{k} \cdot \mathrm{k}_{\ell}$ é a estratégi a de regularização a ser escol hida. Entretanto, para conseguir uma flexibilidade maior, reescrevemos (3.1) como:

$$
\operatorname{Zin}_{Z} \operatorname{posto}(Z)+\lambda k E k_{\ell} \text { 卧杖 que } X=A Z+E
$$


com A sendo um "dicionário" que gera o espaço dos dados. De posse da solução $\left(Z^{*}\left[\mathbb{F}^{*}\right)\right.$ do problema (3.2), temos a matriz $D=A Z^{*}$, que pode ser interpretada como o dado limpo, isto é, sem a interferência do erro original mente presente em $X$. Note que, como posto $\left(A Z^{*}\right) \leq$ $\min \left(\operatorname{posto}(A)\right.$ posto $\left.\left(Z^{*}\right)\right)=\operatorname{posto}\left(Z^{*}\right)$, o produto $A Z^{*}$ também é uma matriz de posto baixo, satisfazendo as condições necessárias para $\mathrm{D}$.

Para resolver o problema (3.2), Zhang et al. iniciaram o estudo por problemas mais simples e construíram a solução geral a partir deles. Suponha então que o dado não possui influência de erro al gum, ou seja, a matriz $E=0$. Dessa forma, o problema(3.2) se torna

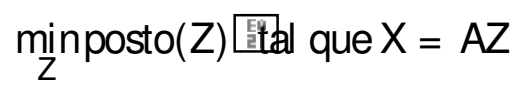

cuja solução pode não ser única. Assim, como de costume para problemas de otimização envolvendo o posto de matrizes, o problema (3.3) foi reescrito como

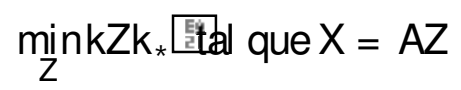

onde $\mathrm{k} \cdot \mathrm{k}_{\star}$ é a norma nucl ear (soma dos val ores singulares da matriz). O teorema abaixo apresenta uma forma fechada para a solução do problema (3.4):

Teorema 1. Se $A \in 0$ e $X=A Z$ possui solução para $X$ e $A$ dados, então $Z^{\star}=A^{\dagger} X$ é a única solução do problema (3.4), onde $A^{\dagger}$ é a pseudo inversa da matriz A.

Vale também o resultado abaixo que faz a ponte entre as soluções de (3.3) e (3.4)

Cor olário 1. Suponha $A € \quad 0$ e que $X=A Z$ possui solução para $X$ e $A$ dados. Seja $Z^{*}$ a solução do problema (3.4), então posto( $\left.Z^{*}\right)=\operatorname{posto}(X)$ e $Z^{*}$ é também solução do problema (3.3).

\section{A prova desses resultados pode ser encontrada no Apêndice.}

Figura 12 - Exemplos de erros comuns presentes no dado: (a) o dado possui perturbações; (b) o dado contém entradas com erros, fal ta de informação, por exemplo; (c) instâncias de dado (colunas) estão distantes. (ZHANG et al., 2014)

(a) Dado com ruído

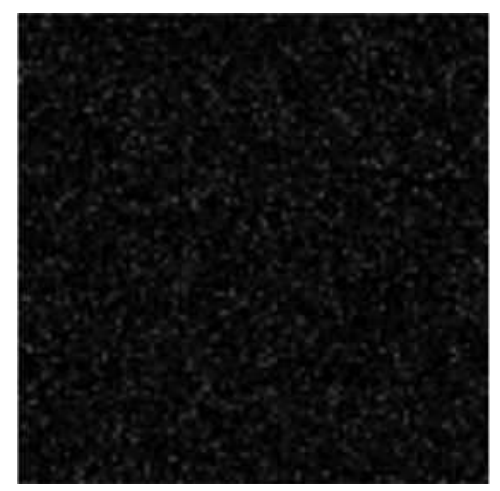

(b) Dado com erros al eatórios

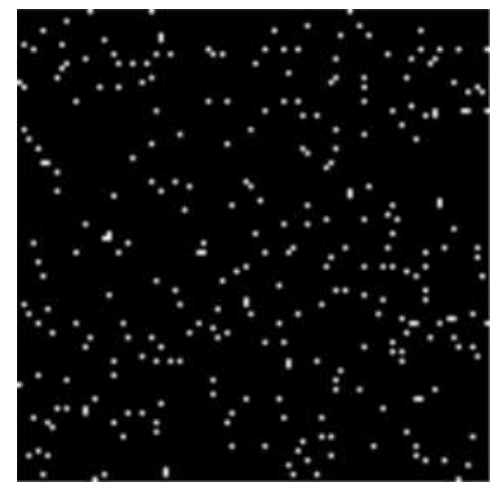

(c) Erros de amostragem (e outliers)

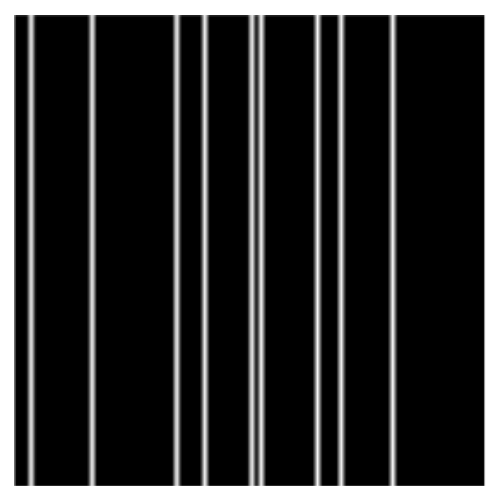


Sabendo que a norma nuclear é adequada para substituir a função posto, Zhang et al . segui ram o estudo do problema anal isando o ef ei to do termo de regularização

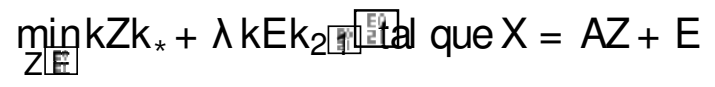

onde $\mathrm{kEk}_{2} \mathrm{I}=\sum_{\mathrm{i}} \mathrm{kE}\left(: \mathrm{ij} \mathrm{k}_{2}\right.$ é uma norma capaz de capturar outliers e erros de amostragem (sample-specific corruptions), Figura 12c. Para ruído Gaussi ano pequeno, Figura 12a, a norma $\mathrm{kEk}_{\mathrm{F}}^{2}$ (Frobeni us ao quadrado) deve ser a estratégia de regularização escolhida e para erros al eatórios, Figura 12b, a norma kEk 1 é a escolha apropriada.

O problema (3.5) pode ser resolvido por vários métodos e, por questão de eficiência, Zhang et al. optaram por resolvêlo utilizando Augmented Lagrange Multiplier (LIN et al., 2009) (ALM). Primei ramente, o problema (3.5) é convertido no seguinte problema equival ente

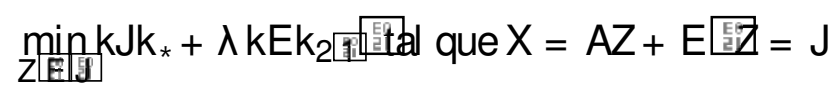

o qual é resolvido pelo ALM através da seguinte função de Lagrange

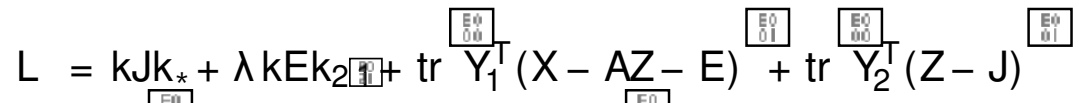

$$
\begin{aligned}
& +\frac{\mu}{2} \frac{\stackrel{E g}{k}}{k X}-A Z-E k_{F}^{2}+k Z-J k_{F}^{2}
\end{aligned}
$$

O problema acima não possui restrição, logo pode ser minimizado com respeito a uma das variáveis por vez - fixando as demais - e então atual izando os multiplicadores $Y_{1}$ e $Y_{2}$. $O$ Algoritmo 1 descreve o procedimento utilizado para resolver o problema.

O passo 1 do Algoritmo 1 pode ser resolvido através do operador Sngular Value Thresholding (SVT) (CAI; CANDÈS; SHEN, 2010), enquanto que o passo 3 é resolvido pelo seguinte Lema:

Lema 1. (YANG et al., 2009) Dada uma matriz Q, seW* é a solução ótima de

$$
\min _{W} a k W k_{2}\left[\frac{1}{2}+\frac{1}{2} \mathrm{~kW}-\mathrm{Qk}_{\mathrm{F}}^{2}\right.
$$

então a i-ésima coluna de W* é

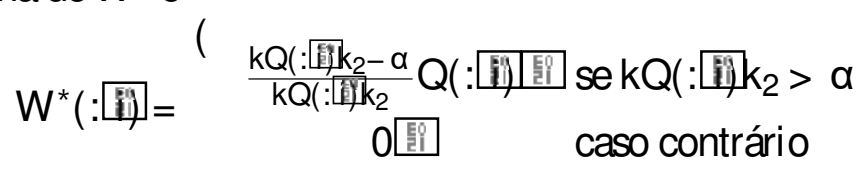

Uma implementação do Algoritmo 1 pode ser encontrada online (LIU, 2016).

De posse da solução $\left(Z * \mathbb{E}^{\star}\right)$ do problema (3.5), Zhang et al. descrevem, através do Algoritmo 2, um método para segmentar o dado $D=A Z$, inspirado pelo método de Shape Interaction Matrix (SIM) (COSTEIRA; KANADE, 1998). O processo consiste em determinar a qual subespaço cada instância do dado pertence baseado no espaço linha da matriz do dado limpo, sem a influência de erro. 


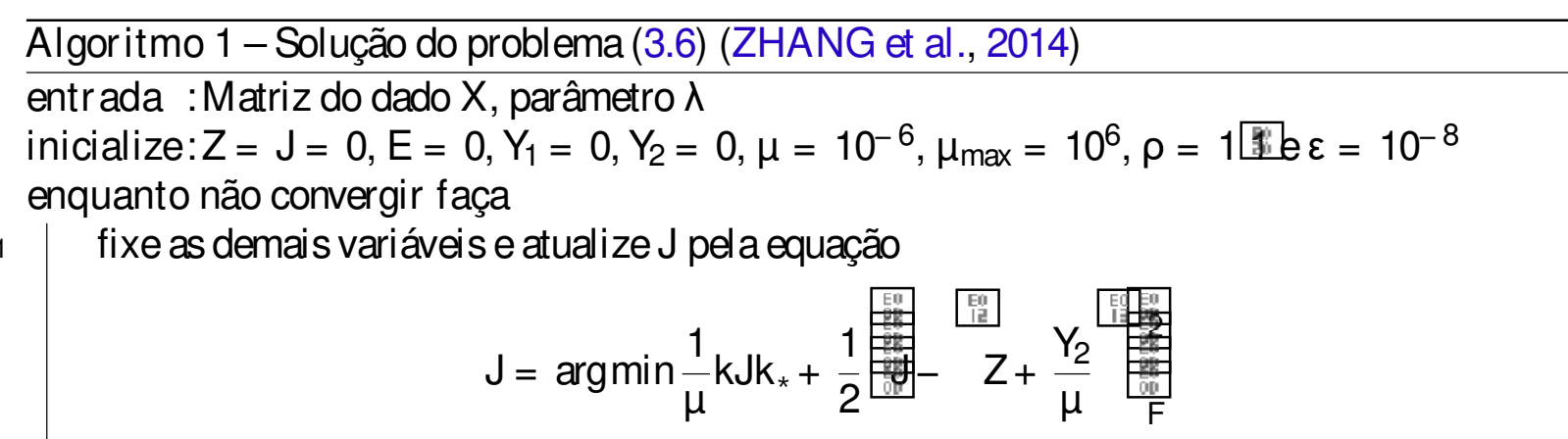

fixe as demais variáveis e atualize Z pela equação

$$
Z=\left(I+A^{\top} A\right)^{-1} A^{\top}(X-E)+J+\frac{A^{\top} Y_{1}-Y_{2}}{\mu}
$$

verifique a convergência

atual ize os multiplicadores

fixe as demais variáveis e atualize E pela equação

$$
\mathrm{E}=\operatorname{argmin} \frac{\lambda}{\mu} \mathrm{kEk}_{2} \text { 橉 }+\frac{1}{2}-\mathrm{X}-\mathrm{AZ}+\frac{\mathrm{Y}_{1}}{\mu} \frac{\mathrm{E}}{\mathrm{F}}
$$

$$
\begin{gathered}
Y_{1}=Y_{1}+\mu(X-A Z-E) \text { 既 } \\
Y_{2}=Y_{2}+\mu(Z-J)
\end{gathered}
$$

atual ize o parâmetro $\mu$ pela equação

$$
\mu=\min \left(\rho \mu \mu_{\max }\right)
$$

$$
\mathrm{kX}-\mathrm{AZ}-E \mathrm{k}_{\infty}<\varepsilon \mathrm{ekZ}-\mathrm{Jk} \mathrm{k}_{\infty}<\varepsilon
$$

\section{Algoritmo 2 - Segmentação do dado em subespaços}

entrada:Matriz do dado $X$, número de subespaços k, solução $Z^{*}$ do problema (3.5)

1 cal cule a decomposição SVD $Z^{*}=U \Sigma V^{\top}$

2 construa a matriz de afinidadeW $=\left[\mathrm{W}_{\mathrm{i}}\right]$, com $\mathrm{w}_{\mathrm{ij}}=\tilde{\mathrm{u}}_{\mathrm{ij}}$, onde $\tilde{\mathrm{u}}_{\mathrm{ij}}$ são as entradas da matriz $\tilde{U}=\left(U \Sigma^{\frac{1}{2}}\right)\left(U \Sigma^{\frac{1}{2}}\right)^{\top}$

3 aplique Normalized Cuts (SHI; MALIK, 2000) e segmente o dado em k grupos

Além disso, um estimador para o número de subespaços é apresentado no Algoritmo $3 \mathrm{e}$ tem como base o fato da matriz de afinidade ter a estrutura de bloco diagonal. A estimativa é feita contando o número de val ores singul ares não nulos da matriz $L$ apl aciana $L$ da matriz de afini dade. Na prática, a matriz de afinidade é aproximadamente bl oco diagonal. Dessa forma, 0 
estimador utiliza um threshold para retornar o número de subespaços:

$$
k=n-i n t \sum_{i=1}^{n} f_{T}\left(\sigma_{i}\right)
$$

onde, n é o número de instâncias do dado, $\sigma_{i}$ são os val ores singulares da matriz $L$, int(·) retorna o inteiro mais próximo, $\mathrm{f}_{\mathrm{T}}(\cdot)$ é dado por

$$
\mathrm{f}_{\mathrm{T}}(\sigma)=\log _{2} 1+\frac{\sigma^{2}}{\mathrm{~T}^{2}} \text { 踓 caso contrário }
$$

e $0<\mathrm{T}<1$ é um parâmetro.

Algoritmo 3 - Estimativa para o número de subespaços

entr ada: Matriz do dado $\mathrm{X}$, matriz de afinidade W do al goritmo 2

1 pajcule a matriz Laplacianam $L=I-D^{\frac{1}{2}} W^{\frac{1}{2}}$, onde $D=$

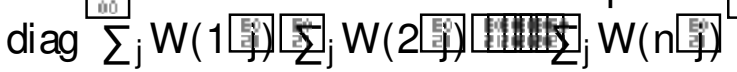

2 estime o número de subespaços $\mathrm{k}$ pela equação (3.8)

\subsection{Linear Discriminant Analysis}

A presentamos agora uma expl icação do funcionamento do método Linear Discriminant Analysis (LDA), que consiste em encontrar uma combinação linear dos atributos capaz de separar o dado em classes. A LDA é comumente utilizada em estatística, reconhecimento de padrões e aprendizado de máquina funcionando como um classificador linear ou para redução de dimensional idade.

Estamos interessados em encontrar um subespaço onde as classes do dado fiquem

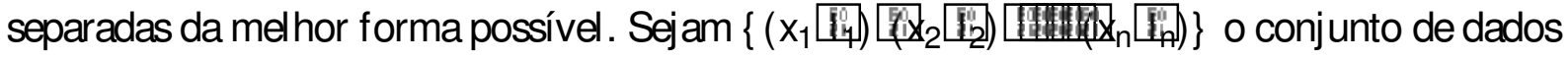

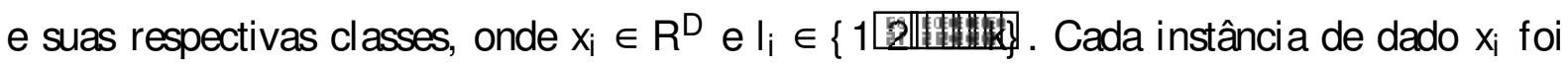
classificada em uma das $k$ cl asses e essa cl assificação recebeu o rótulo $l_{j}$. Denotando o centroide

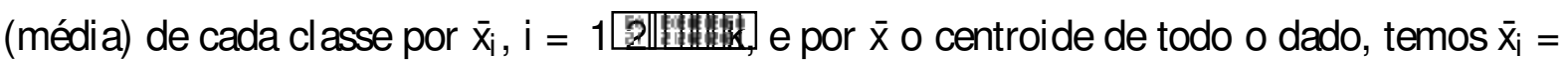
$\frac{1}{n_{i}} \sum_{x_{j} \in C_{i}} x_{j}$, onde $n_{i}$ é o número de instâncias de dado pertencentes a classe $C_{i}, e \bar{x}=\frac{1}{n} \sum_{i=1}^{n} x_{i}$.

Denotemos "

$$
\begin{aligned}
& S_{w}=\frac{1}{n} \sum_{x_{j} \in C_{1}}\left(x_{j}-\bar{x}_{1}\right)\left(x_{j}-\bar{x}_{1}\right)^{\top}+\cdots+\sum_{x_{j} \in C_{k}}\left(x_{j}-\bar{x}_{k}\right)\left(x_{j}-\bar{x}_{k}\right)^{\top} \\
& S_{b}=\frac{1}{n} \sum_{j=1}^{k} n_{j}\left(\bar{x}_{j}-\bar{x}\right)\left(\bar{x}_{j}-\bar{x}\right)^{\top}{ }^{\top}{ }^{\top}
\end{aligned}
$$

Assim $S_{N}$ S $_{\text {\$ }} \in M(D \times D)$ (matrizes $\left.D \times D\right)$. Então,

$$
\begin{aligned}
\operatorname{tr}\left(S_{w}\right) & =\frac{1}{n} \sum_{j=1}^{k} \sum_{i=1}^{n_{j}} k x_{i}-\bar{x}_{j} k^{2} \text { (variância das instâncias em cada classe) } \\
\operatorname{tr}\left(S_{\mathrm{b}}\right) & =\frac{1}{n} \sum_{j=1}^{k} n_{j} k \bar{x}_{j}-\bar{x}^{2} \text { (variância dos centroides) }
\end{aligned}
$$


Note que, se a projeção das instâncias de dado num subespaço resulta em pouca variância dos elementos em cada cl asse e muita variância dos centroides, então existe grande probabilidade de que as classes estejam bem separadas. Se P é a matriz cujas col unas formam uma base do subespaço onde queremos projetar o dado, então

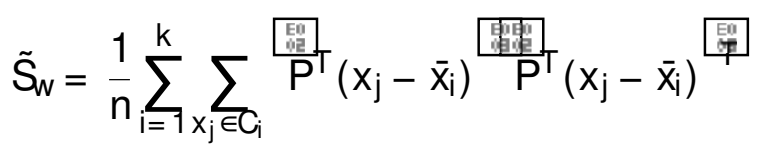

$$
\begin{aligned}
& =\sum_{i=1}^{k} \sum_{j \in C_{i}}^{h} P^{\top}\left(x_{j}-\bar{x}_{i}\right)\left(x_{j}-\bar{x}_{i}\right)^{\top} P^{i} \\
& =\mathrm{P}^{\top} \mathrm{S}_{\mathrm{N}} \mathrm{P}
\end{aligned}
$$

e, anal ogamente, $\tilde{S}_{\mathrm{D}}=\mathrm{P}^{\top} \mathrm{S}_{\mathrm{D}} \mathrm{P}$. Portanto, queremos encontrar $\mathrm{P}$ tal que $\operatorname{tr}\left(\tilde{\mathrm{S}}_{\mathrm{w}}\right)$ seja mínimo e $\operatorname{tr}\left(\tilde{S}_{\mathrm{b}}\right)$ seja máximo. $P$ deve então satisfazer:

$$
P_{\text {opt }}=\underset{P}{\operatorname{argmax}} \frac{\operatorname{tr}\left(\tilde{S}_{\mathrm{O}}\right)}{\operatorname{tr}\left(\tilde{S}_{\mathrm{W}}\right)}=\underset{\mathrm{P}}{\operatorname{argmax}} \frac{\operatorname{tr}\left(\mathrm{P}^{\top} \mathrm{S}_{\mathrm{D}} \mathrm{P}\right)}{\operatorname{tr}\left(\mathrm{P}^{\top} \mathrm{S}_{\mathrm{W}} \mathrm{P}\right)}
$$

Mas como o problema (3.9) é de difícil resolução, resolveremos um problema semel hante:

$$
\underset{P}{\operatorname{argmax} t r}\left(P^{\top} S_{D} P\right)\left(P^{\top} S_{N} P\right)^{-1^{i}}
$$

cuja solução é dada pelo seguinte teorema:

Teorema 2. (BISHOP, 2006) Sejam A e B matrizes si métricas $n \times n$ onde $B$ é definida positiva

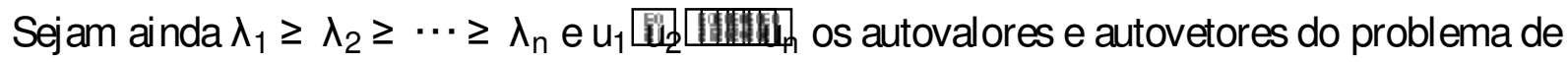
autoval or generalizado

$$
A x=\lambda B x \text { 凅 }
$$

Então

$$
\max _{X \in M(n \times p)} \operatorname{tr}^{h}\left(X^{\top} A X\right)\left(X^{\top} B X\right)^{-1^{i}}=\sum_{i=1}^{p} \lambda_{i}
$$

Dessa forma, a solução do problema (3.10) é dada pelos autovetores associados aos mai ores autoval ores do problema de autoval ores general izado $S_{D} P=S_{w} P \wedge$, onde as col unas de $P$ são os autovetores associados aos autoval ores formando a matriz di agonal $\Lambda$. Para visual ização, utilizaremos $p=2$.

\subsection{Estudando o efeito de subspace clust ering em proje- ções multidimensionais}

Apresentaremos agora um estudo do ef eito da apl icação de técni cas de subspace clustering, como a LRR, no auxílio a projeções mul tidimensionais. Utilizamos a divisão em subespaços 
gerado pela LRR como entrada para as cl asses na LDA e comparamos a qual idade dessas projeções com técnicas bastante conhecidas na literatura como a LAMP (JOIA et al., 2011) e t-SNE (MAATEN; HINTON, 2008). Além disso, propomos uma mudança simples na LAMP para que possa fazer uso da informação de classes do dado.

As principais contribuições desse trabal ho são li stadas abaixo:

覧Utilizamos técnicas de subspace clustering combinadas com técni cas de visual ização para redução de dimensionalidade;

龨studamos a eficácia da classe dos dados nas visual izações comparando com técnicas que necessitem da informação de classe;

覧Uma modificação simples na LAMP para que possa utilizar a informação de classe do dado.

Considere um conjunto de dados de al ta dimensão, queremos visualizar padrões e estruturas intrínsecas pertencentes a esse dado. Supondo que as instâncias do dado foram obtidas de subespaços independentes, utilizamos a LRR para estimar a quantidade de subespaços e a qual subespaço cada instância pertence. Tomamos cada subespaço definido pela LRR como uma classe e as instâncias pertencentes a cada subespaço como pertencentes àquel a classe. Por fim, utilizamos essa informação de classes na LDA para ef etuar a projeção no espaço visual $(p=2)$. A Figura 13 ilustra o pipeline do nosso método.

Figura 13 - Pipeline do método: (a) dado sem informação de classes; (b) dado com a informação de classes gerada pelo subspace clustering; (c) visualização do dado utilizando LDA.

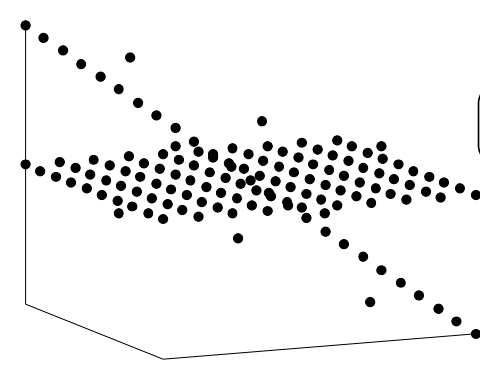

(a)

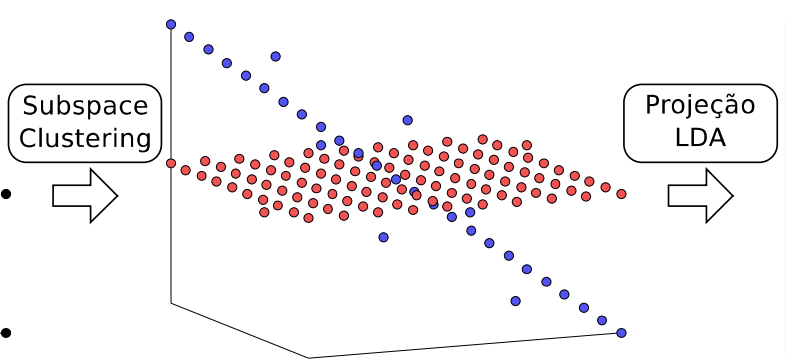

(b)

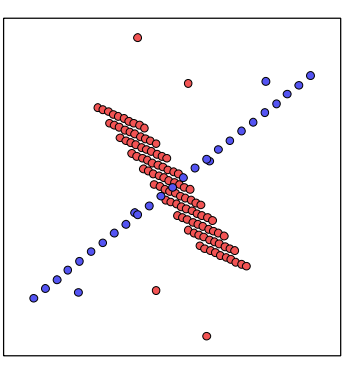

(c)

\subsubsection{Experimentos}

Para validar o método, geramos um dado artificial composto por 50 instâncias pertencentes a $R^{3}, 50$ pertencentes a $R^{7}, 50$ pertencentes a $R^{10}$ e mergul hamos todas as 150 instâncias

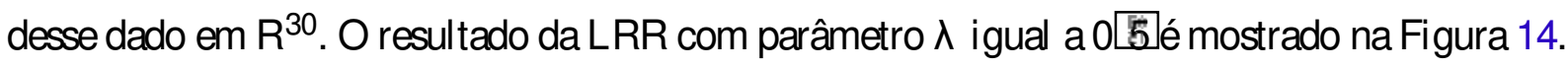
Observe que a representação da matriz $\mathrm{E}$ está em branco denotando que os val ores da mesma são todos zero; ou seja, a LRR, como esperávamos, não detectou nenhuma instância contendo erro (ruído nem outlier). 
Figura 14 - Resultado da LRR no dado artificial .

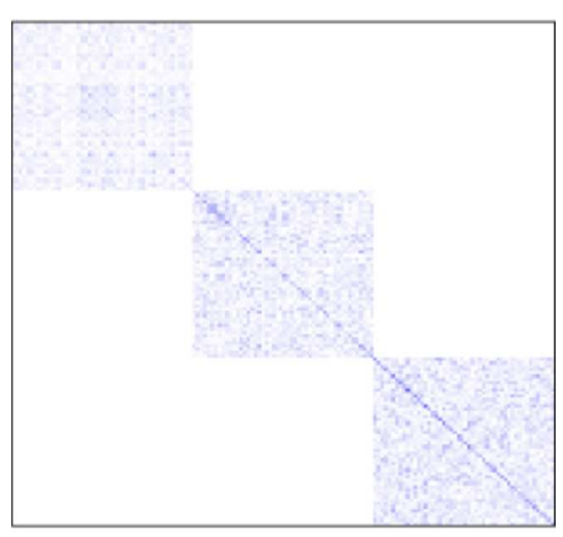

(a) Matriz Z

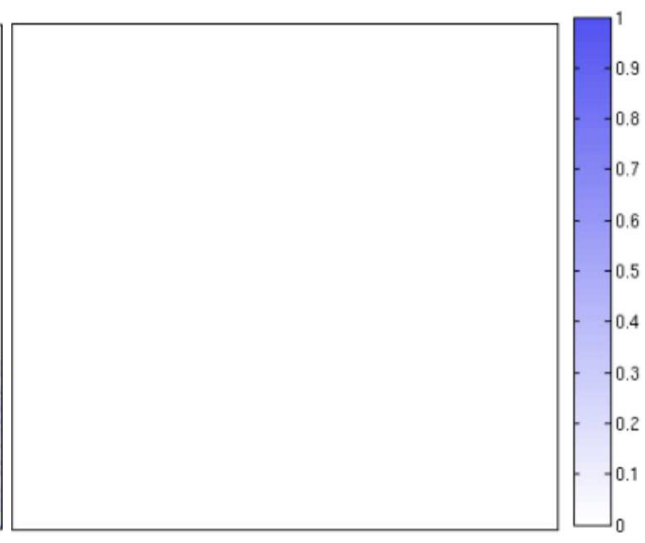

(b) Matriz E

A Figura 15 mostra o resul tado da projeção do dado artificial usando a LDA com classes geradas pela LRR. Como a LRR classificou o dado perfeitamente, a projeção colorida com as classes da LRR e com as classes reai s são idênticas.

Figura 15 - Projeção com LDA do dado artificial.

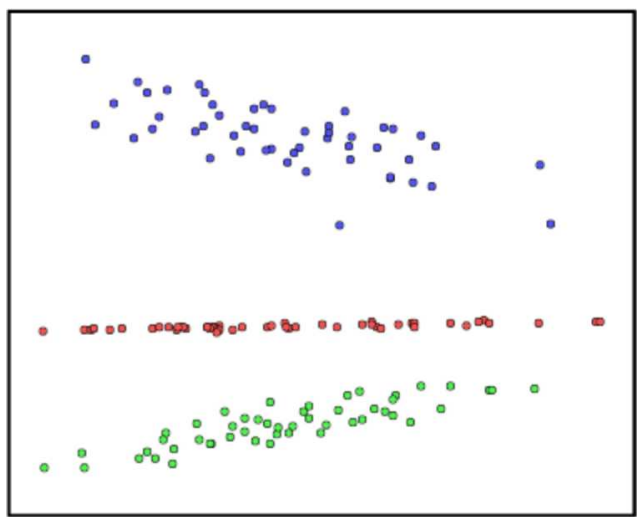

(a) Coloração dada pela LRR

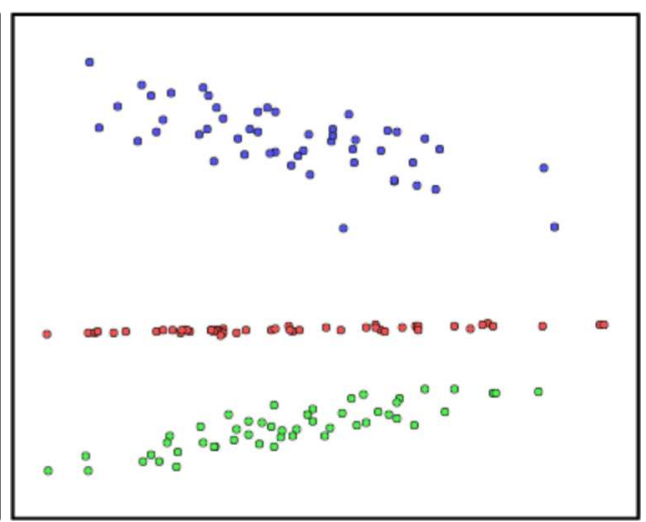

(b) Cor dada pelas classes reais do dado

Como segundo teste, utilizamos o conjunto de dados da flor iris (FRANK; ASUNCION, 2010). O dado é composto por 150 instâncias de dimensão 4 divididas em 3 classes, as espécies daflor iris. O resultado da LRR com parâmetro $\lambda$ igual a 0 Sé exibido na Figura 16. Observe que uma das classes pode ser identificada facilmente, enquanto que as outras duas são mais difíceis de distinguir. $A$ matriz $E$ é nula devido à natureza do dado e ao fato de termos utilizado a normak $\cdot k_{2}$ 興em nosso teste, a qual é sensível a outliers.

Da mesma forma que no experimento anterior, projetamos o conjunto de dados utilizando a LDA e colorimos com a informação de classes gerada pela LRR e com as classes reai s do dado (Figura 17). Aqui podemos ver onde a LRR consegui u classificar melhor o dado em cada subespaço. 
Figura 16 - Resultado da LRR aplicado ao Iris.

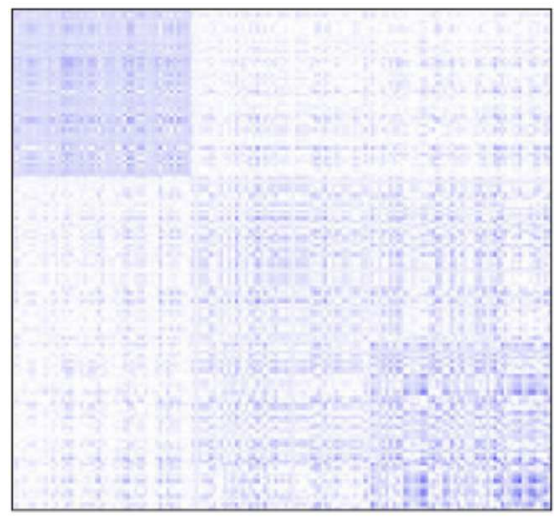

(a) Matriz Z

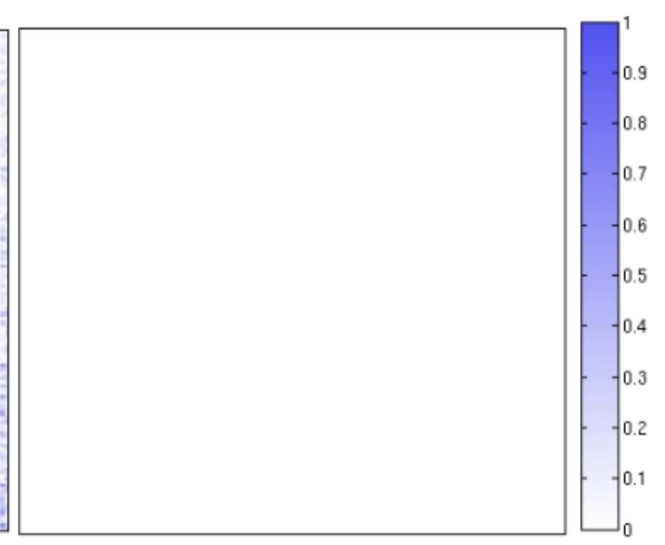

(b) Matriz E

Figura 17 - Projeção com LDA do Iris.

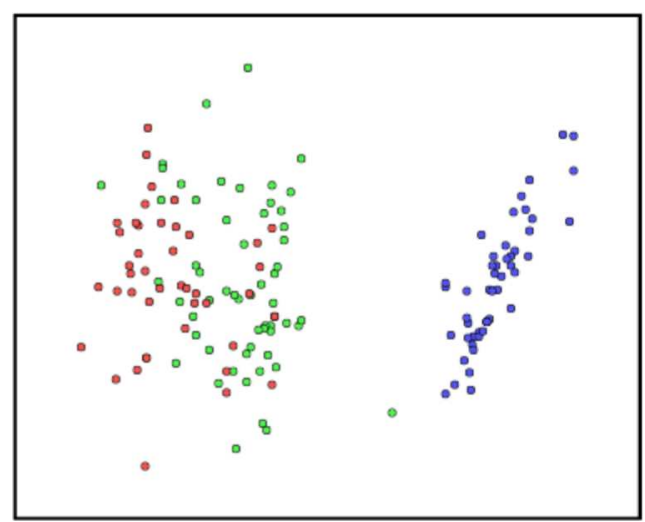

(a) Coloração dada pela LRR

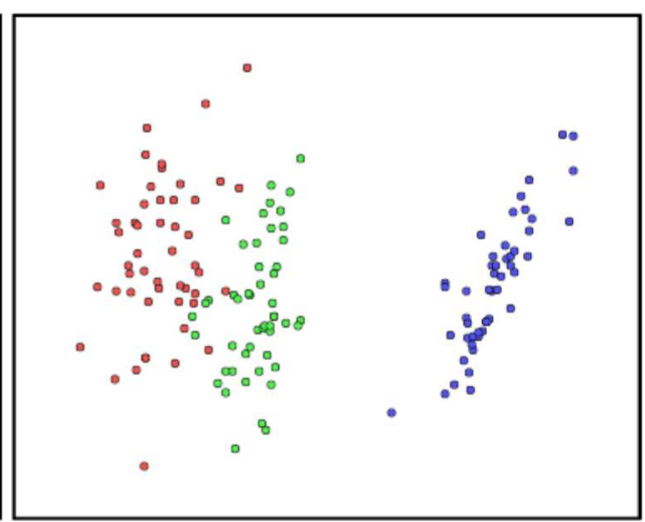

(b) Cor dada pelas classes reais do dado

\subsubsection{Resultados e discussão}

Avaliamos nosso método comparando as projeções obtidas pela LDA com classes ge radas pela LRR com outras três técnicas: LAMP, t-SNE e LAMP modificada. Primeiramente expl icaremos a modificação feita na LAMP para que possa utilizar informação das classes do dado no processo de projeção. Original mente, utilizamos pesos dados por $\alpha_{i}=\frac{1}{k x-x_{i} k^{2}}$, onde x é a instância a ser proj etada e $x_{i}$ é um ponto de controle. Nossa modificação consi ste em cal cular os pesos da seguinte forma:

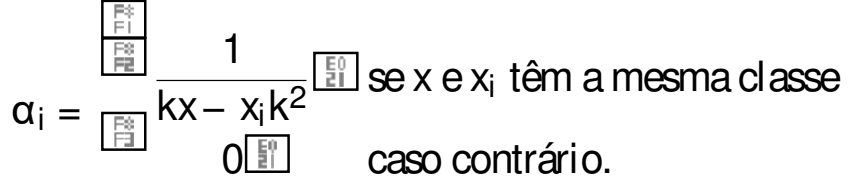

Aval iamos também a qualidade das projeções geradas por nosso método segundo quatro métricas: stress, preservação de vizinhança e duas métricas de silhueta. $A$ função de stress utilizada é dada por

$$
\text { stress }=\frac{1}{\sum_{i j} d_{i j}} \sum_{i j} \frac{\left(d_{i j}-\bar{d}_{i j}\right)^{2}}{d_{i j}^{2}}
$$


onde $d_{i j}$ é a distância medida no espaço original e e $\bar{d}_{i j}$ é a distância no espaço visual. A métrica de preservação de vizinhança conta, para cada instância de dado, quantos dos seus $k$ vizinhos mais próximos no espaço original estão entre os $k$ vizinhos mais próximos no espaço visual. A sil hueta mede coesão e separação das cl asses e é dada por

$$
\text { silhueta }=\frac{1}{n} \sum_{i} \frac{b_{i}-a_{i}}{\max a_{i}\left[b_{i}\right.}
$$

onde $a_{i}$ (coesão) é a média das di stâncias entre a projeção $y_{i}$ (projeção de $x_{i}$ ) e todas as outras instâncias projetadas que estão na mesma classe que $y_{i}$ e $b_{i}$ (separação) é a menor distância entre $y_{i}$ e todas as outras projeções pertencentes as outras classes. Como podemos ver, para cal cular a silhueta, precisamos da informação das classes do dado. Dessa forma, utilizamos ambas informações de classe para avaliar as projeções: classe real do dado (silh1) e classes geradas pela LRR (silh2).

Tabela 1 - Conjuntos de dado utilizados. Da esquerda para direita, as colunas correspondem a: nome do conjunto de dados, número de instâncias, dimensão (número de atributos) e fonte.

\begin{tabular}{lccc}
\hline \multicolumn{1}{c}{ Nome } & Tamanho & Dim & Fonte \\
\hline \hline Iris & 150 & 4 & (FRANK; ASUNCION, 2010) \\
\hline Sintético & 150 & 4 & (GUYON, 2003) \\
\hline Artificial & 150 & 30 & $*$ \\
\hline Wine & 178 & 13 & (FRANK; ASUNCION, 2010) \\
\hline Mammals & 1000 & 72 & (FRANK; ASUNCION, 2010) \\
\hline \hline
\end{tabular}

A Tabela 1 contém os conjuntos de dados utilizados e a Tabel a 2 resume os resul tados obtidos. Comparada com a LAMP, a versão modificada da LAMP obtém resultado mel hor para a silh2 (classes dadas pela LRR) e com pequena diferença em termos de stress. Enquanto o stress da LDA é maior que o da LAMP e o da LAMP modificada (o que é esperado, pois o objetivo da LDA é encontrar o subespaço com mel hor separabilidade entre as classes), ela acaba obtendo resul tados melhores quanto a silh2. Os resultados da LDA indicam que a combinação com a LRR pode ser uma escol ha vál ida para redução de dimensi onal idade ou probl emas de cl assificação sem supervisão onde a classe real das instâncias de dado são desconhecidas.

\subsubsection{Limitações}

Técnicas de subspace clustering assumem que o dado está distribuído em subespaços independentes. Nos casos onde não for possível recuperar uma estrutura de subespaços nos dados, mesmo variando todos os parâmetros extensivamente, é razoável assumir que tal estrutura é inexistente e, portanto, não faz sentido aplicar o método. 
Tabela 2 - Resultados obtidos. Da esquerda para direita as col unas correspondem a conjunto de dado, técnica e métricas: stress, preservação de vizinhança e silhuetas. Val ores em negrito são os mel hores para cada conjunto de dado e métrica.

\begin{tabular}{llcccc}
\hline Dado & Técnica & stress & PV (\%) & silh1 & silh2 \\
\hline \hline \multirow{4}{*}{ Iris } & LAMP & 0.0418 & 81.8 & 0.6371 & 0.3437 \\
& LAMP (M) & 0.0791 & 77.8 & 0.6032 & 0.4221 \\
& LDA & 0.3095 & 63.6 & 0.6889 & 0.6758 \\
& t-SNE & $1.71 \mathrm{e}+6$ & 86.9 & 0.7633 & 0.3392 \\
\hline \multirow{4}{*}{ Synthetic } & LAMP & 0.0597 & 80.9 & 0.8584 & 0.8584 \\
& LAMP (M) & 0.0521 & 82.0 & 0.9045 & 0.9045 \\
& LDA & 0.0862 & 85.7 & 0.9299 & 0.9299 \\
& t-SNE & 6.2266 & 89.4 & 0.9956 & 0.9956 \\
\hline \multirow{4}{*}{ Artificial } & LAMP & 0.0539 & 85.4 & 0.6770 & 0.6770 \\
& LAMP (M) & 0.0749 & 86.0 & 0.7787 & 0.7787 \\
& LDA & 0.3749 & 81.2 & 0.9492 & 0.9492 \\
& t-SNE & 0.2962 & 90.9 & 0.8961 & 0.8961 \\
\hline \multirow{4}{*}{ Wine } & LAMP & 0.0383 & 90.7 & 0.2174 & 0.3629 \\
& LAMP (M) & 0.1371 & 86.9 & 0.2269 & 0.4491 \\
& LDA & 0.9802 & 53.3 & 0.2694 & 0.5314 \\
& t-SNE & 0.9312 & 94.3 & 0.3139 & 0.4262 \\
\hline \multirow{5}{*}{ Mammal } & LAMP & 0.0112 & 87.9 & 0.9825 & 0.9825 \\
& LAMP (M) & 0.0172 & 85.5 & 0.9924 & 0.9924 \\
& LDA & 1.0000 & 81.4 & 0.9311 & 0.9311 \\
& t-SNE & 0.3829 & 87.7 & 0.9653 & 0.9653 \\
\hline \hline
\end{tabular}



CAPÍTULO

\section{4}

.

\section{KERNEL BASED LINEAR PROJECTION}

Neste Capítulo, apresentamos uma nova técnica de projeção mul tidimensional baseada em kernel capaz de lidar com dados imersos no espaço de características implicitamente induzido por um kernel. Este trabal ho foi descrito primeiramente em (BARBOSA et al., 2016). As contribuições do mesmo são listadas a baixo:

国Uma nova técnica de projeção multidimensional chamada Kelp capaz de lidar com dados kernelizados;

IOS uso da Kelp como ferramenta de visual ização para auxiliar em aplicações baseadas em kernel como classificação e segmentação de imagem;

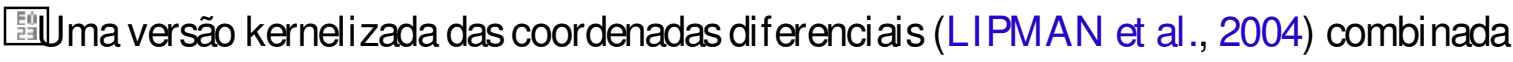
com a Kelp a fim de entender como o kernel af eta as estruturas de vizinhança do dado durante o mapeamento para o espaço de características.

\subsection{Fundamentação matemática}

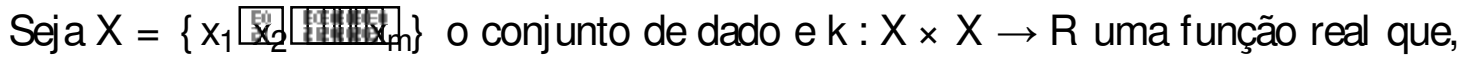

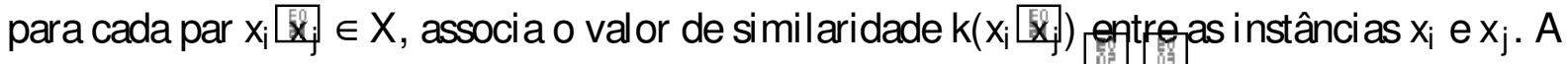
função $k$ é uma função kernel (ou apenas kernel) se a matriz $\mathrm{K}=\mathrm{k}_{\mathrm{ij}}$ (matriz do kernel), onde $k_{i j}=k\left(x_{i} E_{j}\right)$, é simétrica e positiva definida

Associada a cada kernel existe uma aplicação $\varphi: \mathrm{X} \rightarrow \mathrm{H}$ tal que

$$
k\left(x_{i}\left[⿷_{j}\right)=\varphi\left(x_{i}\right)^{\top} \varphi\left(x_{j}\right)\right. \text { 區 }
$$

onde $\mathrm{H}$ é um espaço de características com al ta dimensão (possivel mente de dimensão infinita) onde os dados são mapeados pela apli cação $\varphi$. Dessa forma, o kernel é um produto interno 
no espaço de características H e a matriz K é uma matriz de Gram (SCHÖLKOPF; SMOLA, 2001).

Observe o seguinte exemplo: se $X \subset R^{2}$, temos que $k\left(x_{i} x_{j}\right)=\left(x_{i}^{\top} x_{j}\right)^{2}$ é um kernel e

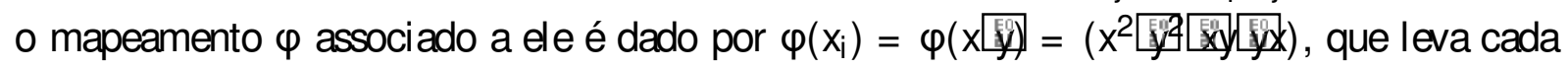
instância de $X$ para o espaço de características, que nesse caso é o $R^{4}$. De fato,

$$
\begin{aligned}
& \varphi\left(x_{i}\right)^{\top} \varphi\left(x_{j}\right)=\varphi\left(x[y)^{\top} \varphi\left(x^{\prime}[y]\right)\right.
\end{aligned}
$$

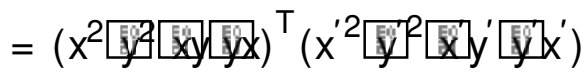

$$
\begin{aligned}
& =x^{2} x^{\prime 2}+y^{2} y^{\prime 2}+x y x^{\prime} y^{\prime}+y x y^{\prime} x^{\prime} \\
& =\left(x x^{\prime}\right)^{2}+2\left(x x^{\prime}\right)\left(y y^{\prime}\right)+\left(y y^{\prime}\right)^{2} \\
& =\left(x x^{\prime}+y y^{\prime}\right)^{2} \\
& =\left(( x \text { 可 } ) ^ { \top } \left(x^{\prime}\left[\begin{array}{l}
y \\
)
\end{array}\right)^{2}\right.\right. \\
& =\left(x_{i}^{\top} x_{j}\right)^{2} \\
& =k\left(x_{i} E_{j}\right)
\end{aligned}
$$

Os kernels mais comuns na literatura são:

Gaussiano: $k\left(x_{i}\right.$ 匷 $)=e^{-\frac{k x_{i}-x_{j} k^{2}}{2 \sigma^{2}}}$

Polinomial: $k\left(x_{i}\left[\mathrm{E}_{j}\right)=\left(x_{i}^{T} x_{j}\right)^{d}\right.$

Sigmoide: $\mathrm{k}\left(\mathrm{x}_{\mathrm{i}} \mathrm{X}_{\mathrm{j}}\right)=\tanh \left(\mathrm{r}\left(\mathrm{x}_{\mathrm{i}}^{\top} \mathrm{x}_{\mathrm{j}}\right)+\theta\right)$

onde $\sigma, \mathrm{\gamma}, \mathrm{d}$ e $\theta$ são parâmetros.

Supondo que a imagem de X por $\varphi$ esteja centrada no espaço de características (a Se ção 4.3 tem os detal hes sobre como central izar o dado quando necessário), ou seja, $\frac{1}{m} \sum_{i=1}^{m} \varphi\left(x_{i}\right)=$ 0 , sua matriz de covariância é dada por

$$
C=\frac{1}{m} \sum_{i=1}^{m} \varphi\left(x_{i}\right) \varphi\left(x_{i}\right)^{\top}
$$

onde $\varphi\left(x_{i}\right)^{\top}$ é o transposto de $\varphi\left(x_{i}\right)$. Como $\varphi$ é uma apli cação definida implicitamente pelo kernel, não podemos, em geral, cal cular a matriz $\mathrm{C}$ diretamente. Para superar essa dificul dade, utilizamos o kernel trick, que consiste em utilizar a informação do produto interno definido pelo kernel no espaço de características, evitando o uso expl ícito das coordenadas do dado mapeado nesse espaço. 
Denotando por $u_{i}$ um autovetor de $\mathrm{C}$ e $\lambda_{i}$ seu autoval or correspondente, da equação (4.1) e de $u_{i}=\lambda_{i} u_{i}$, segue-se que

$$
\begin{aligned}
& \frac{1}{\mathrm{~m}} \sum_{\mathrm{j}=1}^{\mathrm{m}} \varphi\left(\mathrm{x}_{\mathrm{j}}\right) \varphi\left(\mathrm{x}_{\mathrm{j}}\right)^{\top} \mathrm{u}_{\mathrm{i}}=\lambda_{\mathrm{i}} u_{\mathrm{i}} \\
& \begin{array}{l}
\Rightarrow u_{i}=\frac{1}{m \lambda_{i}} \sum_{\text {角 }}^{m} \varphi\left(x_{j}\right) \varphi\left(x_{j}\right)^{\top} u_{i} \\
\Rightarrow u_{i}=\sum_{j=1}^{m} \frac{1}{m \lambda_{i}} \varphi\left(x_{j}\right)^{\top} u_{i} \varphi\left(x_{j}\right)
\end{array}
\end{aligned}
$$

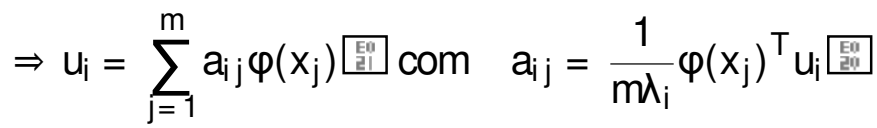

Chamando de $a_{i}=\left(a_{i 1} \text { Tillilidim }\right)^{\top}$ o vetor cujas coordenadas são dadas pelos coeficientes $a_{i j}$, mostraremos que $a_{i}$ é um autovetor da matriz $\mathrm{K}$ do kernel. De fato, substituindo $u_{i}$ na primeira igual dade de (4.2) e multiplicando por $\varphi\left(x_{l}\right)^{\top}$ temos:

$$
\begin{aligned}
& \frac{1}{m} \varphi\left(x_{l}\right)^{\top} \sum_{p=1}^{m} \varphi\left(x_{p}\right) \varphi\left(x_{p}\right)^{\top} \sum_{j=1}^{m} a_{i j} \varphi\left(x_{j}\right)=\lambda_{i} \varphi\left(x_{l}\right)^{\top} \sum_{j=1}^{m} a_{i j} \varphi\left(x_{j}\right) \\
& \Rightarrow \frac{1}{m} \sum_{p=1}^{m} \varphi\left(x_{l}\right)^{\top} \varphi\left(x_{p}\right) \sum_{j=1}^{m} a_{i j} \varphi\left(x_{p}\right)^{\top} \varphi\left(x_{j}\right)=\lambda_{i} \sum_{j=1}^{m} a_{i j} \varphi\left(x_{l}\right)^{\top} \varphi\left(x_{j}\right)
\end{aligned}
$$

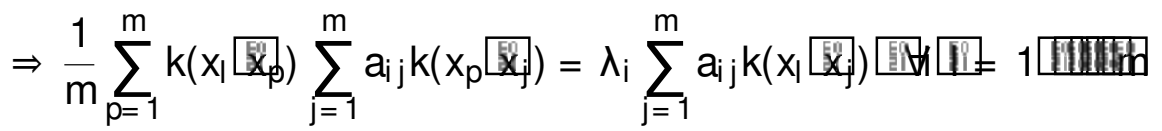

$$
\begin{aligned}
& \Rightarrow \mathrm{K}^{2} \mathrm{a}_{\mathrm{i}}=\mathrm{m} \lambda_{\mathrm{i}} \mathrm{K} \mathrm{a}_{\mathrm{i}} \\
& \Rightarrow \mathrm{Ka}_{\mathrm{i}}=\mathrm{V}_{\mathrm{i}} \mathrm{a}_{\mathrm{i}} \text { 铻 }
\end{aligned}
$$

mostrando que $a_{i}$ é autovetor de $\mathrm{K}$ com autoval or associado $\mathrm{Y}_{i}$. Fica então demonstrada uma importante relação entre os autovetores de $u_{i}$ de $\mathrm{C}$ e os autovetores $\mathrm{a}_{i}$ de $\mathrm{K}$

$$
u_{i}=\sum_{j=1}^{m} a_{i j} \varphi\left(x_{j}\right) \text { 敨 }
$$

Além disso, a equação (4.3) também nos dá a relação $\gamma_{i}=m \lambda_{i}$ entre os autoval ores $\gamma_{i}$ de $K$ e os autoval ores $\lambda_{i}$ deC.

\subsection{A Kelp}

Nossa técni ca utiliza um subconjunto dos dados (pontos de controle) como guia para o

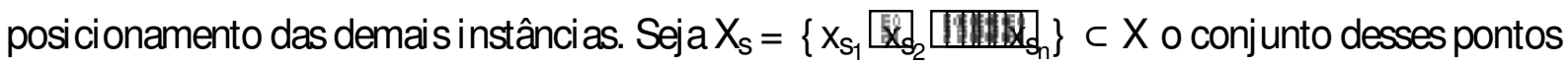
de controle (note que m denota o número de instâncias de $X$ e $n$ o número de pontos de controle)

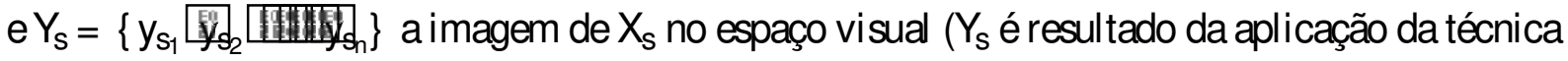
Force Scheme $\mathrm{a} \mathrm{X}_{\mathrm{S}}$ ). Vames denotarppr $\mathrm{K}_{\mathrm{S}}$ a matriz do kernel construída apenas com os pontos de controle, isto é, $\mathrm{K}_{\mathrm{s}}=\mathrm{k}\left(\mathrm{x}_{\mathrm{s}}, \mathrm{Q}_{\mathrm{g}_{\mathrm{j}}}\right)$. 
Supondo que conhecemos a função $\varphi$ associada ao kernel k, queremos encontrar uma transformação linear $\mathrm{M}: \mathrm{H} \rightarrow \mathrm{R}^{2}\left(\mathrm{R}^{2}\right.$ será nosso espaço visual) tal que

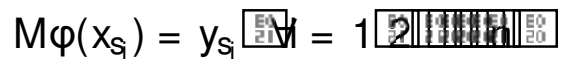

Ou seja, queremos uma transf ormação linear que leve a imagem de cada ponto de controle $\varphi\left(x_{\mathbb{S}_{1}}\right)$ do espaço de características para sua posição $y_{\mathfrak{s}}$ no espaço visual. Esperamos com isso que a estrutura de vizinhança de $\varphi\left(x_{S_{1}}\right)$ seja preservada por $M$, por conta da linearidade.

Podemos escrever a equação (4.5) em forma matricial como

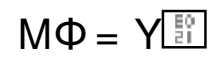

onde

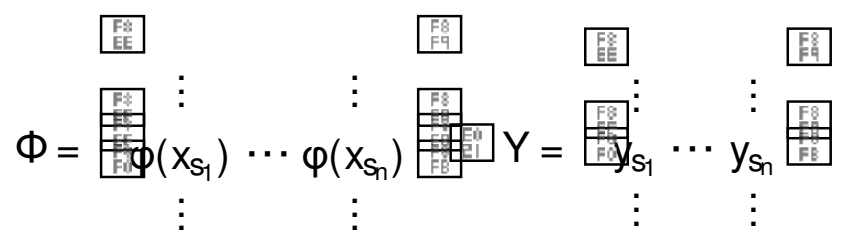

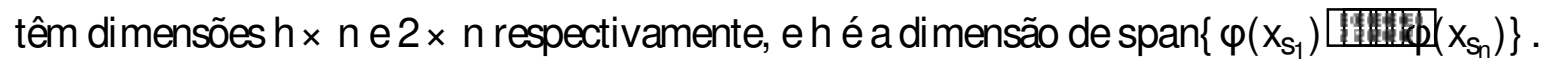

Multiplicando a equação (4.6) por $\Phi^{\top}$, temos

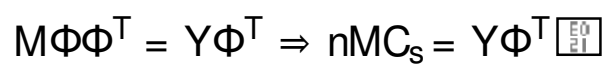

onde $\mathrm{C}_{\mathrm{s}}$ é a matriz de covariância definida na equação (4.1), mas cal culada apenas nos pontos de controle. Como $\mathrm{C}_{\mathrm{s}}$ é simétrica, pode ser decomposta da forma $\mathrm{C}_{\mathrm{S}}=\mathrm{UDU}^{\top}$, onde as colunas de $U$ são ortonormais compostas pelos autovetores $u_{i}$ de $C_{s}$ e $D$ é matriz diagonal contendo os autoval ores $\lambda_{i}$ associados aos autoval ores $u_{i}$. Então, a pseudo-inversa de $\mathrm{C}_{s}$ é dada por $\mathrm{C}_{\mathrm{s}}^{\dagger}=U \tilde{D}^{-1} \mathrm{U}^{\top}$, sendo $\tilde{D}^{-1}$ a inversa de $\mathrm{D}$ considerando apenas os el ementos não nul os da diagonal. Multiplicando ambos os lados de (4.7) por $\mathrm{C}_{\mathrm{s}}^{\dagger}$

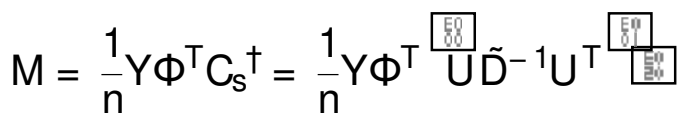

Assim, a projeção da imagem de uma instância qual quer $\varphi(x)$ é dada por

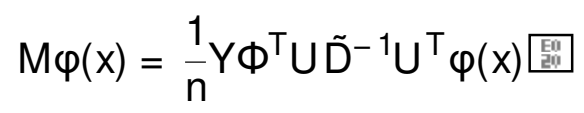

Seja A a matriz cujas colunas são dadas pelos autovetores $a_{i}$ de $K_{s}$ (equação (4.4)) e, abusando da notação, $U$ será a partir de agora a matriz contendo apenas os autovetores de $C_{S}$ cujo autovalor associado seja não nulo. Da equação (4.4), tem-se

$$
U=\Phi A \Rightarrow \Phi^{\top} U=\Phi^{\top} \Phi A \Rightarrow \Phi^{\top} U=K_{S} A
$$

e

$$
\mathrm{U}^{\top} \varphi(\mathrm{x})=(\Phi \mathrm{A})^{\top} \varphi(\mathrm{x})=\mathrm{A}^{\top} \Phi^{\top} \varphi(\mathrm{x})=\mathrm{A}^{\top} \mathrm{k}_{\mathrm{x}}
$$




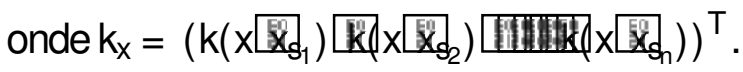

Utilizando a relação entre os autovalores $\gamma_{i}$ de $K_{s}$ e os autoval ores $\lambda_{i}$ de $C_{s}$, dada por $\gamma_{i}=n \lambda_{i}$ (equação (4.2)), escrevemos

$$
\tilde{D}^{-1}=\frac{1}{\lambda_{i}}=n \frac{1}{V_{i}}=\mathrm{n}^{-1}
$$

onde $\Gamma$ é a matriz diagonal com entradas $\gamma_{i}$. A equação (4.11) juntamente com as equações (4.9) e (4.10) nos dão que

$$
M \varphi(x)=\mathrm{YK}_{\mathrm{S}} A \Gamma^{-1} \mathrm{~A}^{\top} \mathrm{K}_{\mathrm{x}}
$$

Dessa forma, escrevemos a projeção $M \varphi(x)$ da imagem de uma instância x qualquer no espaço de característi cas em função apenas de quantidades conhecidas: $Y$ é a matriz com a posição dos pontos de controle no espaço visual, $\mathrm{K}_{\mathrm{s}}$ é a matriz do kernel cal cul ada nos pontos de controle, as col unas de $A$ são os autovetores de $K_{s}$, a diagonal de $\Gamma$ são os autoval ores de $K_{s} e$ o vetor $k_{x}$ é a medida de si milaridade dada pel o kernel entre a instância $x$ a ser projetada e os pontos de controle $x_{S}$. Mais ainda, $Y, K_{s}$, A e $\Gamma$ precisam ser cal culados apenas uma vez, pois não dependem da instância a ser projetada, apenas do kernel e dos pontos de controle.

\subsection{Centralização no espaço de características}

Na seção 4.1 supomos que o dado estaria centrado no espaço de características. Nessa seção expl icaremos como centrar o dado quando necessário. Como não temos acesso as coordenadas do dado no espaço de características, faremos a central ização utilizando a matriz $\mathrm{K}_{\mathrm{s}}$ e o vetor $k_{x}$.

O procedimento para centralizar uma matriz de kernel $\mathrm{K}$ já é conhecido da literatura de aprendizado de máquina (SCHÖLKOPF; SMOLA; MÜLLER, 1998). Suponha $\varphi$ não necessariamente centrada no espaço de características, logo

$$
\tilde{\varphi}\left(x_{i}\right)=\varphi\left(x_{i}\right)-\frac{1}{m} \sum_{j=1}^{m} \varphi\left(x_{j}\right)
$$

estará centrada no espaço de características. Dessa forma, toda teoria desenvolvida na Seção 4.1 vale para $\tilde{\varphi}$. Seja $\tilde{K}$ a matriz do kernel associado à função $\tilde{\varphi}$, temos que $\tilde{K}=\tilde{\varphi}(X)^{\top} \tilde{\varphi}(X)$. Logo, a entrada $\tilde{K}_{i j}$ de $\tilde{K}$ é escrita como

$$
\begin{aligned}
& \tilde{\mathrm{k}}_{\mathrm{ij}}=\tilde{\varphi}\left(\mathrm{x}_{\mathrm{i}}\right)^{\top} \tilde{\varphi}\left(\mathrm{x}_{\mathrm{j}}\right) \\
& =\varphi\left(x_{i}\right)-\frac{1}{m} \sum_{p=1}^{m} \varphi\left(x_{p}\right) \quad \varphi\left(x_{j}\right)-\frac{1}{m} \sum_{q=1}^{m} \varphi\left(x_{q}\right)^{\# "} \\
& =\varphi\left(x_{i}\right)^{\top} \varphi\left(x_{j}\right)-\frac{1}{m} \sum_{p=1}^{m} \varphi\left(x_{p}\right)^{\top} \varphi\left(x_{j}\right)-\frac{1}{m} \sum_{q=1}^{m} \varphi\left(x_{i}\right)^{\top} \varphi\left(x_{q}\right)+\frac{1}{m^{2}} \sum_{p \mid q \neq 1}^{m} \varphi\left(x_{p}\right)^{\top} \varphi\left(x_{q}\right)
\end{aligned}
$$

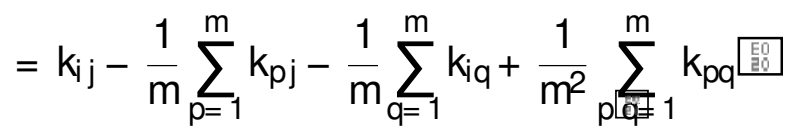


Se chamarmos de $\mathbb{1}_{\mathrm{m}}$ a matriz $\mathrm{m} \times \mathrm{m}$ cujas entradas são todas iguais a $\frac{1}{\mathrm{~m}}$, conseguimos escrever

$$
\tilde{K}=\mathrm{K}-\mathbb{1}_{\mathrm{m}} \mathrm{K}-\mathrm{K} \mathbb{1}_{\mathrm{m}}+\mathbb{1}_{\mathrm{m}} \mathrm{K} \mathbb{1}_{\mathrm{m}}
$$

obtendo a centralização K da matriz K.

I deal izamos a centralização do vetor $\mathrm{k}_{\mathrm{x}}$ inspirados na central ização da matriz K. Com a notação da Seção 4.2, temos que

$$
\tilde{\varphi}\left(x_{s_{i}}\right)=\varphi\left(x_{s_{i}}\right)-\frac{1}{n} \sum_{j=1}^{n} \varphi\left(x_{s_{j}}\right)
$$

será centrada entre o pontos de controle, ou seja, $\frac{1}{n} \sum_{i=1}^{n} \tilde{\varphi}\left(x_{S}\right)=0$. Denotando por $\tilde{k}_{x}=$

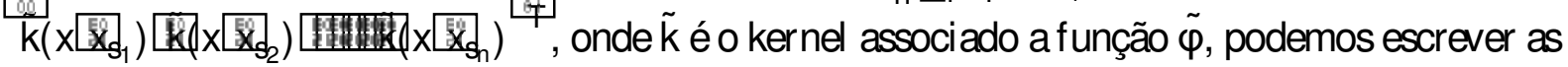
coordenadas de $\tilde{\mathrm{k}}_{\mathrm{x}}$ como

$$
\begin{aligned}
& \tilde{k}_{\mathrm{x}}\left(\mathrm{x} \mathrm{E}_{\mathrm{S}_{\mathrm{s}}}\right)=\tilde{\varphi}\left(\mathrm{x}_{\mathrm{x}}\right)^{\top} \tilde{\varphi}\left(\mathrm{x}_{\mathrm{s}_{\mathrm{i}}}\right) \\
& =\varphi(x)-\frac{1}{n} \sum_{j=1}^{n} \varphi\left(x_{S_{j}}\right)^{\#_{T} "} \varphi\left(x_{s_{i}}\right)-\frac{1}{n} \sum_{p=1}^{n} \varphi\left(x_{S_{p}}\right) \\
& =\varphi(x)^{\top} \varphi\left(x_{s_{j}}\right)-\frac{1}{n} \sum_{p=1}^{n} \varphi(x)^{\top} \varphi\left(x_{s_{p}}\right)-\frac{1}{n} \sum_{j=1}^{n} \varphi\left(x_{s_{j}}\right)^{\top} \varphi\left(x_{s_{j}}\right)+\frac{1}{n^{2}} \sum_{j}^{n} \varphi\left(x_{s_{j}}\right)^{\top} \varphi\left(x_{s_{p}}\right)
\end{aligned}
$$

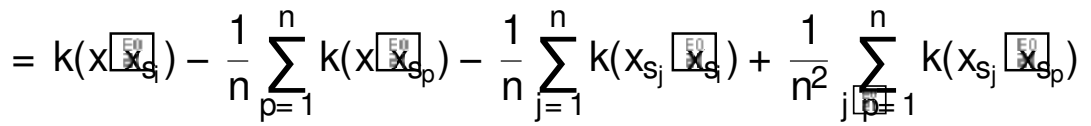

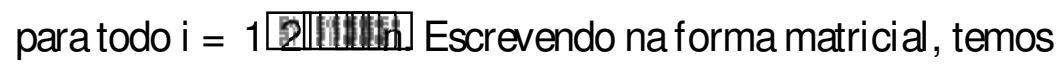

$$
\tilde{k}_{\mathrm{x}}=\mathrm{k}_{\mathrm{x}}-\mathrm{K}_{\mathrm{s}} 1_{\mathrm{n}}-\mathbb{1}_{\mathrm{n}} \mathrm{k}_{\mathrm{x}}+\mathbb{1}_{\mathrm{n}} \mathrm{K}_{\mathrm{s}} 1_{\mathrm{n}}
$$

onde $1_{\mathrm{n}}$ é o vetor com de tamanho $\mathrm{n}$ com todas as coordenadas iguais a $\frac{1}{\mathrm{n}}$.

\subsection{Projeção dos pontos de controle}

Nossa técnica, ef etua no primeiro passo, a projeção dos pontos de controle utilizando o Force Scheme (TEJADA; MINGHIM; NONATO, 2003). Como o Force Scheme utiliza a informação de distância, precisamos das distâncias no espaço de características para poder ef etuar essa projeção inicial. Entretanto, toda informação que temos sobre o dado no espaço de características é a medida de si milaridade dada pelo kernel. Dado um produto interno no espaço de características, temos automaticamente uma medi da de distância proveniente desse

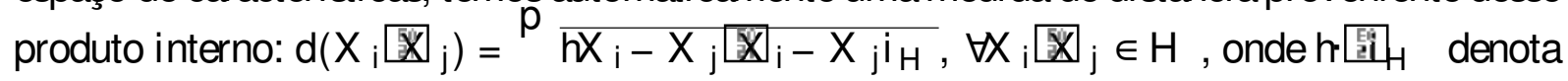
um produto interno no espaço de características $\mathrm{H}$. Como o kernel define um produto interno no espaço de características, temos uma medida de distância definida pel o kernel dada por

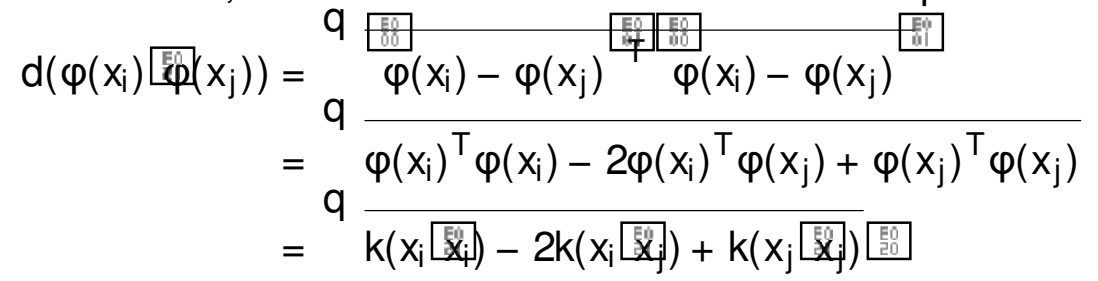


A distância dada pela equação (4.15) é utilizada no cál cul o da posição $Y_{S}$ dos pontos de controle no espaço visual pelo Force Scheme. O Force Scheme calcula, para cada $y_{i}$ no espaço visual, o vetor $v=y_{j}-y_{i}$ e move $y_{j}$ na direção em que $v$ aponta por uma fração $\Delta=\frac{D\left(x_{i} x_{j}\right)-D_{\min }}{D_{\max }-D_{\min }}-d\left(y_{i} E_{j}\right)$ de seu comprimento, com $D$ e d sendo as medidas de distância no espaço original e no espaço visual, respectivamente. Como $\mathrm{M}$ é linear, tem que levar a origem do espaço de características na origem do espaço visual. Portanto, para preservar essa propriedade, após cal cul ar o posi cionamento dos pontos de controle pelo Force Scheme, central izamos $Y_{\mathrm{S}}$ de modo que seu centroide coincida com a origem do espaço visual.

\subsection{Aspectos computacionais}

Na construção da Kelp (Seção 4.2), assumimos que a matriz de covariância C possui colunas ui ortonormais. Então, pela equação (4.4), temos

$$
1=u_{i}^{\top} u_{i}=\sum_{p \in q}^{n} a_{i p} a_{i q} \varphi\left(x_{S_{p}}\right)^{\top} \varphi\left(x_{s_{q}}\right)=a_{i}^{\top} K_{s} a_{i}=v_{i} a_{i}^{\top} a_{i}
$$

mostrando que os autovetores de $\mathrm{K}_{\mathrm{s}}$ definidos na equação (4.4) são ortogonais, mas não são unitários. Porém, como as bibliotecas numéricas usualmente retornam autovetores unitários, para garantir que $\mathrm{ku}_{\mathrm{i}} \mathrm{k}_{2}=1$, temos que multiplicar os autovetores unitários de $\mathrm{K}_{\mathrm{s}}$ (dados pelas bibliotecas numéricas) por $\frac{\sqrt{1}}{\overline{V_{i}}}$.

A parte mai s custosa computacional mente da nossa técnica é o cál culo dos autovetores e autoval ores da matriz $\mathrm{K}_{\mathrm{s}}$, cuja compl exidade computacional é $\mathrm{O}\left(\mathrm{n}^{3}\right)$, onde n é o número de pontos de controle. Entretanto, esse cál culo éfeito apenas uma vez e geral mente para um número pequeno de pontos de controle. O Algoritmo 4 exibe os passos para projeção utilizando a Kelp.

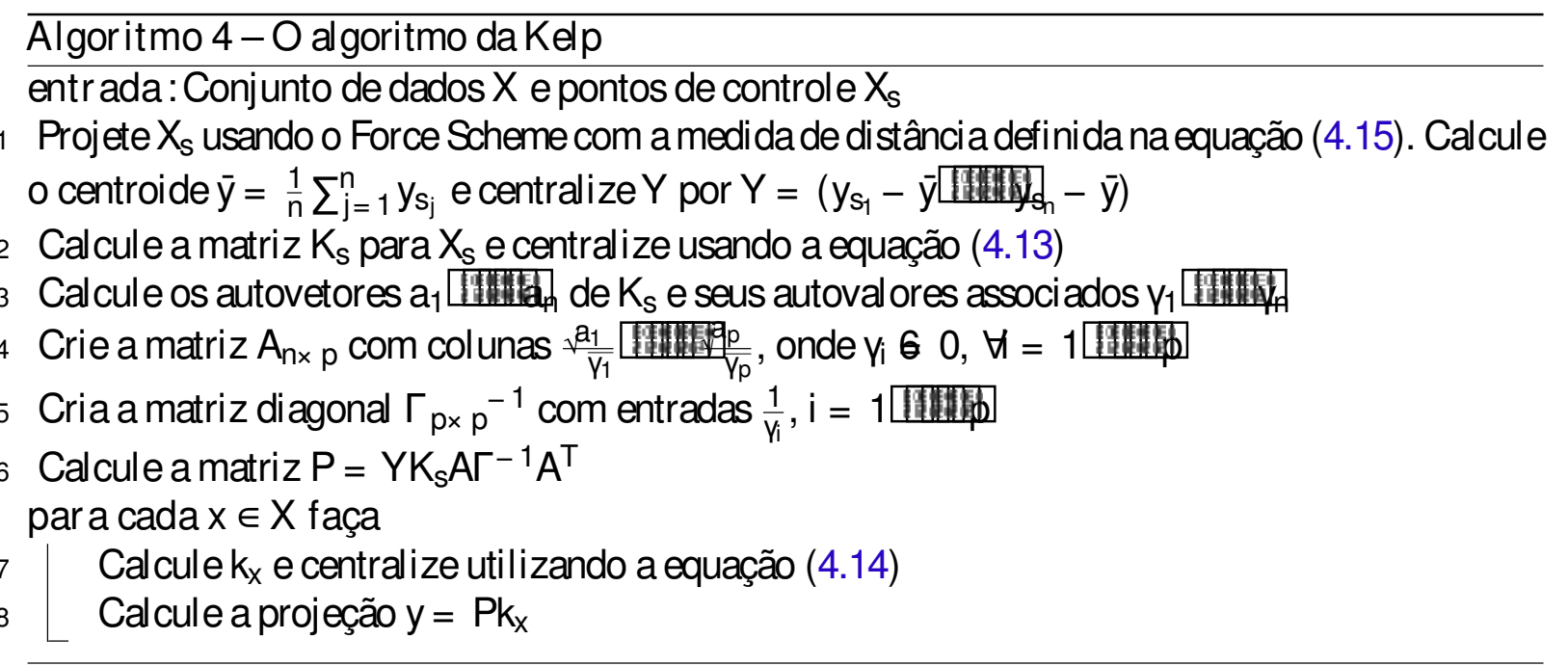




\subsection{Resultados e comparações}

Os resultados apresentados nessa seção, foram gerados utilizando pontos de controle escol hidos al eatoriamente e em quantidade $n=\sqrt{\mathrm{m}}$, onde m é o tamanho de todo o conjunto de dado (uma discussão sobre o tamanho do conjunto de pontos de controle pode ser encontrada em (PAULOVICH; SILVA; NONATO, 2010)). Alguns experimentos utilizam uma estratégia diferente para a escol ha dos pontos de controle, deixaremos esses casos claros no decorrer do texto.

Começaremos aval iando a Kelp quanto à sua preci são e tempo de execução. Comparamos nossa técnica com outras cinco e em oito conjuntos de dados diferentes com variabilidade na quantidade de instâncias e di mensão do dado (Tabela 3). As técnicas utilizadas na comparação foram escol hidas por conta de suas similaridades com a Kelp; mais especificamente: precisam de um conjunto de pontos de controle e são capazes de lidar com a informação de um kernel. Além disso, essas técnicas são bem conhecidas por seu desempenho em termos de precisão e/ou tempo computacional, garantindo que as comparações são justas e se equiparam aos métodos que caracterizam o estado da arte. As técnicas escol hidas foram: Fastmap (FALOUTSOS; LIN, 1995), Hybrid (JOURDAN; MELANCON, 2004), Landmark MDS (SILVA; TENENBAUM, 2004), Pekal ska (PEKALSKA et al., 1999) e PLP (PAULOVICH et al., 2011). Todas apresentam bom desempenho quanto ao stress e tempo. Quanto a implementação, Pekal ska e PLP resolvem um sistema linear e precisam de bibliotecas numéricas para tal. Landmark MDS requer uma implementação eficiente da decomposição SVD, como o al goritmo LAS2 (BERRY, 1992). Fastmap e Hybrid podem ser implementadas diretamente. Assim como a Kelp, PLP e Pekal ska permitem que o usuário manipule interativamente os pontos de controle no espaço visual.

Tabela 3 - Conjuntos de dados utilizados nas comparações, da esquerda para direita as col unas correspondem ao nome do conjunto de dados, tamanho, dimensão e fonte.

\begin{tabular}{lccc}
\hline Nome & Tamanho & Dim & Fonte \\
\hline \hline wdbc & 569 & 30 & (FRANK; ASUNCION, 2010) \\
\hline diabetes & 768 & 8 & (FRANK; ASUNCION, 2010) \\
\hline segmentation & 2.100 & 19 & (FRANK; ASUNCION, 2010) \\
\hline us-countries & 3.028 & 14 & (SHNEIDERMAN; SEO, 2008) \\
\hline wine & 4.898 & 11 & (FRANK; ASUNCION, 2010) \\
\hline letter rcn & 20.000 & 16 & (FRANK; ASUNCION, 2010) \\
\hline mammals & 50.000 & 72 & (FRANK; ASUNCION, 2010) \\
\hline viscontest & 200.000 & 10 & (WHALEN; NORMAN, 2008) \\
\hline \hline
\end{tabular}

Para medir a precisão, utilizamos a função de stress dada por $\frac{1}{\sum_{i j} d_{i j}} \sum_{i j} \frac{\left(d_{i j}-\bar{d}_{i j}\right)^{2}}{d_{i j}^{2}}$, onde $d_{i j}=d\left(\varphi\left(x_{i}\right)\right.$ 凨 $\left.\left(x_{j}\right)\right)$ éa distância dada pela equação (4.15) e e $\bar{i}_{j}$ é a di stância Euclidiana entre as 
imagens de $x_{i}$ e $x_{j}$ no espaço visual. As projeções da Kelp foram produzidas utilizando o kernel Gaussiano com parâmetro $\sigma$ igual a média da variância dos dados e a distância foi cal culada usando a equação (4.15).

O box pl ot azul na Figura 18 mostra os val ores de stress obtidos nas projeções da Kelp e das demais técnicas para cada conjunto de dados da Tabela 3. Podemos facilmente dizer que a Kelp é uma das técnicas mais precisas, sendo comparável às técnicas al tamente precisas como Landmark MDSe Pekalska. O box pl ot amarelo mostra que a Kelp também obtém bons resul tados em termos de tempo de execução, sendo comparável à Fastmap, a qual é conhecida por sua eficiência computacional. Observe que a Kelp é quase uma ordem de magnitude mais rápi da que Landmark MDS e Pekal ska, ambas técnicas semel hantes à Kelp em termos de precisão.

Figura 18 - Box plot do stress e tempo em cada conjunto de dado.

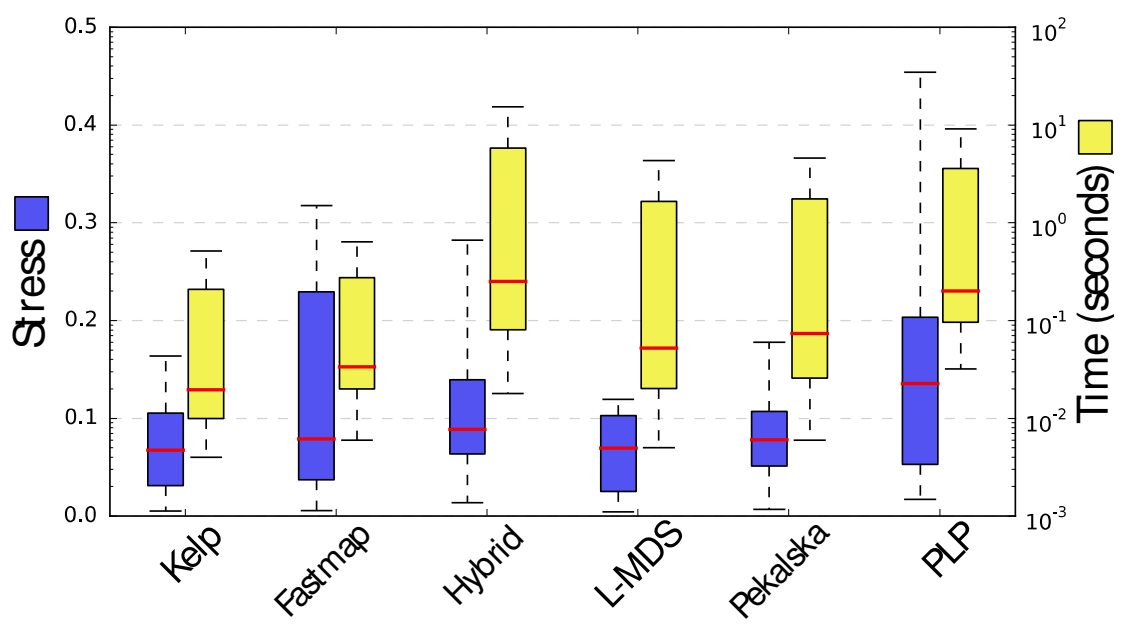

Os gráficos de distância original x distância projetada apresentados na Figura 19 atestam a precisão visual da Kelp. Observe que o formato dos gráficos da Kelp estão próximos da linha de $45^{\circ}$ em quase todos os testes, atestando que a vizinhança dos pontos é preservada no espaço visual. O mesmo não é verdadeiro para outras técnicas como Hybrid e PLP, cujo resul tado está espal hado na direção da diagonal.

Os conjuntos de dados utilizados nas comparações são compostos por instâncias contidas em espaços vetoriais reais, permitindo assim o uso de técnicas al tamente precisas como a LAMP (JOIA et al., 2011). Entretanto, a Figura 20 diz que nossa técnica não é desnecessária para esse tipo de dado, pois as projeções da Kelp têm grupos mel hor definidos que os gerados por projeções que tomam os dados no seu espaço original. As Figuras 20a e 20b mostram que as proj eções resultantes da apli cação da Kelp e da LAMP no conjunto de dados Segmentation e as Figuras 20c e 20d mostram os resul tados num conjunto de dados com 574 artigos científicos composto por três tópicos diferentes (PAULOVICH et al., 2008). As projeções da Kelp na Figura 20 foram produzi das kernel izando o dado utilizando o kernel Gaussi ano com parâmetro $\sigma$ igual a média da variância dos dados (bag-of-words do conjunto de dados de artigos científicos). O layout produzido pela Kelp é mais bem definido, evidenciando os grupos e instâncias similares. 
Figura 19 - Gráfico de distância original x distância projetada. Os números no canto superior significam stress e tempo de execução (em segundos). Val ores em negrito são os melhores para cada conjunto de dado.

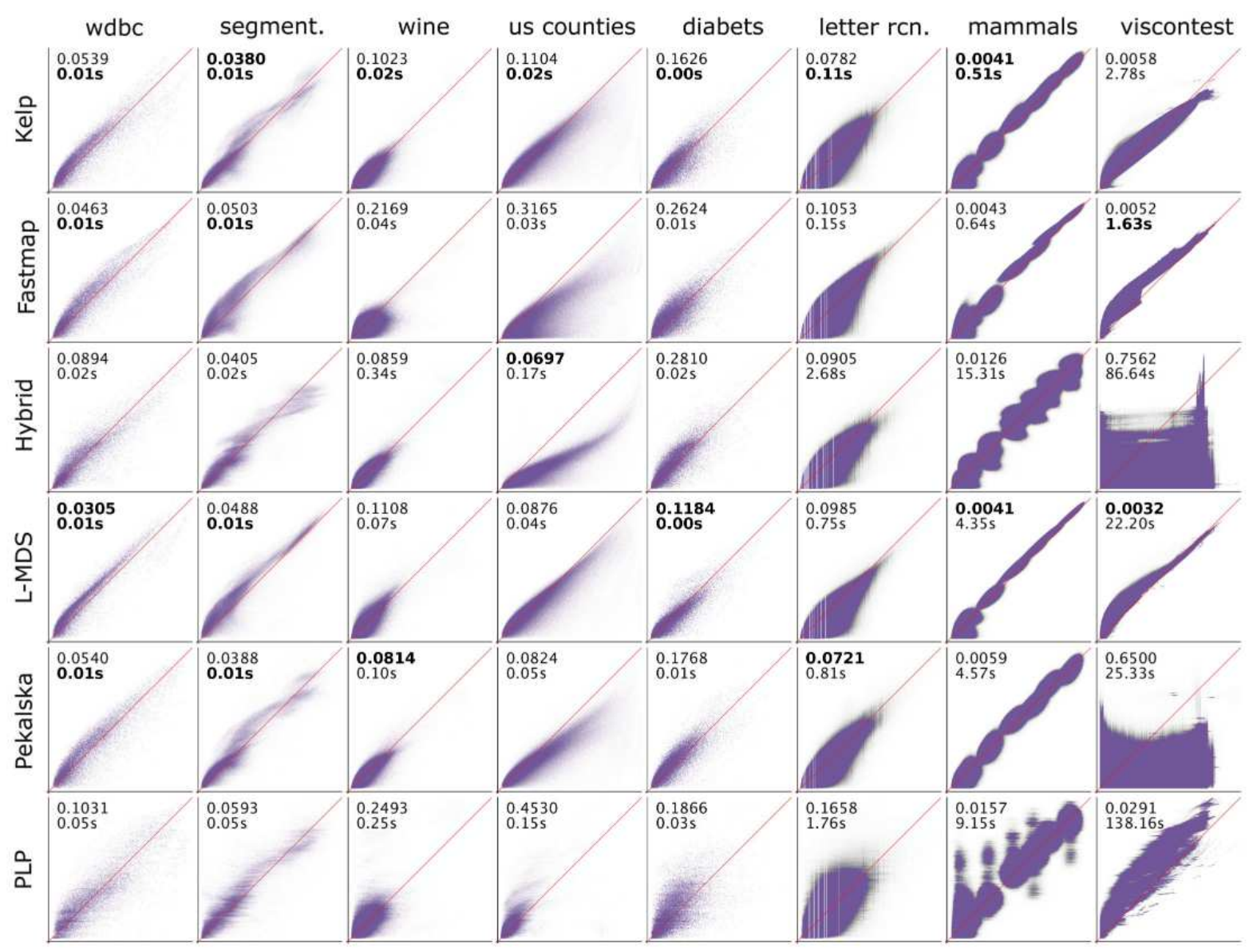

Os resultados da Kelp quanto à silhueta corroboram essa afirmação. A silhueta foi cal culada segundo $S=\frac{1}{m} \sum i \frac{\left(b_{i}-a_{i}\right)}{\max \left\{a_{i}\left[b_{i}\right\}\right.}$ como na Seção 3.3.2. A silhueta varia no intervalo [- 1 國] e, quanto mai or o valor de $S$, melhor é a coesão e a separação dos grupos.

A sensibilidade da Kelp quanto a intervenção do usuário é analisada na Figura 21. A figura no canto superior direi to mostra a posi ção dos pontos de controle, enquanto que a imagem mai or mostra a projeção resultante; a Figura 21 a mostra a projeção produzida pela Kelp com o posicionamento dos pontos de controle dados pelo Force Scheme. As Figuras 21b, 21c e 21d mostram as projeções da Kelp, PLMP e LAMP após a mani pulação do usuário nos pontos de controle, que agrupou o dado segundo suas classes. Observe que a Kelp obtém novamente o mel hor resul tado quanto à silhueta, sendo superior inclusive à LAMP, que é conhecida por ser bem sensível à intervenção do usuário.

A Figura 22 apresenta o comportamento da Kelp quanto à variação no número de pontos de controle. O serril hado no gráfico é devido a sel eção al eatória dos pontos de controle, fenômeno já conheci do na literatura (PAULOVICH; SILVA; NONATO, 2010). Observe que a amplitude da oscilação é pequena, perto de 0 05. Na prática, observamos que a Kelp produz bons resultados mesmo quando utilizamos uma quantidade reduzida de pontos de controle, o que nos permitiu 
Figura 20 - Melhorando a coesão e separabilidade dos grupos usando a Kelp. A silhueta (S) é maior para as projeções da Kelp comparada com técnicas baseadas em distância Euclidiana.

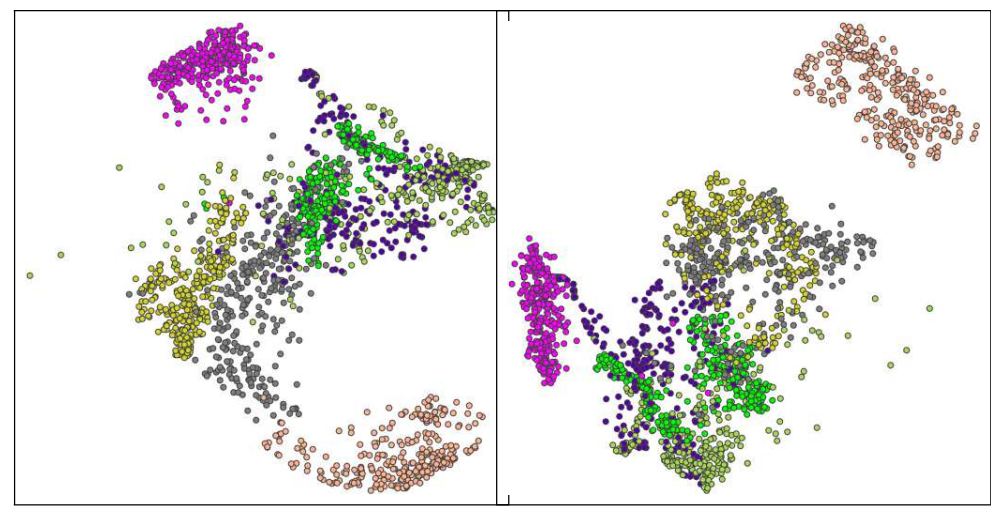

(a) $\mathrm { Kelp } \mathrm { S } = 0 \longdiv { 3 2 3 }$

(b) LAMPS $= 0 \longdiv { 2 0 3 }$

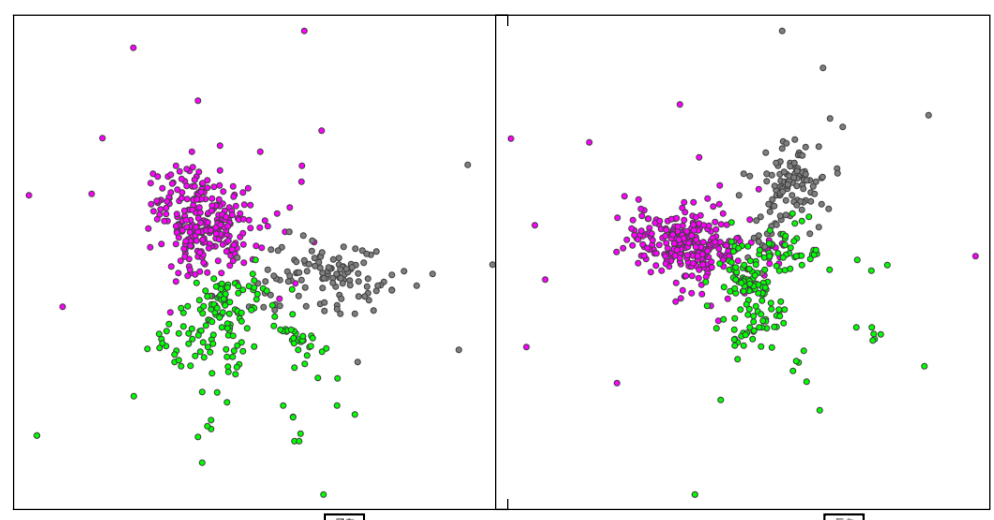

(c) $\mathrm { Kelp } \mathrm { S } = 0 \longdiv { 5 9 9 }$

(d) LAMPS $=0[411$

tomar ${ }_{\bar{m}}$ nos nossos experimentos.

A nal isamos também a Kelp segundo al guns artefatos que podem aparecer em projeções multidimensionais, denominados tears e falsos vizinhos, seguindo a metodologia CheckViz desenvolvida em (LESPINATS; AUPETIT, 2011). Tears aparecem quando instâncias vizinhas no espaço original são mapeadas distantes no espaço visual, enquanto que fal sos vizinhos, como o nome induz, são instâncias que foram mapeadas próximas no espaço visual mas que são distantes no espaço original. Esses artefatos podem ser detectados através de duas medi das de stress:

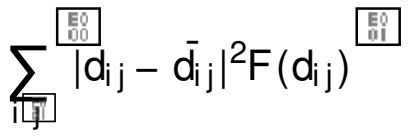

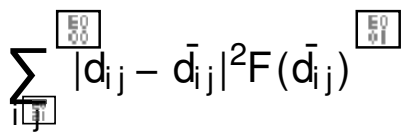

onde $d_{i j}$ e $\bar{d}_{\mathrm{ij}}$ representam as medidas de distância no espaço original e no espaço visual e $F$ é uma função de peso. Supondo $d_{i j}$ grande e $\bar{d}_{i j}$ pequeno, as instâncias i e j são fal sos vizinhos. Como na equação (4.16) $\mathrm{F}$ depende apenas de $\mathrm{d}_{\mathrm{i} j}$, podemos escol her $\mathrm{F}$ de modo que o resultado da soma seja pequeno, fazendo assim com que a equação (4.16) aponte tears quando seu valor for al to. Analogamente, se $d_{i j}$ é pequeno e $\bar{d}_{\mathrm{ij}}$ é grande, temos que as instâncias $\mathrm{i}$ e j são tears e podemos utilizar a equação (4.17) para apontar falsos vizinhos quando seu val or for 
Figura 21 - Comparando a sensibilidade da Kelp quanto a intervenção do usuário. Canto superior direito mostra a posição dos pontos de controle.

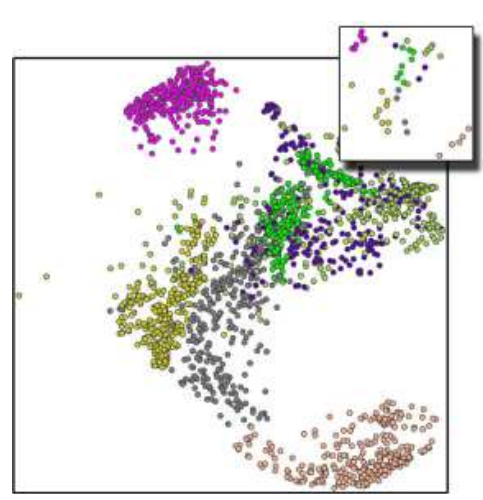

(a) Kelp original $\mathrm { S } = 0 \longdiv { 3 2 3 }$

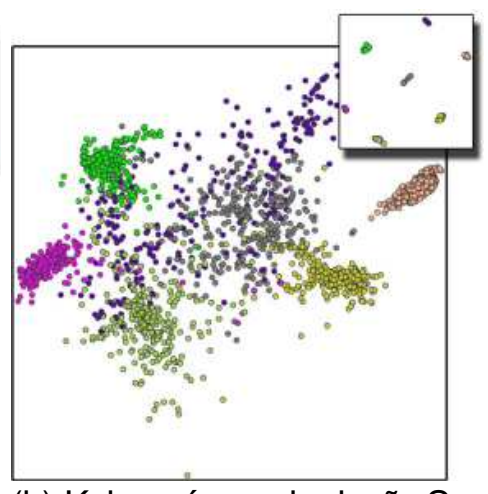

(b) Kelp após manipulação $S=$ 0449
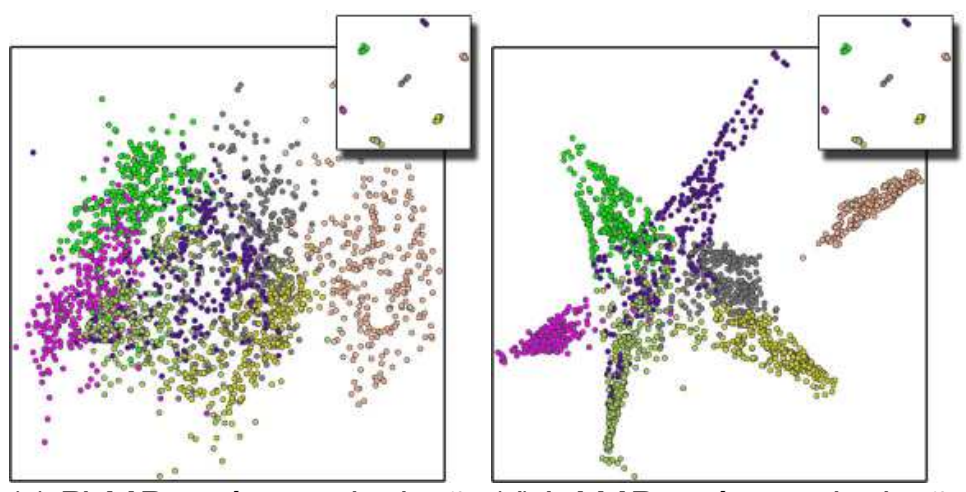

(c) PLMP após manipulação $S = 0 \longdiv { 1 8 9 }$

$S = 0 \longdiv { 4 8 2 }$

Figura 22 - Variando o número de pontos de controle: o stress estabiliza próximo dos $5 \%$ do número de instâncias.

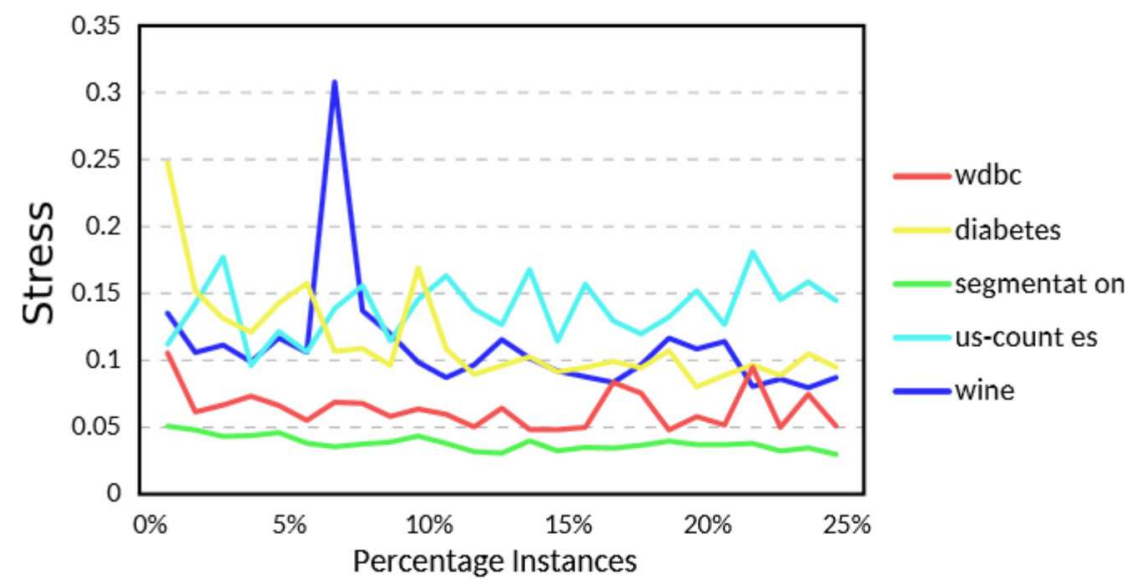

alto. Lespinats e Aupetit (2011) recomendam a escolha de F como a função de peso Heaviside:

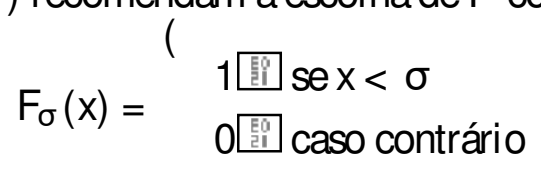

Utilizamos o seguinte código de cores para representar essas di storções: roxo paraindicar os fal sos vizinhos, verde indicando tears, preto indica que a instância sof re de ambas distorções 
simultaneamente e branco representando as instâncias sem distorções. Definindo, para cada instância $x_{i}$, o par ordenado ( $f_{i}$ ifi), onde

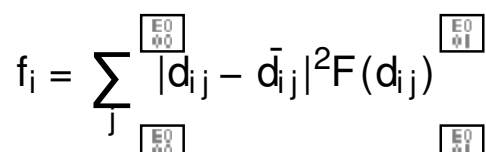

$$
\begin{aligned}
& t_{i}=\sum_{j}\left|d_{i j}-\bar{d}_{i j}\right|^{2} F\left(\bar{d}_{i j}\right)
\end{aligned}
$$

podemos visualizar o código de cor que descreve os tipos de distorção no plano e, mais ainda, quantificar a intensi dade dessas cores (Figura 23).

Figura 23 - Espaço de cores utilizado na anál ise de tears e fal sos vizinhos.

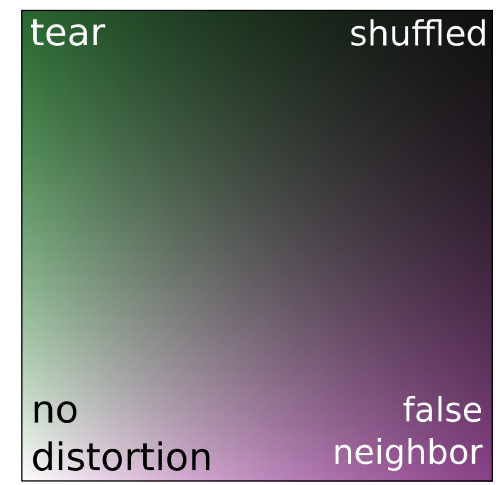

Lespinats e Aupetit (2011) se basei am em duas regras para anal isar os resultados:

䀦Regra da separação: se várias instâncias roxas são disjuntas, então o espaço entre elas é verdadeiro no espaço original. Pois, caso contrário, essas instâncias corresponderiam a tears e deveriam assumir a cor verde ou preto.

的Regra da sobreposição: se várias instâncias verdes estão próximas umas das outras ou se sobrepõe, então estão local izadas próximas umas das outras no espaço original. Caso contrário, deveriam assumir a cor roxa ou preta.

A Figura 24 mostra o resultado obtido pela Kelp na metodologia Check Viz. As instâncias interiores aos grupos indi cam a presença de tears, mas fal sos vizinhos são observados apenas para pontos posi cionados na frontei ra dos grupos (entre os grupos). Pel as regras aci ma, temos a mel hor configuração possível, pois dentro dos grupos a metodol ogia indica uma verdadei ra sobreposi ção e na fronteira dos grupos as instâncias são apontadas como falsos vizinhos indicando uma verdadeira separação no espaço visual.

\subsection{Aplicações}

Nesta seção ilustramos a utilidade de Kelp em três aplicações di stintas. A primeira aplicação é motivada pel a di scussão feita no início deste capítul o: queremos entender o comportamento 
Figura 24 - Verificando a qual idade da projeção segundo a metodologia CheckViz: (a) projeção de um conjunto de dados artificial com 150 instâncias e quatro dimensões (GUYON, 2003); (b) regiões roxas indicam fal sos vizinhos e regiões indicam tears.

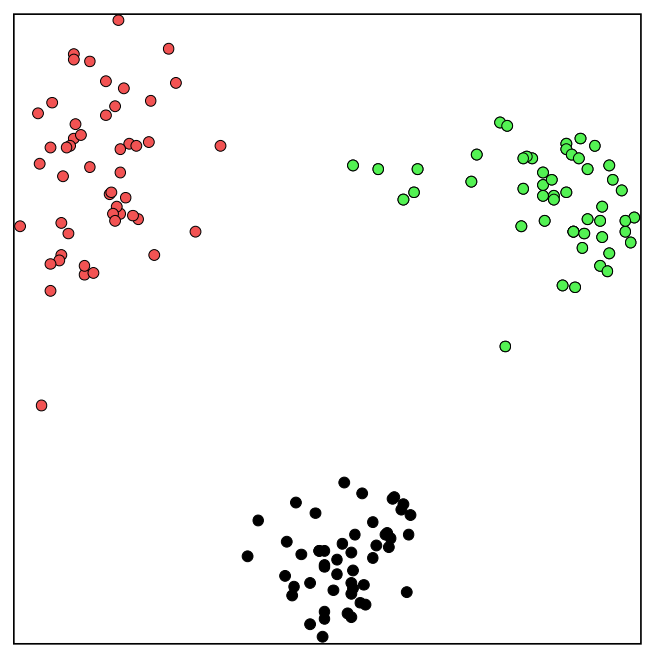

(a) Projeção da Kelp

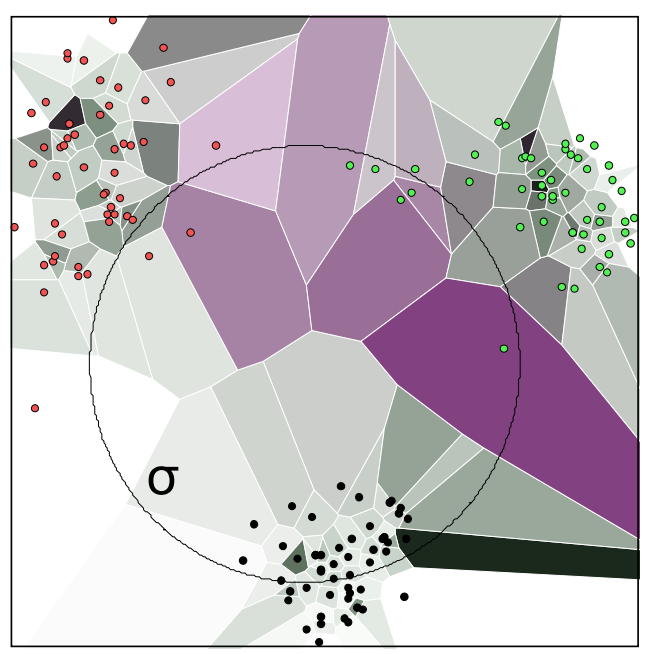

(b) Análise CheckViz

da função $\varphi$ definida impli citamente pelo kernel. Mais especificamente, utilizamos a Kelp como ferramenta para anal isar o ef eito do kernel nas relações de vizinhança do dado. A segunda aplicação explora a interatividade da Kelp para auxiliar tar ef as de classificação utilizando Support Vector Machine (SCHÖLKOPF; SMOLA, 2001) (SVM). A última aplicação mostra como o processo de visual ização pode tirar proveito de técni cas baseadas em kernel como a Kelp.

\subsubsection{Mudança de vizinhança induzidas pelo kernel}

Como motivado no início do Capítulo, entender o ef eito de um kernel nas estruturas de vizinhança do dado é de fundamental importância para uma escol ha apropriada, construção e aprimoramento de um kernel para uma tarefa específica.

Nossa abordagem utiliza uma métrica para comparar as estruturas de vizinhança definidas no espaço original (usual mente Cartesiano), onde o dado se encontra, e sua imagem no espaço de características induzido pelo kernel. A métrica é definida da seguinte forma: seja $\delta_{i}=$ $x_{i}-\frac{1}{\# N_{i}} \sum_{j \in N_{i}} x_{j}$ a coordenada diferencial de $x_{i}$, onde $N_{i}$ denota os índices dos $k$ vizinhos mais próximos de $x_{i}$ e $\# N_{i}$ é a cardinal idade do conjunto $\mathrm{N}_{i}$. Assim, a norma $k \delta_{i} k$ mede o quão longe $x_{i}$ está do centroide dos seus vizinhos. A norma da coordenada diferencial $\delta_{\varphi}$ de $\varphi_{i}=\varphi\left(x_{i}\right)$ no 
espaço de características é dada por $k \delta_{\varphi} \mathrm{k}=\stackrel{\mathrm{q}}{{\overline{\delta_{\varphi}}}^{\top} \delta_{\varphi}}$. Logo

$$
\begin{aligned}
& \mathrm{k}_{\varphi_{i}} \mathrm{k}^{2}=\varphi_{1}-\frac{1}{\# \mathrm{~N}_{\mathrm{i}}} \sum_{j \in N_{\mathrm{i}}} \varphi_{\mathrm{j}}^{!} \quad \varphi_{\mathrm{T}}-\frac{1}{\# \mathrm{~N}_{\mathrm{i}}} \sum_{\mathrm{j} \in \mathrm{N}_{\mathrm{i}}} \varphi_{\mathrm{j}} \\
& =\varphi_{i}^{\top} \varphi_{i}-\frac{1}{\# N_{i}} \sum_{j \in N_{i}} \varphi_{1}^{\top} \varphi_{j}-\frac{1}{\# N_{i}} \sum_{j \in N_{i}} \varphi_{j}^{\top} \varphi_{i}+\frac{1}{\left(\# N_{i}\right)^{2}} \sum_{j \in S \in N_{i}} \varphi_{j}^{\top} \varphi_{s}
\end{aligned}
$$

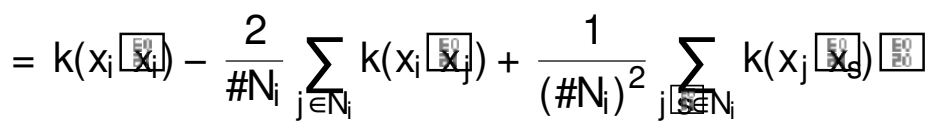

A equação (4.18) mostra que a norma da coordenada di ferencial no espaço de características pode ser obtida a partir do kernel, tornando possível medir quão longe cada instância está do centroi de de seus vizinhos nesse espaço, mesmo sem saber as coordenadas da instância nem dos vizinhos.

As cores nas Figuras 25a e 25b representam os val ores correspondentes de $k \delta_{i} k$ e $k \delta_{\varphi} k$ cal cul ados em cada instância (no conjunto de dados artificial (GUYON, 2003)). O layout dos pontos foi gerado pela PLMP e pela Kelp, respectivamente. Regiões em vermel ho correspondem a val ores al tos de $k \delta_{i} k$ e $k \delta_{\varphi p} k$, enquanto que regiões em azul correspondem a val ores baixose regiões em verde são val ores intermediários. Escolhemos PLMP para projetar o dado a partir do espaço original, porque, como a Kelp, a PLMP faz uso de uma transformação linear, tornando a comparação mais justa. Observe que, mai s uma vez, a projeção baseada em kernel fez os grupos ficarem melhor definidos.

A razão $k \delta_{i} k\left[{ }_{k} \delta_{\varphi} k\right.$ mede a mudança na vizinhança quando o dado é levado no espaço de características pela $\varphi$ defini da impl icitamente pelo kernel. Val ores próximos de 1 indicam que a estrutura da vizinhança não mudou, valores próximos de 0 indicam que as instâncias ficaram mais distantes dos seus vizinhos e val ores mai ores que 1 significa que as instâncias ficaram central izadas com rel ação a seus vizinhos quando não eram centradas no espaço original. Utilizando uma função de transferência como da Figura 26, podemos visual izar as regiões onde a vizinhança é mais af etada pelo kernel. O fundo da Figura 25 foi colorido interpolando o val or da coordenada diferencial (ou de sua razão) de cada instância para uma grade regular no fundo. Figura 25b nos diz que o kernel Gaussiano posi ciona mel hor os pontos em termos dos vizinhos que estão intragrupo; ou seja, o kernel Gaussi ano tende a posicionar instâncias mais próximas do centroide do seu grupo. Entretanto, a Figura 25c claramente mostra que, anal isando a razão entre as normas das coordenadas diferenciais, as regiões em vermel ho (val ores próximos de zero e mai ores que um) aparecem no interior dos grupos. Como $k \delta_{\varphi} \mathrm{k}$ é pequeno no interior de grupos bem defini dos (Figura 25b) e os grupos não se espal haram pela ação do kernel, concluímos que os al tos valores da razão são devidos a um agrupamento mais apertado feito pelo kernel Gaussiano. Portanto, como esperado, o kernel Gaussiano tende a criar grupos melhor definidos.

A mesma anál ise pode ser feita com outros kernels al ém do Gaussiano, como ilustrado nas Figuras 25d e 25e. A Figura 25d descreve $k \delta_{\varphi} k$ quando o kernel polinomial dado por 
Figura 25 - Visualizando como o kernel af eta as estruturas de vizinhança: magnitude das coordenadas diferenciais com layout gerado pela PLMP com distância Euclidiana em (a), pela Kelp com kernel Gaussiano em (b) ekernel polinomial em (d); magnitude da razão com Kelp-Gaussiano em (c) e Kelp-Polinomial em (e).

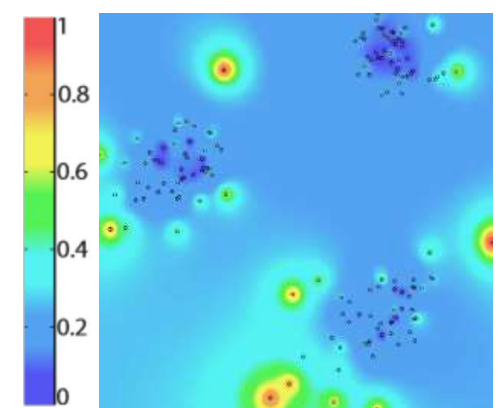

(a) $k \delta_{i} k$ (PLMP)

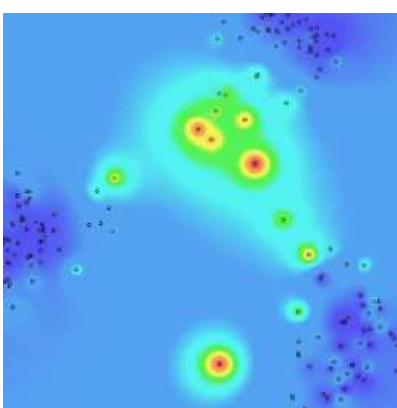

(b) $k \delta_{\varphi_{1}} k$ (Kelp-Gauss.)

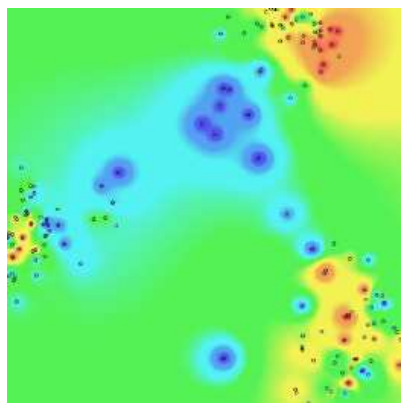

(c) $\frac{k \delta_{i} k}{k \delta_{\phi} k}$ (Kelp-Gauss.)

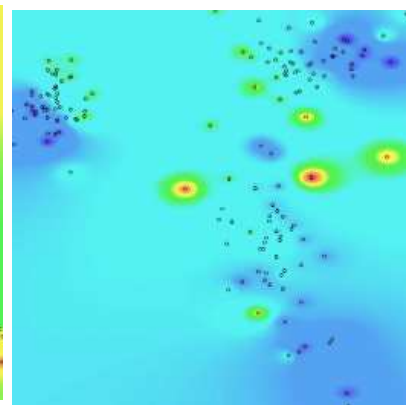

(d) $k \delta_{\varphi_{1}} k\left(K e l p-h-\left[\mathrm{El}^{2}\right)\right.$

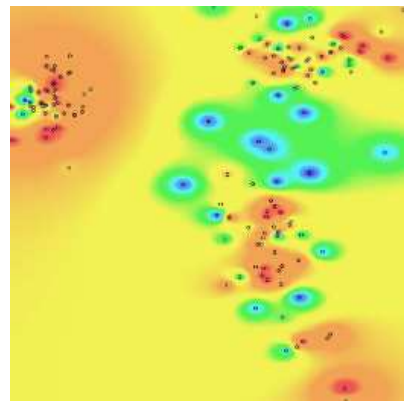

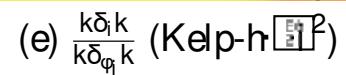

Figura 26 - Função de transf erência

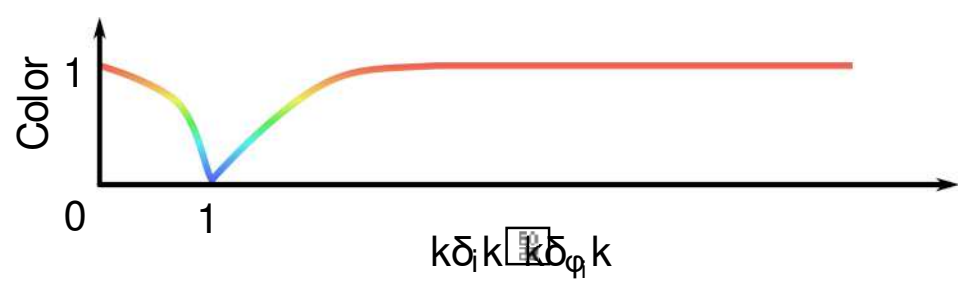

$\mathrm{k}\left(\mathrm{x}_{\mathrm{i}} \mathrm{E}_{\mathrm{j}}\right)=\left(\mathrm{x}_{\mathrm{i}}^{\top} \mathrm{x}_{\mathrm{j}}\right)^{2}$ é usado. Kernels polinomiais são menos intuitivos que o kernel Gaussiano, dificul tando seu uso em aplicações práticas. Usando nossa ferramenta visual, podemos ver que o kernel polinomial acima se comporta quase que da mesma forma que o kernel Gaussiano, evitando a criação de "outliers" próximos dos grupos enquanto que aperta as instâncias dentro dos mesmos.

Como podemos ver claramente, coordenadas diferenciais são bastante efetivas para visual ização das mudanças na estrutura de vizinhança induzi das por um kernel. Vale mencionar que, até onde sabemos, essa é a primeira vez que coordenadas diferenciais foram utilizadas para medir a variação da vizinhança no contexto de dados envolvendo kernel, sendo essa mais uma contribuição do nosso trabal ho. 


\subsubsection{Visualização de SVM}

Support Vector Machine (SVM) é um classificador linear que opera no espaço de características onde o hiperplano de separação tem margem máxima. Intuitivamente, instâncias distantes da margem no espaço de características são cl assificadas com um grau de confiabi lidade maior do que instâncias mais próximas das margens. A Figura 27 ilustra o que acontece no espaço de características durante o processo de classificação do SVM.

Figura 27 - Modelo intuitivo da separação feita no espaço de características quando aplicamos SVM.

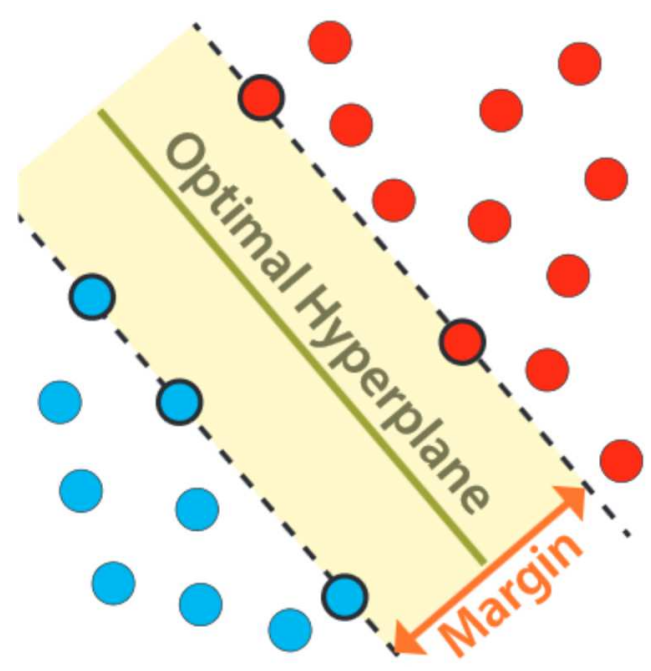

Nós tiramos proveito da interatividade da Kelp para mudar a posição dos pontos de controle no espaço visual de modo a separar os dados como no modelo intuitivo que temos do SVM. A Figura 28 apresenta a projeção do conjunto de dados wdbc (Tabela 3) usando kernel Gaussiano. O mesmo kernel Gaussiano foi usado no SVM. Utilizando a biblioteca LIBSVM (CHANG; LIN, 2011) para executar a classificação com SVM, nós obtemos, para cada instância, a probabilidade dela pertencer a cada uma das classes. Cores mais escuras na Figura 28 indicam mai or probabilidade da instância real mente pertencer aquel a classe, enquanto que cores mais claras indicam instâncias cuja cl assificação não é tão confiante. A linha preta corresponde a região onde a probabilidade interpol ada é igual a 50\%. Observe na Figura 28a que as regiões de confiabilidade não podem ser determi nadas quando os pontos de controle não estão separados no espaço visual. Como o conjunto de dados utilizado possui um número pequeno de instâncias, nós utilizamos 10\% das instâncias para compor o conjunto dos pontos de controle.

Entretanto, quando organizamos os pontos de controle interativamente separando as classes, como na Figura 28b, o layout resultante claramente tem a forma do modelo intuitivo do SVM, tornando fácil interpretar o comportamento do classificador. Observe que inclusive a margem onde o cl assificador fica em dúvida é exibida corretamente. O fundo da Figura 28 é col orido interpolando a probabilidade (dada pelo SVM) de cada instância pertencer a uma das classes.

É importantesal ientar que outros métodos capazes de visual izar o resultado do SVM (HA- 
Figura 28 - Realizando o modelo intuitivo do SVM: (a) projeção inicial onde a linha de separação não é clara e (b) projeção após a manipulação dos pontos de controle. A figura no canto superior apresenta o posicionamento dos pontos de controle.

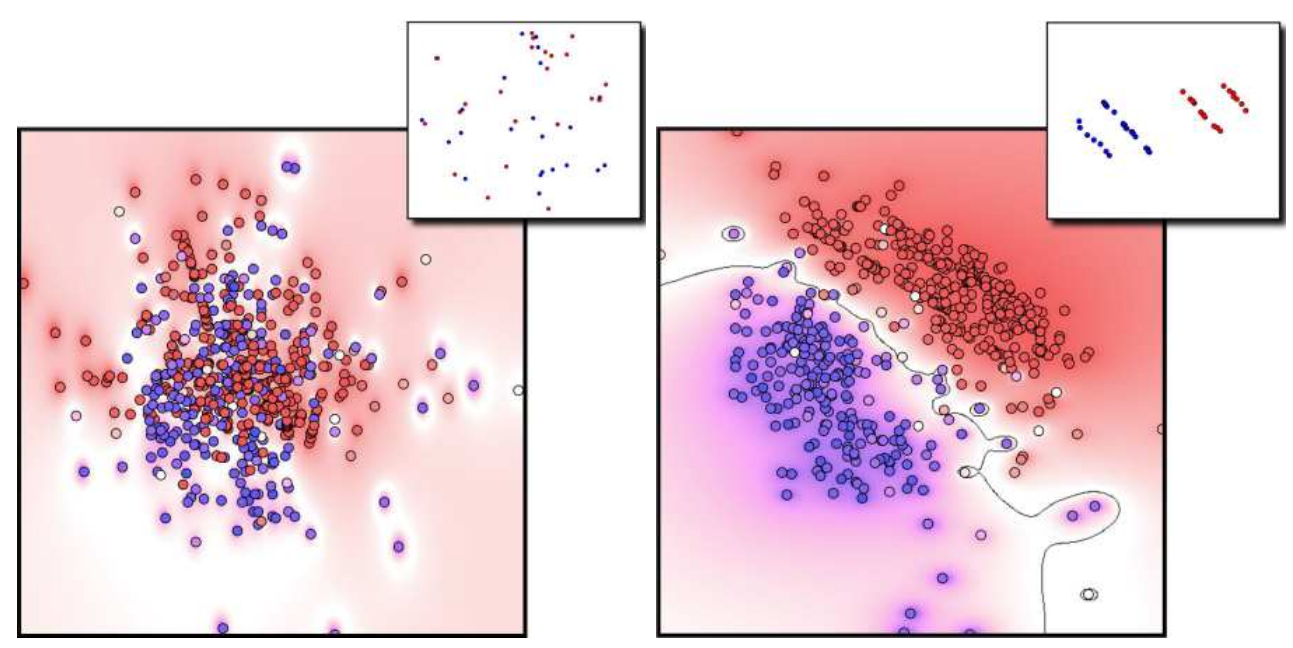

(a)

(b)

MEL, 2006; JAKULIN et al., 2005) assumem que o dado pode ser imerso num espaço cartesiano e o kernel é utilizado apenas no classificador, enquanto que a Kelp utiliza exclusivamente a informação do kernel.

\subsubsection{Segmentação de imagem baseada em kernel}

Interação com usuário é uma característica que define uma classe importante dos métodos de segmentação. Nesse contexto, técnicas que permitem que o usuário interaja no espaço da imagem guiando o processo de segmentação são mai oria (CASACA et al., 2013). Entretanto, técnicas que operam no espaço de características não são comuns, apesar de trabal hos recentes mostrarem vantagem em tarefas como col oração e retrieval (CASACA et al., 2012; MAMANI et al., 2013).

A seguir, mostraremos como a Kelp pode ser utilizada para auxiliar num processo interativo de segmentação que opera diretamente no espaço de características. Mais especificamente, construímos um kernel baseado na filtragem bilateral (TOMASI; MANDUCHI, 1998) que permite utilizar a Kelp como ferramenta para que o usuário interaja di retamente no espaço de características.

Sejam I a imagem original (dado de entrada) e I a imagem resultante da filtragem bilateral:

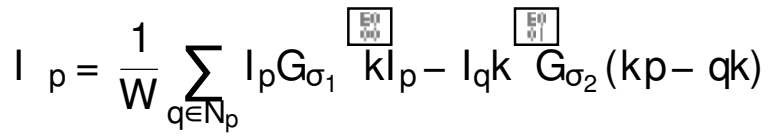

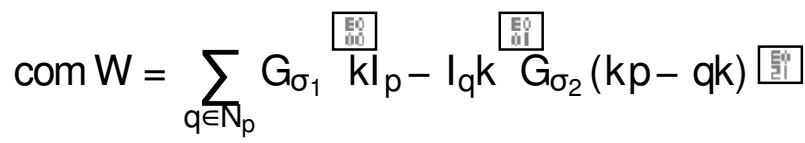


onde $G_{\sigma}(x)=e^{-\frac{x^{2}}{2 \sigma^{2}}}$. Os valores I $I_{p}$ l p são a cor no sistema CIE-Lab do pixel $p$ da imagem I el , respectivamente, $\sigma^{2}$ é a variância tipicamente utilizada em filtros Gaussianos e $N_{p}$ éa vizinhança quadrada ao redor do pixel $\mathrm{p}$.

Definimos o kernel k como

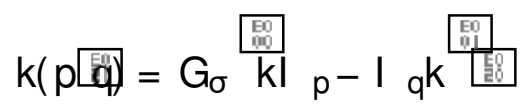

A Figura29b mostra a projeção resultante da Kelp utilizando o kernel definido na equação (4.19), onde cada pixel da imagem na Figura 29a é uma instância de dado. A cor de cada ponto na projeção é a cor do pixel correspondente. Observe na projeção gerada pela Kelp que o amarelo da banana é claramente separado do amarelo do fundo da imagem (Figuras 29c e 29d). Além disso, o usuário pode definir os grupos da segmentação interativamente na projeção, o que é equival ente a definir essas regiões no espaço de características e, consequentemente, no espaço original, como mostrado nas Figuras 29 e e $29 f$.

\subsection{Discussão e limit ações}

Os resul tados e comparações apresentados na Seção 4.6 claramente mostram a eficiência da Kelp, que apresenta um bom balanço entre preci são e tempo de execução. A formul ação matemática sól ida e a facilidade de implementação (requer essencial mente o cál culo de autovetores e autoval ores) são aspectos que mostram a força da Kelp. Um outro ponto interessante da técnica se deve ao fato de ser facilmente paral elizável: após o cál culo da matriz $\mathrm{YK}_{\mathrm{S}} \mathrm{A} \Gamma^{-1} \mathrm{~A}^{\top}$, a projeção das instâncias de dado podem ser feitas de forma independente.

Uma limitação que não está propriamente na formulação da Kelp, mas que afeta seu funcionamento é o kernel utilizado na aplicação e seus parâmetros. O kernel Gaussiano, por exemplo, depende do parâmetro $\sigma$ e esse val or af eta o resultado da classificação do SVM, a redução de dimensionalidade do KPCA e da Kelp, pois todas essas técnicas dependem dos val ores do kernel. Encontrar o val or correto para cada parâmetro do kernel é uma tarefa difícil. Em nossos testes utilizamos a média da variância do dado, mas não há garantia que isso irá funcionar para todo conjunto de dados. Acredi tamos que, devido às suas capacidades, a Kelp pode ser uma ferramenta bastante útil para auxiliar no entendimento do efeito de um kernel permitindo uma melhor escolha desses parâmetros, bem como a criação de um novo kernel através de kernels já conhecidos. 
Figura 29 - Nosso pipeline de segmentação: a imagem de entrada é projetada, onde cada pixel é uma instância de dado, em seguida os grupos são definidos na projeção e o resultado desse agrupamento é exibido como uma imagem segmentada.

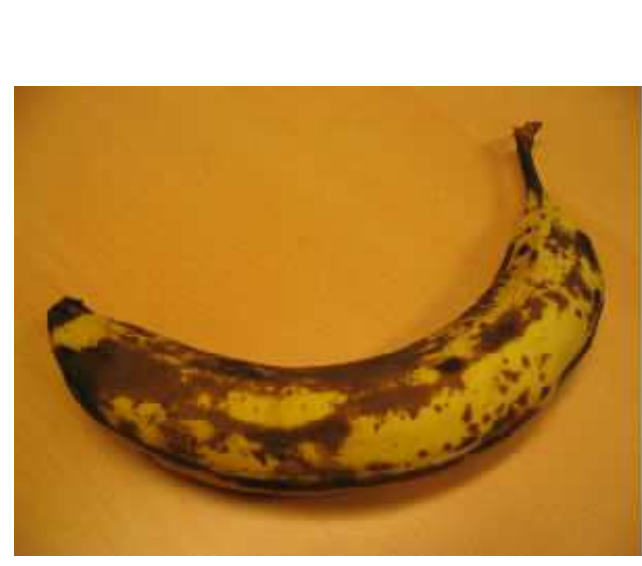

(a) Imagem original

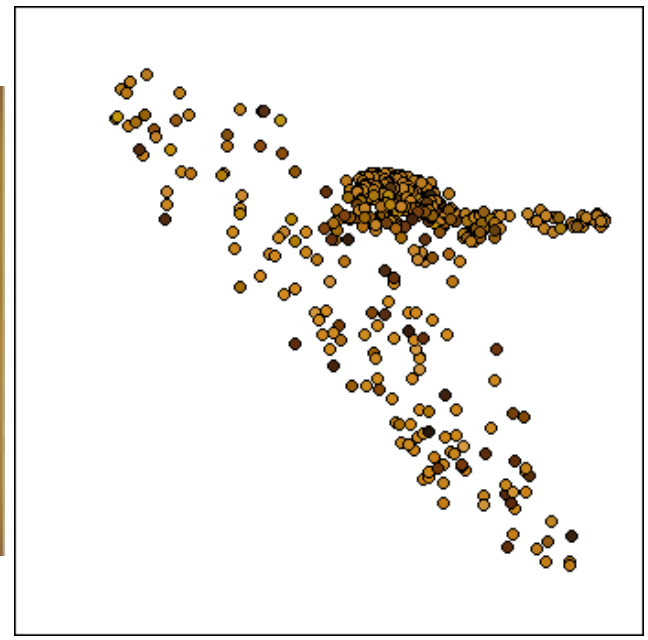

(b) Projeção da Kelp

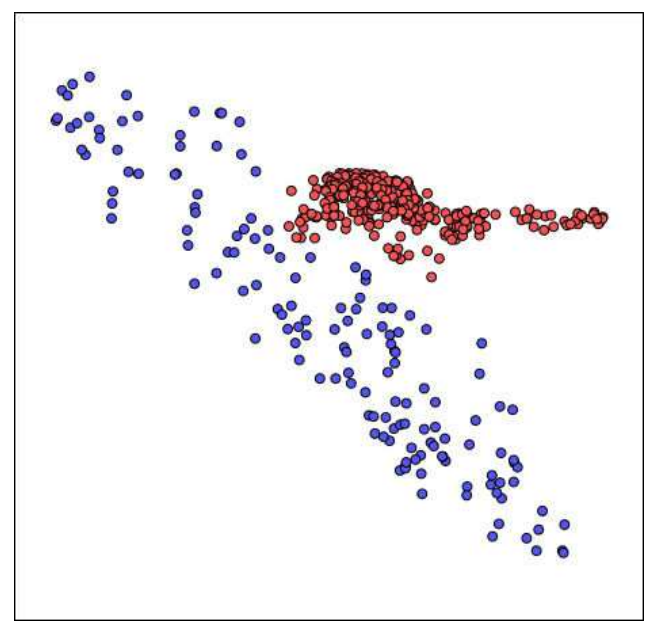

(c) Segmentação em 2 grupos

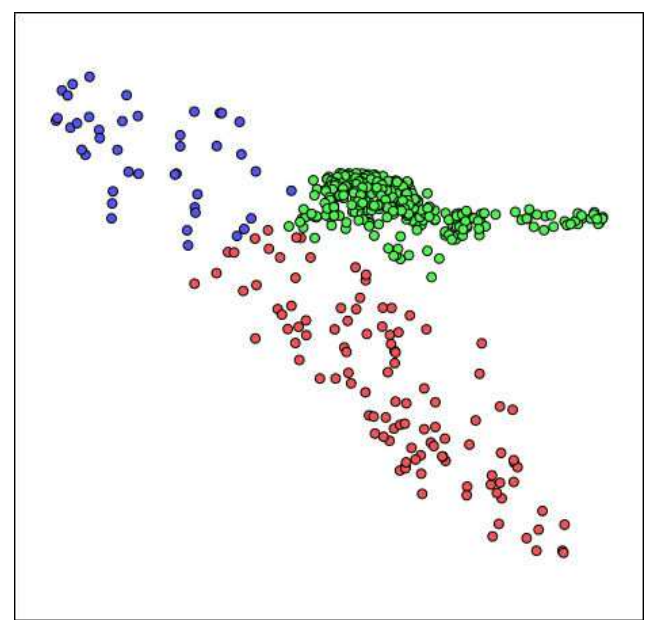

(e) Segmentação em 3 grupos

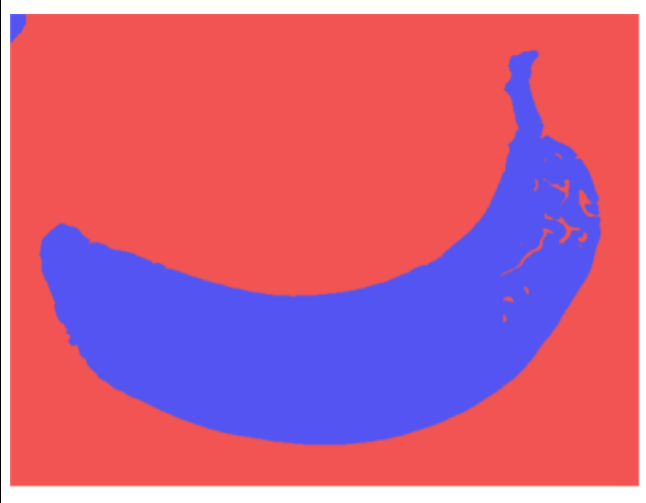

(d) Imagem segmentada 
CAPÍTULO

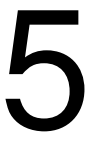

(n)

CONCLUSÃO

Estatese apresentou estudos práticos sobre a utilização de técni cas de subspace cl ustering e métodos de kernel para auxiliar projeções multidimensionais e a criação de uma técnica completamente nova baseada em kernel que possui capacidades até então não exploradas.

Técni cas de subspace clustering se mostram ferramentas promissoras para a análise da estrutura de subespaço intrínseca do dado. Por outro lado, quando o dado não possui tal estrutura, as técnicas não podem ser aplicadas. A informação de classe gerada pela LRR nos permite utilizar técni cas como a LDA em tar ef as como classificação e redução de dimensional idade com uma boa qual idade em termos das métricas que testamos.

Estimar a dimensão e uma base para esses subespaços são taref as que pretendemos executar em trabal hos futuros, além de estudar o ef eito e a eficiência dessas novas informações em taref as de redução de dimensionalidade.

Do lado dos métodos de ker nel, propomos uma nova técnica de projeção multidimensional, chamada Kelp, que possui uma base matemática sólida e com desempenho, em termos de precisão e tempo de execução, comparável e até mel hores do que o das técnicas que são o estado da arte. A Kelp apresentou ótimos resultados em tarefas baseadas em kernel e, por conta disso, possui um grande potencial em tarefas gerais, bastando que um kernel próprio para tal aplicação seja utilizado. Além disso, suaflexibilidade, eficiência e facilidade de implementação a torna uma técnica de projeção multidimensional muito atrativa para aplicações em geral, particularmente, para aplicações que possam tirar proveito de métodos de kernel. Um trabal ho sobre a construção de novos kernels através da combinação de kernels conhecidos já está em andamento. 

AGARWAL, P. K.; MUSTAFA, N. H. K-means projective clustering. In: Proceedings of the Twenty-third ACM SIGMOD-SIGACT-SIGART Symposium on Principles of Database Systems. New York, NY, USA: ACM, 2004. (PODS '04), p. 155-165. ISBN 158113858X. Citado na página 32.

ALZATE, C.; SUYKENS, J. Kernel component analysis using an epsilon-insensitive robust loss function. IEEE Transactions on Neural Networks, IEEE Press, Piscataway, NJ, USA, v. 19, p. 1583-1598, 2008. ISSN 1045-9227. Citado na página 43.

BARBOSA, A.; PAULOVICH, F. V.; PAIVA, A.; GOLDENSTEIN, S.; PETRONETTO, F.; NONATO, L. G. Visualizing and interacting with kernelized data. IEEE Transactions on Visualization \& Computer Graphics, IEEE Computer Society, Los Alamitos, CA, USA, v. 22, n. 3, p. 1314-1325, 2016. ISSN 1077-2626. Citado nas páginas 21, 29, 30 e 57.

BARBOSA, A.; SADLO, F.; NONATO, L. G. An initial study on high-dimensional data visual ization through subspace clustering. In: . [S.I.]: Sociedade Brasilei ra de Computação, 2015. Citado nas páginas 28, 30 e 45.

BERRY, M. W. Large-scale sparse singular value computations. International Journal of Super computer Applications, v. 6, n. 1, p. 13-49, 1992. Citado na página 64.

BISHOP, C. M. Pattern Recognition and Machine Learning. Secaucus, NJ, USA: SpringerVerlag New York, Inc., 2006. ISBN 0387310738. C Citado nas páginas 21, 28, 31, 40, 50 e 87.

BOULT, T. E.; BROWN, L. G. Factorization-based segmentation of motions. In: Proceedings of the IEEE Workshop on Visual Motion. [S.I.: s.n.], 1991. p. 179-186. Citado na página 32.

BRADLEY, P. S.; MANGASARIAN, O. L.; PARDALOS, P. k-plane clustering. Journal of Global Optimization, v. 16, n. 1, p. 249-252, 2000. Citado na página 32.

CAI, J.; CANDÈS, E.; SHEN, Z. A singular val or thresholding al gorithm for matrix completion. SI AM J. on Optimization, v. 20, n. 4, p. 1956-1982, 2010. Citado na página 47.

CASACA, W.; GOMEZ-NIETO, E.; FERREIRA, C. O.; TAVARES, G.; PAGLIOSA, P.; PAULOVICH, F.; NONATO, L. G.; PAIVA, A. Colorization by multidimensional projection. In: IEEE. Confer ence on Graphics, Patterns and Images (SIBGRAPI). [S.I.], 2012. p. 32-38. Citado na página 74.

CASACA, W.; PAIVA, A.; GOMEZ-NIETO, E.; JOIA, P.; NONATO, L. G. Spectral image segmentation using image decomposition and inner product-based metric. Jour nal of mathematical imaging and vision, Springer, v. 45, n. 3, p. 227-238, 2013. Citado na página 74.

CHANG, C.-C.; LIN, C.-J. LIBSVM: A library for support vector machines. ACM Transactions on Intelligent Systems and Technology, v. 2, p. 27:1-27:27, 2011. Software available at <http: //www.csie.ntu.edu.tw/ cjlin/libsvm>. Citado na página 73. 
CHOI, H.; CHOI, S. Kernel isomap. Electronics Letters, v. 40, n. 25, p. 1612-1613, 2004. ISSN 0013-5194. Citado na página 43.

COSTEIRA, J.; KANADE, T. A multibody factorization method for independetly moving objects. International Journal of Computer Vision, v. 29, n. 3, p. 159-179, 1998. Citado nas páginas 27, 32 e 47.

DERKSEN, H.; MA, Y.; HONG, W.; WRIGHT, J. Segmentation of multivariate mixed data via lossy coding and compression. IEEE Transactions on Pattern Analysis and Machine Intelligence, v. 3, p. 1546-1562, 2007. Citado na página 32.

ELHAMIFAR, E.; VIDAL, R. Sparse subspace clustering. In: Proceedings of the Confer ence on Computer Vision and Pattern Recognition. [S.I.: s.n.], 2009. p. 2790-2797. Citado na página 32.

FALOUTSOS, C.; LIN, K. FastMap: A fast al gorithm for indexing, datamining and visualization of traditional and multimedia databases. In: ACM SIGMOD. [S.I.: s.n.], 1995. p. 163-174. Citado na página 64.

FRANK, A.; ASUNCION, A. UCI machine learning repository. 2010. Disponível em: <http: //archive.ics.uci.edu/ml>. Citado nas páginas 52, 54 e 64.

GEAR, C. W. Multibody grouping from motion images. Inter national Journal of Computer Vision, Springer Netherlands, v. 29, n. 2, p. 133-150, ago. 1998. Citado na página 32.

GOWER, J.; DIJKSTERHUIS, G. Procrustes Problems. [S.I.]: Oxford University Press, 2004. (Oxford Statistical Science Series). ISBN 9780198510581. Citado na página 37.

GUYON, I. Design of experiments of the NIPS 2003 variable selection benchmark. In: NIPS 2003 workshop on feature extraction and feature selection. [s.n.], 2003. Disponível em: <http://www.nipsfsc.ecs.soton.ac.uk/datasets/>. Citado nas páginas 54, 70 e 71.

HAM, J.; LEE, D. D.; MIKA, S.; SCHÖLKOPF, B. A kernel view of the dimensionality reduction of manifolds. New York, NY, USA: ACM, 2004. 47-54 p. (ICML '04). ISBN 158113-838-5. Citado nas páginas 21, 41 e 42.

HAMEL, L. Visualization of support vector machines with unsupervised learning. In: IEEE Symposium on Computational Intelligence and Bioinformatics and Computational Biology. [S.I.: s.n.], 2006. p. 1-8. Citado na página 74.

HONG, W.; WRIGHT, J.; HUANG, K.; MA, Y. Multi-scal e hybrid linear models for lossy image representation. IEEE Trans. on Image Processing, v. 15, n. 12, p. 3655-3671, 2006. Citado na página 27.

INABA, F.; SALLES, E.; RAUBER, T. W. Kernel sammon map. In: SIBGRAPI. [S.I.: s.n.], 2011. p. 329-336. Citado nas páginas 42 e 43.

JAKULIN, A.; MOZINA, M.; DEMSAR, J.; BRATKO, I.; ZUPAN, B. Nomograms for visualizing support vector machines. In: ACM SIGKDD. [S.I.: s.n.], 2005. p. 108-117. Citado na página 74.

JOIA, P.; COIMBRA, D.; CUMINATO, J. A.; PAULOVICH, F. V.; NONATO, L. G. Local affine multidimensional projection. IEEE Trans. on Visualization and Computer Graphics, v. 17, n. 12, p. 2563-2571, 2011. Citado nas páginas 21, 28, 37, 38, 51 e 65. 
JOIA, P.; GOMEZ-NIETO, E.; NETO, J. B.; CASACA, W.; BOTELHO, G.; PAIVA, A.; NONATO, L. G. Class-specific metrics for multidimensional data projection applied to CBIR. The Visual Computer, Springer-Verlag, v. 28, p. 1027-1037, 2012. ISSN 0178-2789. Citado nas páginas 21, 38 e 39.

JOURDAN, F.; MELANCON, G. Multiscal e hybrid mds. In: Infor mation Visualization. [S.I.: s.n.], 2004. Citado nas páginas 21, 34 e 64.

KANATANI, K. Motion segmentation by subspace separation and model sel ection. IEEE Int. Conf. on Computer Vision, v. 2, p. 586-591, 2001. Citado na página 27.

LESPINATS, S.; AUPETIT, M. Checkviz: Sanity check and topological clues for linear and nonlinear mappings. Computer Graphics For um, Wiley Online Library, v. 30, n. 1, p. 113-125, 2011. Citado nas páginas 67, 68 e 69.

LIN, Z.; CHEN, M.; WU, L.; MA, Y. The augmented Lagrange multiplier method for exact recovery of corrupted low-rank matrices. [S.I.], 2009. Citado nas páginas 21 e 47.

LIPMAN, Y.; SORKINE, O.; COHEN-OR, D.; LEVIN, D.; ROSSI, C.; SEIDEL, H.-P. Differential coordinates for interactive mesh editing. In: IEEE. Shape M odeling Applications, 2004. Proceedings. [S.I.], 2004. p. 181-190. Citado nas páginas 29 e 57.

LIU, G. Implementação da técnica L ow-Rank Representation. 2016. Disponível em: <https: //sites.google.com/site/guangcanliu/>. Citado na página 47.

LIU, S.; WANG, B.; THIAGARAJAN, J. J.; BREMER, P.-T.; PASCUCCI, V. Visual Exploration of High-Dimensional Data through Subspace Analysis and Dynamic Projections. Computer Gr aphics For um, The Eurographics Association and John Wiley \& Sons Ltd., p. 271-280, 2015. Citado na página 32.

MAATEN, L. van der; HINTON, G. Visualizing data using t-SNE. Journal of Machine Learning Research, v. 9, p. 2579-2605, 2008. Citado nas páginas 21, 28, 39 e 51.

MAMANI, G. M.; FATORE, F. M.; NONATO, L. G.; PAULOVICH, F. V. User-driven feature space transformation. In: WILEY ONLINE LIBRARY. Computer Graphics Forum. [S.I.], 2013. v. 32, n. 3, p. 291-299. Citado na página 74.

PAULOVICH, F. V.; ELER, D. M.; POCO, J.; BOTHA, C. P.; MINGHIM, R.; NONATO, L. G. Piecewise Laplacian-based projection for interactive data exploration and organization. Computer Graphics For um, v. 30, n. 3, p. 1091-1100, 2011. Citado nas páginas 21, 27, 37, 38 e 64.

PAULOVICH, F. V.; NONATO, L. G.; MINGHIM, R.; LEVKOWITZ, H. Least square projection: A fast high-precision multidimensional projection technique and its application to document mapping. IEEE Transactions on Visualization and Computer Graphics, v. 14, n. 3, p. 564575, 2008. Citado nas páginas 21, 34, 35 e 65.

PAULOVICH, F. V.; SILVA, C. T.; NONATO, L. G. Two-phase mapping for projecting massive data sets. IEEE Trans. on Visualization and Computer Graphics, v. 16, n. 6, p. 1281-1290, 2010. Citado nas páginas 21, 35, 36, 64 e 66. 
PEKALSKA, E.; RIDDER, D. de; DUIN, R. P. W.; KRAAIJVELD, M. A. A new method of generalizing Sammon mapping with application to algorithm speed-up. In: Annual Conf. Advanced School for Comput. Imag. [S.I.: s.n.], 1999. p. 221-228. Citado nas páginas 33 e 64 .

SAMMON, J. W. A nonlinear mapping for data structure analysis. IEEE Transactions on Computers, IEEE Computer Society, Washington, DC, USA, v. 18, p. 401-409, 1969. ISSN 0018-9340. Citado nas páginas 33 e 42.

SCHÖLKOPF, B.; SMOLA, A. Learning with Kernels: Support Vector Machines, Re gularization, Optimization, and Beyond. Cambridge, MA, USA: MIT Press, 2001. ISBN 0262194759. Citado nas páginas 21, 28, 58 e 70.

SCHÖLKOPF, B.; SMOLA, A.; MÜLLER, K.-R. Nonlinear component analysis as a kernel eigenvalue problem. Neur al Computation, MIT Press, Cambridge, MA, USA, v. 10, p. 12991319, 1998. ISSN 0899-7667. Citado nas páginas 21, 40, 41 e 61.

SHI, J.; MALIK, J. Normalized cuts and image segmentation. IEEE Trans. Pattern Analysis and M achine I ntelligence, p. 888-905, 2000. Citado na página 48.

SHNEIDERMAN, B.; SEO, J. Hier ar chical Clustering Explorer for Inter active Explor ation of Multidimensional Data. 2008. Disponível em: <http://www.cs.umd.edu/hcil/hce/examples/ application_examples.html>. Citado na página 64.

SILVA, V. de; TENENBAUM, J. B. Spar se multidimensional scaling using landmark points. [S.I.], 2004. Citado na página 64.

TEJADA, E.; MINGHIM, R.; NONATO, L. G. On improved projection techniques to support visual exploration of multidimensional data sets. Information Visualization, v. 2, n. 4, p. 218231, 2003. Citado na página 62.

TIPPING, M. E.; BISHOP, C. M. Mixtures of probabilistic principal component analysers. Neural Computation, v. 11, n. 2, p. 443-482, 1999. Citado na página 32.

TOMASI, C.; MANDUCHI, R. Bilateral Filtering for Gray and Color Images. In: Proceedings of the Sixth International Conference on Computer Vision. Washington, DC, USA: IEEE Computer Society, 1998. (ICCV '98), p. 839+. ISBN 81-7319-221-9. Citado na página 74.

TSENG, P. Nearest q-flat to m points. Journal of Optimization Theory and Applications, v. 105, n. 1, p. 249-252, 2000. Citado na página 32.

VIDAL, R. A tutorial on subspace clustering. I EEE Signal Processing Magazine, v. 28, n. 2, p. 52-68, 2010. Citado na página 32.

WHALEN, D.; NORMAN, M. L. Competition data set and description. In: 2008 IEEE Visualization Design Contest. [s.n.], 2008. Disponível em: <http://vis.computer.org/VisWeek2008/vis/ contests.html>. Citado na página 64.

YANG, A. Y.; WRIGHT, J.; MA, Y.; SASTRY, S. S. Unsupervised segmentation of natural images via lloss data compression. Computer Vision and I mage Under standing, v. 110, n. 2, p. 212-225, 2008. Citado na página 27. 
YANG, J.; YIN, W.; ZHANG, Y.; WANG, Y. A fast al gorithm for edge-preserving variational multichannel image restoration. SI AM J. Imaging Sciences, v. 2, n. 2, p. 569-592, 2009. Citado na página 47.

ZELNIK-MANOR, L.; IRANI, M. Degeneracies, dependencies and their implications in multibody and multi-sequence factorization. IEEE Conf. on Computer Vision and Pattern Recognition, v. 2, p. 287-293, 2003. Citado na página 27.

ZHANG, C.; BITMEAD, R. Subspace system identification for training based MIMO channel estimation. Automatica, v. 41, n. 9, p. 1623-1632, 2005. Citado na página 27.

ZHANG, H.; LIN, Z.; ZHANG, C.; GAO, J. Robust latent low rank representation for subspace clustering. Neur ocomputing, v. 145, p. 369-373, 2014. ISSN 0925-2312. Citado nas páginas $21,28,32,45,46,48$ e 87. 



\section{Apêndices}





\section{APÊNDICE}

\section{A}

\section{DEMONSTRAÇÕES}

Mostraremos aqui al gumas das demonstrações referentes ao trabal ho de Zhang et al. (2014). Para provar o Teorema 1 precisamos dos seguintes resultados:

Lema 2. Sejam U, V e M matrizes com dimensões compatíveis. SuponhaU eV ortogonais, então

$$
\mathrm{kMk}_{*}=\mathrm{kUMV}^{\top} \mathrm{k}_{*}
$$

Prova: Tomea Pecomposiçãąem Val oresSingulares (BISHOP, 2006) (SVD) de $M=U_{M} \Sigma_{M} V_{M}{ }^{\top}$, logo $U M V^{\top}=U U_{M} \Sigma_{M} V_{M}{ }^{\top} V^{\top}=\left(U U_{M}\right) \Sigma_{M}\left(V V_{M}\right)^{\top}$. Como $\left(U U_{M}\right)^{\top}\left(U U_{M}\right)=U_{M}^{\top} U^{\top} U U_{M}=$ $U_{M}^{\top} U_{M}=I$ e $\left(V V_{M}\right)^{\top}\left(V V_{M}\right)=V_{M}^{\top} V^{\top} V V_{M}=V_{M} V_{M}=I$, assim $\left(U U_{M}\right) \Sigma_{M}\left(V_{M} V\right)^{\top}$ é a decomposição $S V D$ deUMV ${ }^{\top}$. E pela definição da norma nuclear, temos $k M k_{*}=\operatorname{tr}\left(\Sigma_{M}\right)=\operatorname{kUMV}^{\top} k_{*}$.

Lema 3. Se B, C, D e F são matrizes com dimensões compatíveis, então

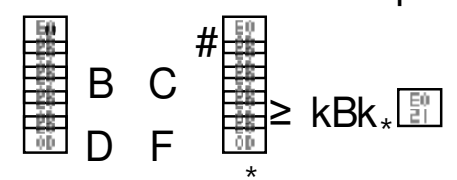

onde a igual dade acontece se, e somente $\mathrm{se}, \mathrm{C}=0, \mathrm{D}=0 \mathrm{e} F=0$.

Prova: Como $k\left[M[\mathbb{N}] k_{\star} \geq \mathrm{kMk}_{\star}\right.$ e $\mathrm{k}[\mathrm{M} ; \mathrm{N}] \mathrm{k}_{\star} \geq \mathrm{kMk}_{\star}$, o resultado segue diretamente, ondea igual dade acontece quando $\mathrm{N}=0$.

Lema 4. Sejam U, V e M matrizes com dimensões compatíveis e suponha $U$ e $V$ com colunas ortogonais, então

$$
\operatorname{mink}_{\mathrm{Z}} \mathrm{k}_{*} \text { 斯al que } \mathrm{U}^{\top} Z \mathrm{~V}=\mathrm{M}
$$

tem uma solução única, $Z^{\star}=U M V^{\top}$. 
Prova: Mostraremos inicialmente que $\mathrm{kMk}_{*}$ é o val or mínimo da função objetivo e $Z^{*}=$ $U M V^{\top}$ é uma sol ução. Para uma sol ução $Z$, tome sua decomposição $S V D Z=U_{Z} \Sigma_{Z} V_{Z}{ }^{\top}$. Sejam $\mathrm{B}=\mathrm{U}^{\top} \mathrm{U}_{Z} \mathrm{eC}=\mathrm{V}_{Z}^{\top} \mathrm{V}$. Assim, a restrição do problema pode ser reescrita como

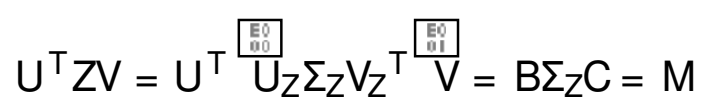

Além disso,

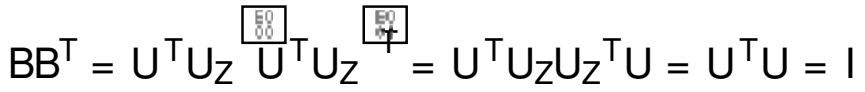

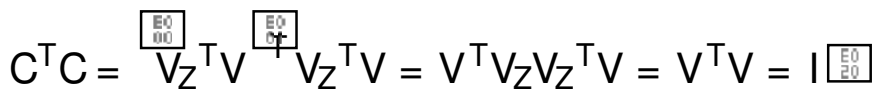

Tomando os complementos ortogonais $\mathrm{B}^{\perp} \mathrm{eC}^{\perp}$, construímos as matrizes ortogonais $\left[\mathrm{B} ; \mathrm{B}^{\perp}\right] \mathrm{e}$ [C圈 ${ }^{\perp}$ ] (caso $\mathrm{B}^{\perp}=\varnothing$ ou $^{\perp}=\varnothing$, a o argumento ainda é válido). Assim,

$$
\mathrm{kZk}_{*}=\mathrm{k} \Sigma_{\mathrm{Z}} \mathrm{k}_{*}=\mathrm{k}\left[\mathrm{B} ; \mathrm{B}^{\perp}\right] \Sigma_{\mathrm{Z}}\left[\mathrm{C} \mathrm{C}^{\perp}\right] \mathrm{k}_{*}=\begin{array}{cc}
\mathrm{B} \Sigma_{\mathrm{Z}} \mathrm{C} & \mathrm{B} \Sigma_{\mathrm{Z}} \mathrm{C}^{\perp} \\
\mathrm{B}^{\perp} \Sigma_{\mathrm{Z}} \mathrm{C} & \mathrm{B}^{\perp} \Sigma_{\mathrm{Z}} \mathrm{C}^{\perp}
\end{array}
$$

Portanto, $\mathrm{kMk}_{*}$ é o valor mínimo da função objetivo. Pelo Lema 2, temos $\mathrm{kZ}^{*} \mathrm{k}_{\star}=$ $\mathrm{kUMV}^{\top} \mathrm{k}_{\star}=\mathrm{kMk}_{*}$. Então, $Z^{*}=U \mathrm{UV}^{\top}$ é uma solução do problema.

Para mostrar que a sol ução $Z^{*}=U M V^{\top}$ é única, suponha que $Z_{1}=U M V^{\top}+H$ é outra solução. Assim, $U^{\top} Z_{1} V=M e U^{\top} H V=0$. De modo anál ogo a primeira parte da demonstração, podemos construir matrizes ortogonais $\left[\mathrm{U} ; \mathrm{U}^{\perp}\right]$ e $\left[\mathrm{V}\left[\mathrm{g}{ }^{\perp}\right]\right.$, logo

$$
\begin{aligned}
& \mathrm{kMk}_{*}=\mathrm{KZ}_{1} \mathrm{k}_{*}=\mathrm{kUMV} \mathrm{V}^{\top}+\mathrm{Hk}_{*}=\mathrm{k}\left[\mathrm{E} ; \mathrm{U}^{\perp}\right]\left(U \mathrm{UV}^{\top}+\mathrm{H}\right)\left[\mathrm{V}^{\mathrm{V}} \mathrm{V}^{\perp}\right] \mathrm{k} \\
& =\begin{array}{cc}
M & U^{\top} H V^{\perp} \\
U^{\perp^{\top}} H V & U^{\perp \top} H^{\perp}
\end{array}
\end{aligned}
$$

Pelo Lema 3, a igual dade acimaé válida se, e somente se,

$$
U^{\top} H V^{\perp}=U^{\perp^{\top}} H V=U^{\perp^{\top}} H^{\perp}=0
$$

e portanto, $\mathrm{H}=0$, provando a unicidade da solução.

\section{Demonstremos então o Teorema 1:}

Prova: Como $X \in \operatorname{span}(A)$, temos posto( $[X[$ 囵 $])=$ posto $(A)$. Cal culando a decomposição SVD da matriz $\left[X[A]=U \Sigma V^{\top}\right.$, chame $V=\left[V_{X} ; V_{A}\right]$, onde $X=U \Sigma V_{X}^{\top}$ e $A=U \Sigma V_{A}^{\top}$. Dessa forma, temos que $V_{A}{ }^{\top}$ tem posto de linhas completo, ou seja, se denotarmos a decomposição SVD de $V_{A}^{\top}=U_{1} \Sigma_{1} V_{1}^{\top}, U_{1}$ será uma matriz ortogonal. Dessa forma,

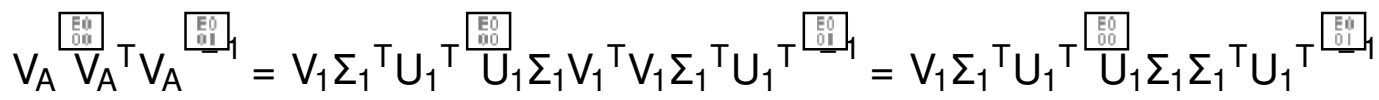

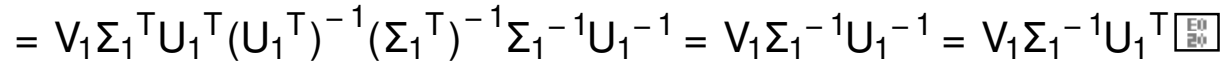


Além disso,

$$
\begin{aligned}
X=A Z & \Rightarrow U \Sigma V_{X}^{\top}=U \Sigma V_{A}^{\top} Z \Rightarrow V_{X}^{\top}=V_{A}^{\top} Z \Rightarrow V_{X}^{\top}=U_{1} \Sigma_{1} V_{1}^{\top} Z \\
& \Rightarrow \Sigma_{1}^{-1} U_{1}^{\top} V_{X}^{\top}=V_{1}^{\top} Z \text { 䜿 }
\end{aligned}
$$

Assim, o problema (3.4) pode ser escrito como

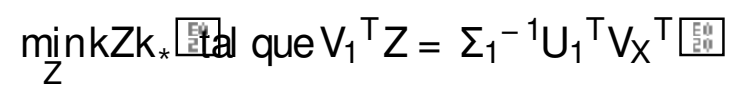

Pelo Lema 4, o problema acima tem solução única $Z^{*}=V_{1} \Sigma_{1}^{-1} U_{1}^{\top} V_{X}^{\top}=V_{A}\left(V_{A}^{\top} V_{A}\right)^{-1} V_{X}{ }^{\top}$. Como $V_{A}^{\top}=\Sigma^{-1} U^{\top} A$ e $V_{X}^{\top}=\Sigma^{-1} U^{\top} x$, temos então

$$
\begin{aligned}
Z^{*} & =A^{\top} U \Sigma^{-1}\left(\Sigma^{-1} U^{\top} A A^{\top} U \Sigma^{-1}\right)^{-1} \Sigma^{-1} U^{\top} X \\
& =A^{\top} U\left(U^{\top} A A^{\top} U\right)^{-1} U^{\top} X \\
& =\left(U^{\top} A\right)^{\dagger} U^{\top} X \\
& =\left(\Sigma_{A} V_{A}^{\top}\right)^{\dagger} U^{\top} X \\
& =\left(U \Sigma_{A} V_{A}^{\top}\right)^{\dagger} X \\
& =A^{\top} X\left[{ }^{\top}:\right.
\end{aligned}
$$

Partimos agora para a demonstração do Corolário:

Prova: Como $X \in \operatorname{span}(A)$, temosposto $\left(A^{\dagger} X\right)=\operatorname{posto}(X)$. Dessaforma, $\operatorname{posto}\left(Z^{*}\right)=\operatorname{posto}(X)$. Além disso, para qualquer solução $Z$ de (3.4), temosposto( $Z) \geq$ posto( $(Z)=$ posto( $X)$. Portanto, $Z^{*}$ também é solução de (3.3). 